\title{
The missing link : on the relationship between values and attitudes
}

Citation for published version (APA):

Dreezens, E. (2006). The missing link : on the relationship between values and attitudes. [Doctoral Thesis, Maastricht University]. Datawyse / Universitaire Pers Maastricht. https://doi.org/10.26481/dis.20060519ed

Document status and date:

Published: 01/01/2006

DOI:

10.26481/dis.20060519ed

Document Version:

Publisher's PDF, also known as Version of record

\section{Please check the document version of this publication:}

- A submitted manuscript is the version of the article upon submission and before peer-review. There can be important differences between the submitted version and the official published version of record.

People interested in the research are advised to contact the author for the final version of the publication, or visit the DOI to the publisher's website.

- The final author version and the galley proof are versions of the publication after peer review.

- The final published version features the final layout of the paper including the volume, issue and page numbers.

Link to publication

\footnotetext{
General rights rights.

- You may freely distribute the URL identifying the publication in the public portal. please follow below link for the End User Agreement:

www.umlib.nl/taverne-license

Take down policy

If you believe that this document breaches copyright please contact us at:

repository@maastrichtuniversity.nl

providing details and we will investigate your claim.
}

Copyright and moral rights for the publications made accessible in the public portal are retained by the authors and/or other copyright owners and it is a condition of accessing publications that users recognise and abide by the legal requirements associated with these

- Users may download and print one copy of any publication from the public portal for the purpose of private study or research.

- You may not further distribute the material or use it for any profit-making activity or commercial gain

If the publication is distributed under the terms of Article $25 \mathrm{fa}$ of the Dutch Copyright Act, indicated by the "Taverne" license above, 
The missing link:

The relationship between values and attitudes 
Colophon

Lay-out/Graphic design: Ellen Dreezens

Cover: Hugo Alberts

Production: Datawyse Universitaire Pers Maastricht

(c) Ellen Dreezens, Maastricht 2006

All rights reserved

ISBN-10: $905278519-8$

ISBN-13: 978-90 $5278519-6$

This research was supported by a grant from ZonMw (014-12-001) 


\section{The missing link: \\ The relationship between values and attitudes}

Proefschrift

ter verkrijging van de graad van doctor aan de Universiteit Maastricht, op gezag van de Rector Magnificus, prof. mr. G.P.M.F. Mols,

volgens het besluit van het College van Decanen, in het openbaar te verdedigen op vrijdag 19 mei 2006 om 14.00 uur door

\section{Ellen Dreezens.}

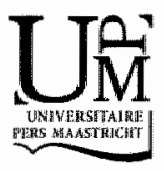


Promotor

Prof. dr. N. K. De Vries

Prof. dr. G. Kok

Co-promotor

Dr. C. Martijn

Beoordelingscommissie

Prof. dr. A. T. M. Jansen (voorzitter)

Dr. R. W. Holland (Radboud Universiteit Nijmegen)

Dr. R. A. C. Ruiter

Prof. dr. Ir. W. H. M. Saris

Prof. dr. B. Verplanken (University of Tromsa, Noorwegen) 


\section{Contents}

Generallintroduction 7

\section{Part 1}

Values and attitudes:

An examination of values underlying attitudes toward food-innovations

19

\section{Chapter 1}

Food and values:

An examination of values underlying attitudes toward genetically modified and organically grown food products

21

\section{Chaptrit 2}

Food and the relation between values and attitude characteristics.

\section{Part 2}

The missing link between values and attitudes

41

\section{Chapter 3}

Is priming enough?

The effect of activated values on related attitudes and behavior

43

\section{Chapter}

The missing link: On strengthening the relation between values and attitudes

61

\section{Chapter 5}

Unraveling the link effect: The role of demand characteristics and self awareness

General Discussion $\quad 85$

Summary 95

Nederlandse samenvatting 101

Dankwoord 107

Curriculum Vitae 109

References 111 
Although lay theories may suggest otherwise, people's values are not always predictive of their attitudes and behavior. In this dissertation, a series of studies will be reported on the relation between values and attitudes. Although the focus of this dissertation lies on the relation between values and attitudes, we will use a well-known study of Darley and Batson (1973) on the lack of correspondence between values and behavior, to illustrate the core issue of our studies. In their so called Good Samaritan study, Darley and Batson confronted a sample of theological students with an emergency situation that obviously demanded their help. Beforehand, some of these students were instructed to give a short talk on the parable of the Good Samaritan, who helped a stranger, other students on a non-helping relevant topic. Supposedly, the talk would be recorded in another bullding and half of the students were instructed to hurry whereas the other half were not. When the students passed an alley on their way to the other building, they encountered a shabbily dressed person who was obviously in need of help. Overall, sixty percent of the subjects ignored the victim and occasionally, a student literally stepped over the victim as he continued on his way. Especially when in a hurry, only ten percent of the students stopped to help. Of the non-hurried students about two-third offered their help. In contrast to what might be reasonable to expect, thinking of the biblical parable of a man who was left stripped and beaten and subsequently ignored by priests on their way to church, did not raise the likelihood of seminary students to act like Good Samaritans. Darley and Batson concluded that increasing the sallience of benevolent and altruistic values, such as helping someone in need is a less strong determinant of helping behavior than situational demands.

The present dissertation focuses on the role of personal norms and values. The main goal of the research is to understand when values are likely to prevail. In contrasit to early studies that examined the direct correspondence between values and behavior (i.e. the bystander intervention, see for examples Darley \& Latané, 1968 or Schwartz \& Clausen, 1970), we will study an earlier phase of value prevalence. More specifically, a series of studies will be reported that examine under what circumstances people"s attitudes and opinions are likely to reflect their personal values. Obviously a wide range of attitude issues is eligible to examine the relation with people's underlying values. For this dissertation, we choose the topic of food innovations. A first reason for this choice was that new production methods such as genetic modification or organic food production are currently much debated and represent an important issue in society (Moses, 1999; Frewer, Howard, \& Shepherd, 1996; Bredahl, 1999; Cook, Kerr, \& Moore, 2002; Gaskell, Bauer, Durant, \& Allum, 1999; Shanahan, Scheufele, \& Lee, 2001). Discussions about the advantages and disadvantages of genetically modified food are lively as ever, which makes this an interesting and societal relevant issue for attitude research. A second reason is that, given our main research question on the correspondence between values and attitudes, food choice in general, or the acceptance or rejection of food innovations in particular, does seem to be related to personal values. For example, some people's preference for organically grown food is guided by their desire for "naturalness" and "pureness" (Schifferstein \& Oude Ophuis, 1998). Likewise, for most vegetarians their diet is not simply a food pattern without meat but also signifies an ideology of how one should live one's life (Lindeman \& Sirelius, 2001). Thus, without denying the influence of more down-to-earth factors such as taste, prize, availability and nutritional value on food choice and preference, it seems reasonable to assume that food related attitudes are at least partly affected by ethical considerations. 
The remainder of this introductory chapter continues with a brief discussion of the most important concepts and their interrelations. The chapter concludes with an overview of the main research questions and an overview of the present dissertation.

\section{Values}

Schwartz and Bilsky (1990) describe values as (1) concepts or beliefs (2) about desirablie end states or behaviors (3) that transcend specific situations (4) guide the selection or evaluation of behavior and (5) are ordered by relative importance. A person's value system represents a learned organization of rules for making choices and for resolving conflicts (Rokeach, 1968, pp. 159-160). In investiglating walues, researchers have studied all kinds of factors related to values. For example, researchers have examined culture (Schwartz; 1992; Schwartz \& Bilsky; 1987), religion (Schwartz \& Huismans, 1995), consumption pattems (Thogersen \& Olander, 2002; Thompson \& Troester, 2002), lifestyle (Brunso, Scholderer, \& Grunert, 2004) and values and behavior (Maio, Olson, Allen, \& Bermard, 2001; Rohan, 2000; Bardi \& Sichwartz, 2003).

A taxonomy of values that proved to be rellatively stable among cultures was developed by Schwartz (1992; Schwartz \& Bilsky, 1990). According to this taxonomy, there are ten motivational value types that are culturally shared. Motivational value types can be regarded as serving a higher order goal or ideal (Austin \& Vancouver 1996 ). These motivational value types range from security to hedonism and from achievement to conformity. They are displayed in a circle, to show conflicts and compatibilities between the different values. The ten values and their circular arrangement are depicted in Figure 1. People in all cultures acknowledge these values and the only individual and cultural differences consist of which values are found most important and which are guiding for attitudes and behavior.

\section{Attitudes}

In everyday life, people are constantly exposed to a large number of objects. Whether the object is a cigarette, tomato soup or concepts such as war or kindiness, people evaluate these objects to make the world around them less complex. The positive or negative evaluations of objects form the attitudes toward them. These evaluations can be cognitive, emotional or behavioral in nature (Eagly \& Chaiken, 1998). Anything that can be discriminated or evaluated can serve as an attitude-object. Attitude-objects can be abstract (friendship) or concrete (tulips), as well as individual (George W. Bush) or collective (politicians) (Eagly \& Chaiken, 1998). Thus, an attitude can be seen as a disposition to evaluate attitude-objects with some degree of favor or disfavor (Eagly \& Chaiken, 1993). 
Flaure 1 . the ten notwational value types and thet arcular arrangement Adapted from Schwortz (1992)

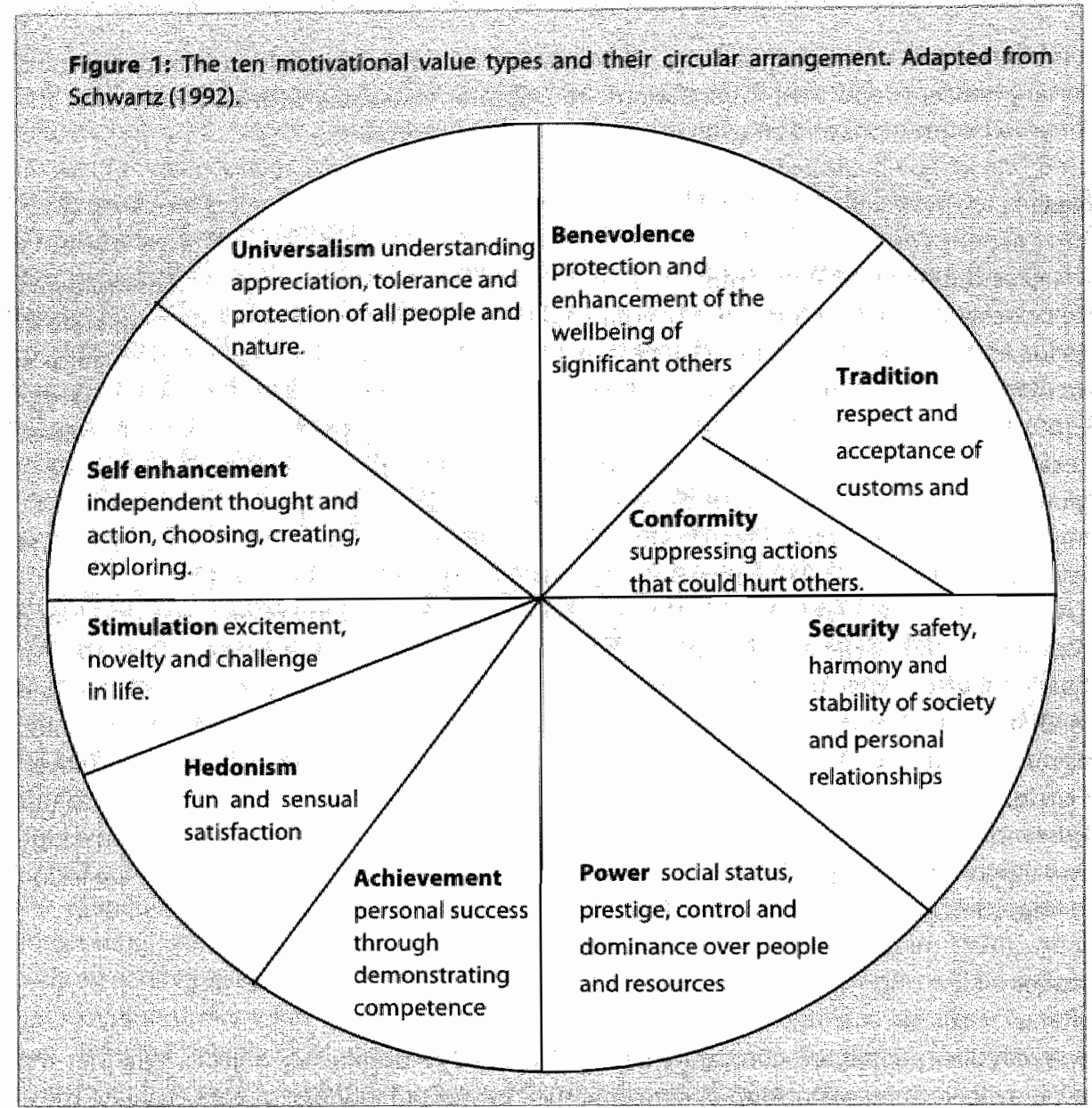

Attitudes have been a topic of active research in the past years. For instance, it has been shown how novel attitudes are deduced from existing evaluations (Prislin, Wood, and Pool, 1998) or from conditioning (Walther, 2002), that attitudes can be defined as temporary constructions, (Wilson \& Hodges, 1992), but also that they can be relatively stalble (Cook \& Flay, 1978; Alport, 1935), that there is a direct effect of personal relevance on attitudes (Liberman \& Chaiken, 1996), that attitudes can be biased (Biek, Wood, \& Chaiken, 1996), that attitudes are related to self-esteem and stereotypes (Greenwald \& Banaji, 1995), that attitudes influence how information is processed (Eagly, 1993) and that attitudes can be either implicit or explicit (Karpinski \& Hilton, 2001; Greenwald, McGhee, \& Schwartz, 1998; McConnell \& Leibold, 2000). Furthermore, attitude studies have used several topics of interest, like capital punishment (Prislin, Wood, \& Pool, 1998), recycling (Thogersen, 1996), donating bone marrow (Bagozzi, Lee, \& Van Loo, 2001) the environment (Iwata, 2001) and consumer decision making (Sanbomatsu \& Fazio, 1990; Wilson \& Dunn, 1986). 


\section{The relationship between values and attitudes}

In social psychological theory, there are many conceptions of the relation between values and attitudes. Values serve as prototypes from which attitudes are derived (Homer \& Kahlle, 1988; Luzar \& Cosse, 1998). One of the prominent functions of attitudes is to express personal values $(K a t z, 1960)$ and attitudes can be influenced by or related to the values that they express. Although there are many similarities between values and attitudes, it seems important to also stress the differences between them for a better understanding of the two concepts.

Values and attitudes can both be measured on two dimensions: valence (whether you consider the value or attitude to be positive or negative) and importance (how important the value or attitude is to you personally). For attitudes, valence is the defining dimension, whereas importance is a less defining feature. Attitudes help make decisions about approach or avoidance; they divide the world in positive and negative things (Wilson, Lindsey, \& Schooler, 2000; Fazio \& Williams, 1986; Katz, 1960). Some attitudes are more important than others, but this is not their most basic feature. Conversely, for values the valence dimension is not as salient as the importance dimension. All values are considered to be relatively positive, but not all of them are equally important to a person (Bem, 1970; Rokeach, 1973; Schwartz, 1992). A person can only live up to a limited number of values, because certain values oppose each other. Therefore, some values are more important than otheirs, but all of them are rated positively. The second difference between values and attitudes is that values are more general than attitudes and therefore transcend specific situations and objects, whereas attitudes do not. Furthermore, values have a guiding influence on the lives of the people that adhere to them. Because they transcend specific situations and are guidelines or ideals, values have motivational power (Schwartz, 1992). In contrast, an attitude only motivates a person to act when this attitude is really important for this person's self-concept, but not generally speaking (Eagly \& Chaiken, 1995). Despite these marked differences, the two concepts are related to each other and attitudes are often based on one or more important values.

The effect of values on attitudes is probably best described as an indirect effect. Thus, values do not have an impact on an attitude as a whole but rather on its specific components. Each attitude is based on several cognitive components (beliefs). Not all beliefs are equally important for the attitude at hand and, hence, do not influence the attitude to the same extent. Important and therefore influential beliefs are likely to reflect the underlying values that are central to a person's self-concept. For example, someone's attitude toward a vegetarian diet may consist of beliefs such as "a vegetarian diet is not very tasty", "a vegetarian diet is complicated to follow", and "a vegetarian diet respects nature and animal welfare". If the person in this example highly values universalism (appreciation for all people and nature), the thiird belief will be most important because it most closely matches universalism. Therefore, this person's attitude is likely to turn out positive because the belief will outweigh the other two beliefs, despite their negative implications for accepting vegetarianism. In contrast, if a person regards hedonism (fun and sensual sensation) as a highly guiding personal value, his or her attitude is likely to be negative because the assumed tastelessness and complexity of vegetarianism do not match hedonism and will therefore gain more importance in attitude formation. Note that in this example, values have an impact on belief importance in two ways: a belief may be either consonant or dissonant with a value centrall to a person's self-concept. Both types of relations, consonance or dissonance, may enhance the importance of a belief. 
The first central question that will be addressed in this dissertation relates to whether values indeed play a role in forming and expressing attitudes toward food. And if walues help to understand attitudes better, can a systematic relationship between specific values and specific attitudes be found? Are certain attitudes always influenced by particular values? And does adhering to certain patterns of values result in certain patterns of related attitudes? A further question related to the relation between values and attitudes concerns the relationship that beliefs have with both values and attitudes toward food. Are the beliefs that form the attitudes toward organically grown- or genetically modified food indeed influenced by the values that underlie these two attitudes, or do values influence attitudes through another pathway? Chapter 2 of this dissertation investigates the relationship between values, attitudes and beliefs and will provide an answer to these two questions.

\section{Values and attitude structure}

In most cases, a specific attitude is not an isolated entity, but is embedded into a larger set of related concepts. The structure that encompasses values, beliefs and attitudes is called an intra-attitudinal structure. The attitude toward organically grown food can for instance be influenced by the values "security" (harmony and stability of society and personal relationships? and "universalism" (respect for all people and for nature), but also by beliefs like "organically grown food is healthy" or "organically grown food is produced without pesticides". These associations differ greatly across persons and attitude-abjects, both in their specific content as well as in their number (Eagly \& Chaiken, 1995). Illustrations of research that investigates the intra-attitudinal structure are abundant. Researchers have for instance aimed at the relation between attitudes and beliefs (Fishbein, 1963), attitudes and affect (GinerSorolla, 2001; Verplanken, Hofstee, \& Janssen, 1998; Breckler \& Wiggins, 1989), attitudes and values (Bernard, Maio, \& Olson, 2003; Homer \& Kahle, 1988) and attitudes and behavior (Bem, 1972; Luzar \& Cosse, 1998).

One particular attitude can be related to a number of other attitudes. These relationships are called the inter-attitudinal structure and thils structure can encompass a large number of attitudes. How a person feels toward an issue such as "organically grown food" is probably related to his or her attitude toward "protein rich food" and "fast food". Thus, a supporter of organically grown food will probably have a negative attitude toward fast food, but maybe a positive or neutral attitude toward protein rich food. Research on the inter-attitudinal structure has focused on relationships between attitudes and other attitudes (Juidd "Drake, Downing, \& Krosnick, 1991), values (Feather, 1995; Katz, 1960, Rokeach, 1968; Verplanken \& Holland, 2002), beliefs (Fishbein, 1963; Tourangleau, Rasinski, Bradburn, \& D'Andrade, 1989; Harreveld, Van Der Pligt, De Vries, \& Andreas, 2000), and the self (Greenwald, 1989). An example of a hypothetical inter- and intra-attitudinal structure is shown in Figure 2. 


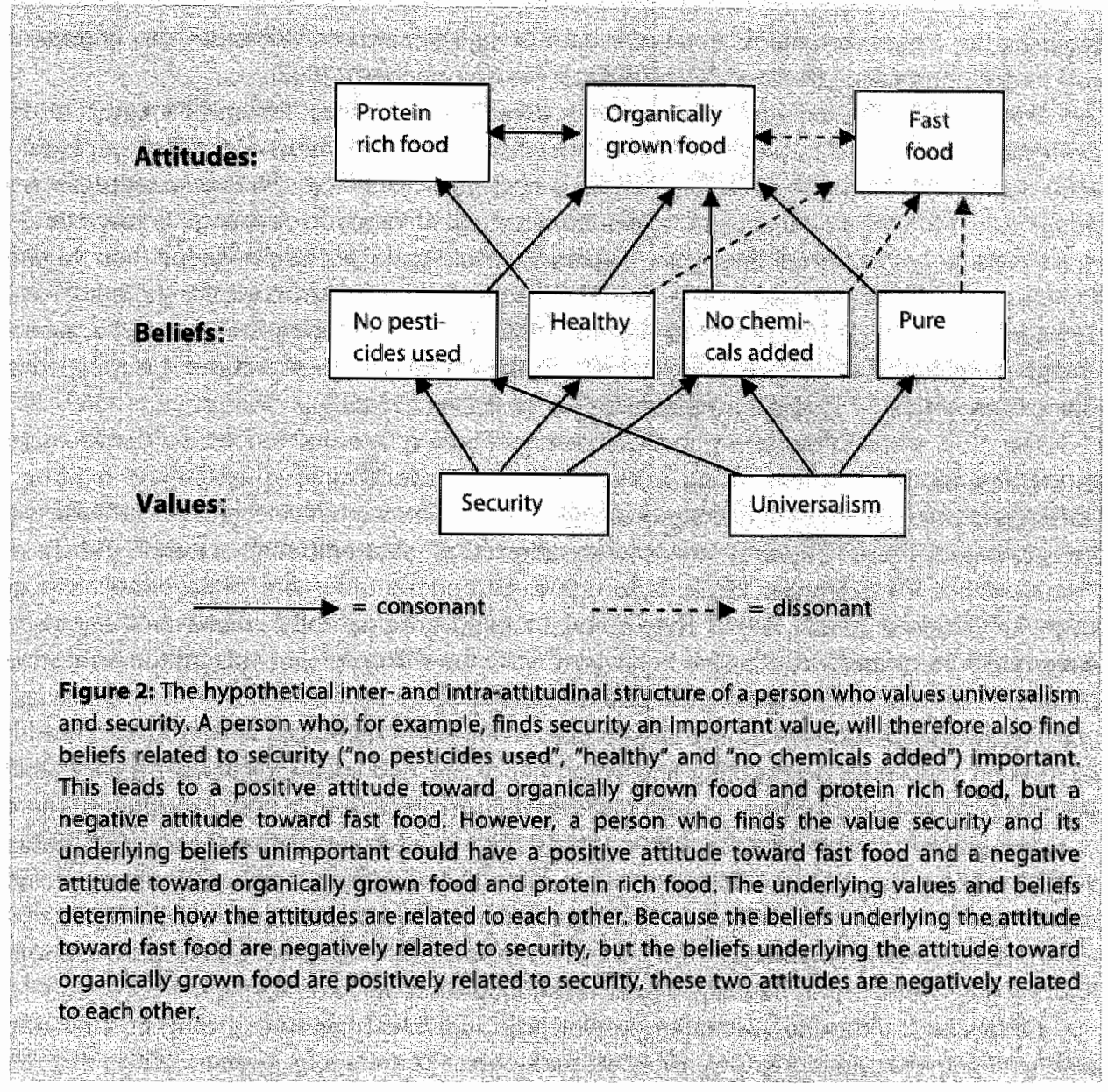

\section{Values and attitude strength}

Attitudes that are highly embedded into their inter- and intra-attitudinal structure are called strong attitudes. People's attitudes become stronger when they have more direct experience with an attitude-object, when they are more involved with the attitude-object or when they have expressed their attitude frequently (Krosnick, Boninger, Chuang, Berent, \& Carnot, 1993; Lord, Lepper, \& Mackie, 1984). Attitude strength can be seen in terms of two important strength dimensions: centrality and commitment (Holland, Verplanken, \& van Knippenberg, 2002). The attitudes that are strongly tied to theilr underlying values and beliefs are called "central" attitudes. Centrality of an attitude refers to the importance of the attitude to the selfconcept and to personal values. Thus, central attitudes are strongly embedded into their intraattitudinal structure (Judd \& Krosnick, 1982; Ostrom \& Brock, 1968). Commitment to an attitude refers to the certainty or conviction about the attitude. People who are very certain that their attitude is correct are said to have allighly cormmitted attitude. An attitude to which 
a person has a high commitment comes to mind very easily and therefore plays an important role in decision-making (Holland, Verplanken, \& van Knippenberg, 2002).

Strong attitudes have two consequences: durability and impact (Krosnick \& Petty, 1995). Durability is manifested by persistence and resistance. Persistence refers to the fact that strong attitudes do not change easily. Resistance to change occurs because strong attitudes are embedded into their underlying inter-and intra attitudinal structure. A change in the attitude must lead to a change in the entire structure, resulting in a chain reaction, and in the fundamental restructuring of all the elements in the attitudinal structure (Eagly \& Chaiken, 1995; Judd \& Krosnick; 1982; Johnson \& Eagly, 1989). This restructuring is necessary because a change in one attitude leads to an imbalance in the whole attitude structure. This imbalance can only be corrected if other attitudes also change (Heider, 1946).

The two most important manifestations of impact are influences on information processing and the fact that strong attitudes guide behavior (Eagly \& Chaiken, 1998). Strong attitudes lead to selective cognitive processing. Information that is in line with the attitude will be processed more efficiently than information that contradicts an attitude (Chaiken, Pomerantz \& Giner-Sorolla, 1995; Fazio, 2000). Strong attitudes are highly predictive of behavior (Fishbein et al. 2001). They come to mind automatically whenever the person encounters an attitude-object. The behavior that follows from seeing this attitude-object is therefore very often influenced by this particular attitude.

To measure whether an attitude is strong or weak, different indicators of attitude strength have been proposed. Accessibility and ambivalence are two such indicators. An accessible attitude is an attitude that comes to mind easily when an attitude-object is encountered. There is a strong link in memory between the attitude-object and its evaluation (Fazio, 1995; Fazio, 2000; Sanbonmatsu \& Fazio, 1990). Accessible attitudes are generally not easily changed and have a strong relationship with behavior, because upon exposure to the attitude-object, the evaluation in memory springs easily to one's mind and therefore influences behavior. Accessibility will be experimentally influenced in Chapters 4, 5 and 6 .

Ambivalence refers to a situation in which an individual has both strong positive and strong negative evaluations toward an attitude-object (Armitage \& Conner, 2000; Van der Pligt, De Vries, Manstead, \& Van Harreveld, 2000). In other words, people simultaneously see advantages and disadvantages of the attitude-object, and this gives them an unresolved or unpleasant feeling. A problem is that ambivalence and indifference/neutrality cannot be separated from each other purely on the basis of the answers that participants give on a likert scale (both would bring about an answer in the middle range of the scale). However, ambivalence is structurally different from indiffence or neutrality ${ }_{3}$ as these are characterized by a lack of positive and negative feelings toward the attitude issue (Cacioppo, Gardner „ \& Berntson, 1997; Jonas, Diehl, \& Brömer, 1997; Thompson, Zamna, \& Griffin, 1995). There is a negative relationship between attitude strength and ambivalence. The more ambivalent an attitude is, the less strong it is. Ambivalent attitudes are therefore less guiding for behavior and less persistent over time. Ambivalence toward organically grown food and genetically modified food and its relationship to underlying values is investigated in Chapter 3 of this dissertation. There, the third central question of this dissertation will be answered: What are the structural relations between values and the three most important attitude characteristics: centrality, commitment and ambivalence? 


\section{Preconditions for a strong relationship between values and attitudes}

There is a lot of proof to assume that values can influence related attitudes (Homer Kahle, 1988; Verplanken \& Holland, 2002; Maio \& Olson, 1994). However, studies show that activating a specific value does not necessarily lead to activation of a related attitude, or propose certain preconditions for this relationship (Verplanken \& Holland, 2002; Feather \& Norman, 1998). Snyder and Kendzierski (1982) suggest that making a value more accessible by retrieving it from memory is not sufficient to influence attitudes. The valtue must also be regarded as having implications for the attitude. Verplanken and Holland (2002, Experiments 2 and 3). showed that even when a value is retrieved from memory and has implications for an attitudie, this is not enough to ensure that the value influences related attitudes. Values also have to be a part of participants' self concept before they can influence related attitudes.

Taken together, these studies suggest that three conditions should be met in order to establish a relation between values and attitudes. Values should be (1) accessible, (2) persianally relevant, and (3) people should perceive that their commitment to a certain value implicates the specific attitude at hand. These preconditions for a strong relation between attitudes and values were tested in Chapters 3 and 4 . These chapters will lead to the identification of another precondition for a strong value-attitude congruence. In Chapter 5. research will focus on how exactly this precondition has its influence on the value-attitude relationship by investigating the effect that self activation has on the value-attitude consistency.

In this dissertation, the main focus lies on unraveling the relation between values and attitudes toward food innovations and to determine under what conditions such a relation is present or not: To examine this relationship, two types of food innovations (genetically modified food and organically grown food) will be studied. The choice for these two types of products was made because the attitudes toward them are based on underlying values (Honkanen \& Verplanken, 2004). More important, the two attitude issues have a presumed incompatibility. Organically grown food (OGF) and genetically modified food (GMF) are considered to be negatively related because their underlying ideas are opposed to each other. OGF stands for producing products in the most natural and pure way, whereas GMF stands for manipulation and human interference. This incompatibility enables us to investigate which values underlie these two attitude-objects, and more importantly, how specific combinations of these values are reflected in specific combinations of attitude positions.

\section{Genetic modification}

Genetic modification (GM) is the change of hereditary material by placing properties of one organism (micro-organism, plant, animal) into another organism (Hautvast \& Van de Wiel, 2001). For instance, genes from flowers (e.g. dlaffodils) can be placed inside rice, in order to create a rice variety that contains more vitamin A. Using this technique, pliant varieties can be created that are, for instance, richer in vitamins, lower in fat, resistant against herbicides or growing faster (Niaba, 2001). Genetically modified ingredients can be found in a large number of products like cookies, chocolate, sauces and cheese. Furthermore, a great number of fruits and vegetables currently available in our supermarkets, like soy and corn, have been genetically modified. Probably all of us have consumed genetically modified food at least once, with or without knowing so. 
The consequences of modern biotechnology in general and GM in particular have been discussed heavily and opinions on this issue are strongly diverging. Some people regard GM as a positive development. They stress the innovative and progressive aspects of GM and modern biotechnology and view it as an opportunity to improve food or to increase world-food production. However, a large number of people see GM as a negative development. These people consider GM dangerous because of the general uncertainty regarding the long-term effects of consuming GMF, or reject it for ethical reasons (Bredahl, 1999, Moses, 1999). Ecological reasons also play an important role in negative attitudes toward $\mathrm{GM}$.

\section{Organically grown food}

Organically grown food (OGF) is an upcoming market for people who are worried about food safety and the environment. Apart from avoiding genetic modification (GM), OGF production also refiains from using synthetic chemicals like pesticides and fertilizers. Furthermore, livestock is not treated preventively with medication in order to avoid diseases. Therefore, organic end products are unlikely to contain residues of those chemicals (Schifferstein \& Oude Ophuis, 1998). Many people consider OGF to be more natural and pure than normal food or genetically modifled food.

Health, environmental concern and food safety are the most important motives for buying OGF (Grankvist \& Biel; 2001; Grunert \& Juhl, 1995; Schifferstein \& Oude Ophuis; 1998). Since OGF is produced without using chemicals and with more concern for the environment, it is considered to be more environmentally friendly and sustainable than other production techniques. Environmentall concern has therefore been found to be a major determinant of buying OGF. OGF consumption can be seen as part of a way of life. People who buy OGF overall are more concerned with health-related issues than people who do not buy OGF. Also, they rate certain characteristics like self-fulfillment, self-respect and excitement higher than other people, suggesting that their underlying value system differs from that of others (Grunert \& Juhl, 1995).

\section{Overvlew of the present dissertation}

In this dissertation we systematically examine the relationship between values and attitudes. Furthermore, the preconditions that might contribute to a stronger correspondence between values and attitudes are investigated. In addition, we aim at finding an effect of a heightened value-attitude correspondence on related attitudes.

\section{Part 1: values and attitudes: An examination of values underlying attitudes toward food- innovations}

In Chapter 1, the selection of two, presumably opposing food-issues enabled us to study whether specific attitude positions are linked to specific patterns of values. In the study in this chapter, 100 students were asked about the values that they adhered to, about their attitudes toward genetically modified food (GMF) and organically grown food (OGF) and about a number of beliefs toward GMF and OGF. We predicted that different vallues are related to these two attitude issues and that values influence these attitudes by influencing the beliefs that comprise them. 
Chapter 2 focused on the relation between values and the attitude characteristics that make up the attitudes toward new food technologies. In this chapter, it is predicted that the three most important attitude strength characteristics, centrality, commitment and ambivalence will have different relationships with the values underlying the attitudes toward GMF and OGF. Centrality is predicted to be highly related to the values that underlie an attitude, whereas the influence of values on commitment and ambivalence is supposed to be much smaller. Investigating the influence that values have on attitude characteristics provides us with a better understanding of how values exert their influence on related attitudes.

\section{Part 2: The missing link between values and attitudes}

In Chapter 3, two studies are described that focus on actually activating values and measuring an effect on related attitudes. Study 3.1 was designed to prime students with the values power and universalism and to measure an effect of these primed values on the attitudes toward GMF and OGF. Study 3.2 focuses on the same question, only here also behavior related to the attitudes toward OGF and GMF was measured. Furthermore, the participants that took part in studly 3.2 were non-student consumers.

In Chapter 4 , we specifically focus on the preconditions that ensure a high value-attitude correspondence. It is predicted that only when participants see the link between a value and an attitude, a strong relationship between vallues and attitudes can be found. Study 4.1 tested the hypothesis that suggesting the link between the value universalism and the attitude toward OGF resulted in a higher value-attitude correspondence. Study 4.2 tested the same hypothesis, only here a manipulation was used that was developed to be less responsive to demand characteristics.

After discussing studies that investigate whether a strong value-attitude correspondence can be obtained by linking a value to an attitude, we then turn to a more thorough investigation of the effect of linking on the value-attitude relationship. In Chapter 5, a study is discussed that was designed to find out to what extent the correspondence between values and attitudes is influenced by self activation. Study 5.1 aimed at investigating whether activating the self affected the relation between values and attitudes. The manipulation used in this study caused a difference in the amount of self activation and we measured whether this difference in self activation resulted in different strengths of the relationship between attitudes and values. In the discussion, we summarize the main findings of our studies and discuss their theoretical implications, as well as directions for further research.

Finally, alllow me to finish with a note for those who want to read only one or a few parts of this dissertation. The empirical chapters that make up this book have been written as separate papers. This means that they can be read independently from the rest of the dissertation. At the same time, this implies that the reader who is dedicated to read the whole dissertation will find similarities and overlap between the chapters, especially in the introduction sections. 
Part 1

Values and attitudes: An examination of values underlying attitudes toward food-innovations 
$\frac{\pi}{20}$

20 


\section{Chapter 1}

\section{Food and values: An examination of values underlying attitudes toward genetically modified-and organically grown food products ${ }^{1}$}

This study addresses which specific values play a role in predicting participants' attitudes. toward genetically modified food and organically grown food. The first central question is whether the attitudes toward genetically modified food and organically grown food are influenced by specific values and beliefs. The second central question is whether the attitudes toward genetically modified food and organically grown food are related to each other, and whether the specific values underlying these two attitudes are also related to each other. A total of 100 participants responded to the Schwartz Value Survey and two questionnaires about genetically modified food and organically grown food. When respondents scored high on the value power (dominance, submission), they rated genetically modified food positively and orglanically grown food negatively. Respondents who rated the walue universalism (welfare for all people and protection of nature) high, rated organically grown food as positive. The relationship between attitudes and values however was mediated by belliefs. These findings imply a meaningful relationship between specific values, beliefs, and these food-related attitudes, and suggest that values might play some role in explaining attitudes toward genetically modified-and organically grown food products.

1 This chapter based on the following article: Dreezens, E, Martijn, $C_{1,}$ Tenbült, P., Kok, G., B de Vries, N. K. (2005). Food and values: An examination of walues underlying attitudes toward genetically modified-and organically grown food products. Appetite, 44, 115-122. 
Although taste, prize, avallability and nutrition value are important factors, some people decide what, or what not to eat on the basis of moral considerations. For example, in the past few years, consumers have been confronted with television images of thousands of animal corpses that were "preventively" slaughtered to stop the spread of epidemics such as swine fever and foot-and-mouth disease. Although most of these animal diseases do not affect human health, some people banned meat partly or completely from their diet or decided to buy only organic meat because the way animals were treated in bio-industry contravened their principles of animal welfare. This paper examines what monal considerations underlie people's choices for certain food types.

The interest for food-related issues seems to be growing. Shanahan, Scheufele, and Lee (2001) for example, report an increase in media coverage of food related topics. Moreover in reaction to recent outbreaks of BSE and hormone scandals, people have become more aware of the food they are eating (Kirk, Greenwood, Cade, \& Pearman, 2002; Kubberød, Ueland, Tronstad, \& Risvik, 2002). Dieting styles like vegetarianism, veganism and organically grown foods have become more common. Recent studies have shown that the number of vegetarians has grown in several countries over the last few years (Allen \& Baines, 2002; Kirk et al., 2002; Kubberød et al., 2002; Lea \& Worsley, 2001; Povey, Wellens, \& Conner, 2001).

Povey et al. (2001) found that norms and values play an important role in the decision to adopt a vegetarian or vegan diet. Both vegetarians and vegans report health related, humanitarian and environmental reasons for their diet. They consider the eating of meat barbaric $_{n}$ environment unfriendly and unhealthy. Therefore it seems that environmental values as well as humanitarian values play a central role in deciding to adopt a certain dietary style.

In this chapter we report a study that explores whether people's attitudes toward food products are related to the basic human values they adhere to in life. We focused on two types of food products: genetically modified food (GMF) and organically grown food (OGF). The choice for these two types of products was made because of their presumed incompatibility. It seems likely that attitudes toward OGF and GMF are negatively related because the most central features of OGF are "naturalness" and "pureness" (Schifferstein \& Oude Ophuis, 1998) whereas GMF is manipulated and altered by human hands. Therefore, it seems unlikely that a positive attitude toward OGF co-occurs with a positive GMF-attitude. The selection of two, presumably irreconcilable food-issues enabled us to study whether specific attitude positions are linked to specific patterns of values. Thus, our first question was whether attitude positions (e.g. a positive OGF attitude or a negative GMF attitude) are influenced by specific values and bellefs. Our second question was whether specific combinations of attitude positions (e.g. a positive OGF attitude and a negative GMF attitude) are reflected in specific combinations of vàlues.

Until now, most studies focused on revealing the underlying values-attitude structure within one production technology, for example organic beer versus organic bread (Grunert \& Juhl, 1995; Grankvist \& Biel, 2001; Magnusson, Arwola, Hursti, Åberg, \& Sjödén, 2003) or genetically modified beer versus genetically modified bread (Magnusson \& Hursti, 2002; Pfister, Böhm, \& Junglermann, 2000; Bredahl, 1999; Bredahl, 2001). However, as farr as we know, none of these studies compared attitudes and their underlying values between distinct production technologies that represent two possibly contrasting food-issues. 


\section{Genetically modified food and organically grown food}

Genetic modification is the change of hereditary material by placing properties of one organism (micro-organism, plant, animal) into another organism (Hautvast \& van de Wiel, 2001). Using this technique, plant varieties can be created that are for instance, richer in vitamins, lower in fat, resistant against herbicides and diseases, or that grow faster (Niaba, 2001). Genetically modified ingredients can be found in a large number of products like cookies, chocollate, sauces and cheese. Furthermore, a great number of fruits and vegetables currently available in our supermarkets, like soy and maize, have been genetically modified. Probably all of us have consumed genetically modified food at least once, with or without knowing so.

Organically grown food (OGF) is produced without the use of synthetic chemicals; suchas pesticides and fertilizers and is, by diefinition, not genetically modified. Furthermore, livestock is not treated preventively with medication in order to avoid diseases. Therefore, organic end products are unlikelly to contain residues of those chemicals (Schifferstein \& Oude Ophuis, 1998).

\section{Attitudes and values}

An attitude is a psychological tendency that is expressed by evaluating a particular entity with some degree of favor or disfavor (Eagly \& Chaiken, 1995). The internall structure of attitudes consists of mental representations of these evaluative responses. These responses can be based upon feelings, cognitions or prior experience. Values and beliefs are thought to be the building blocks of attitudes (Eagly \& Chaiken, 1995; Verplanken \& Holland, 2002). Values can be seen as the most abstract cognitions or extreme global attitudes, as goals to provide general orientation and organization for life (Austin \& Vancouver, 1996), and they serve, as Rokeach (1968) puts it, as "standards" or models for beliefs, attitudes and behavior. Values, beliefs and attitudes form a hierarchical structure with values higher in the hierarchy (generall level) and beliefs and attitudes at the bottom (specific level). The entire set of cognitive, affective and behavioral responses, together with values and beliefs within an attitude, constitutes the intra. attitudinal structure.

Attitudes are not only linked to values and beliefs, but also to each other. This is called an inter-attitudinal structure and it can encompass a large number of attitudes. An example of how a person feels toward an issue such as "dog races" is probably related to his or her opinion on "circus acts with animals" and "equal rights for men and animals". Thus, people who loath dog races probably also disapprove of elephants doing a handstand. The binding element between these different attitudes may be one and the same underlying value, such as "equolity for all living creatures" or "protection of nature and wildife" "A taxonomy of values that proved to be relatively stable armong cultures was developed by Schwartz 11992; 5chwartz \& Bilsky, 1990). According to this taxonomy, there are ten motivational value types that can be found in every culture. These motivational value types range from security to hedonism and from achievement to conformity. In the Schwartz Value Survey (1992), that was designed to measure the importance attached to values, each of the ten motivational values types consists of a number of subdivisions or more specific values.

Several researchers have shown a value-attitude-behavior relationship (Luzar \& Cosse, 1998; Maio \& Olsen, 1994; Thøgersen \& Ölander, 2002; Homer \& Kahle, 1988; Bernard, Maio, \& 
Olsen, 2003, Stienstra, Riuelle, Bartels, 2002). It is commonly believed that the causality flows from values through attitudes to behavior, and not the other way around. This means that walues thave an impact on attitudes, which in turn influence peoples behavior. Values are generally understood as extremely stable constructs that are not easily changed, even if considerable effort is invested.

Values affect attitudes by focusing not simply on the whole attitude, but by making some specific aspects of an attitude more salient or important. For example, imagine a person who holds the following beliefs about glass recycling: "recycling glass saves natural resources" and "recycling glass takes time and effort". If this person considers the value universalism (protection for all people and for nature) as a guiding principle in his or her life, the first belief is probably more important and salient to this person than the second belief. Because of the match between this person's value and a specific belief $f^{\prime}$ such a belief is likely to influence a person's overall attitude toward glass-recycling to a greater extent than beliefs that do not match personal values, Vice versa, if a person considers hedonism (pleasure, enjoying life) as a guiding principle in life, the bellief about the (immaterial) costs of glass recycling will probably influence the attitude most.

It is important to note that values infiuence attitudes only under certain conditions. Only those values that are related to an attitude, that are part of a person's self concept; and that are activated within a specific behavioral context have an impact on attitudes. In a series of studies, Verplanken and Holland (2002) showed that the activation of specific values could change attitudes and choice behavior. In one of their studies, environment-related values were activated through a priming procedure: This procedure consisted of presenting participants with 20 values, and asking them to form an impression of a person who adheres to these values. In the priming condition, 12 of these 20 values were related to the environment, whereas in the control condition, they were all unrelated to the environment. These activated values directed attention to value-relevant information (information about the environment) and heightened the weight of value-relevant attributes. Participants in the priming condition of the study by Verplanken and Holland chose television sets that scored higher on environment-aspects than participants in the control condition, but only when environment related values were part of the person's self concept.

\section{The present research}

In this chapter, we report a study in which we examined which values underlie attitudes toward genetically modified-and organically grown food products. We focused on genetically modified food (GMF) versus organically grown food (OGF) products because these are both relatively recent, but presumably opposing developments. Values could be a useful tool in predicting or explaining peoples' attitudes toward issues like GMF or OGF.

Previous research has already shown some relations between specific values and foodrelated attitudes. Povey et al. (2001) found that environmental- and humanitarian values play an important role in the decision to adopt a vegetarian or vegan diet. Thøgerson and Ölander (2002) have shown that there is a predominant causal influence between values like universalism (welfare for all people and protection of nature) and benevolence (welfare of close others) and environment-friendly attitudes and behavior. Homer and Kahle (198:8) showed that values like hedonism (pleasure or sensuous gratification for oneself) and stimulation (need for variety and stimulation) had an effect on attitudes toward nutrition. Other researchers. 
(Grankvist \& Biel, 2001; Grobe, Douthitt, \& Zepeda, 1999, Grunert \& Juhi, 1995; Schifferstein \& Oude Ophuis, 1998), have also shown that values like spirhtuality (meaning and inner hamonyl. benevolence and universalism have a positive relation to envirommental attitudes. We predict that the attitude toward OGF will be predicted by similar values. As we assume that GMF opposes OGF, values that are opposed to universalism and benevolence, such as achievement and power, are expected to be related to GMF.

With findings like these in mind, we propose the possibility that specific values underlie attitudes toward GMF and OGF. The central questions of this study are based on the idea of the existence of an intra-attitudinal structure and an inter-attitudinal structure (Eagly \& Chaiken, 1995). The first question is whether the attitudes toward GMF and OGF are influenced by specific values and beliefs. Because, theoretically, beliefs are positioned between values and attitudes; the possibility was raised that beliefs might mediate the relationship between attitudes and walues. The second question is whether specific combinations of attitude positions are reflected in specific combinations of values.

\section{Method}

\section{Participants}

A total of hundred students of Maastricht University took part in our study and received a monetary reward for their participation. The mean age of the participants was 20.2 years $(5 \mathrm{D})=$ 3.50 , ranging from 18 to 50 ).

\section{Procedure}

Participants were invited to the laboratory. After explaining the procedure and the purpose of the survey ${ }_{n}$ each participant was seated behind a computer. A computer-controlled program was used to generate the questionnaires. Participants first filled out the Schwartz Value Survey (SVS). The values were shown on the computer screen and consilsted of catchwords (e.g. "equality"), followed by a brief extension (e.g., "equal chances for everybody"). When

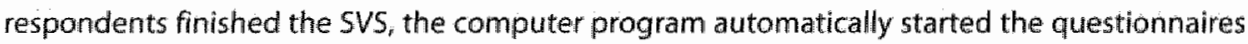
about GMF and OGF. When the participants finished filling out the questionnaires, they were debriefed, thanked and paid.

\section{Measures}

The following measures were taken:

(i) Schwartz Value Survey. The Dutch version of this survey (Schwartz \& Huismans, 1995) consists of ten motivational walue types (like "tradition"), which are tested by asking people to rate how important they find 58 sub-values (like "respect for tradition" and "humble") (see also Table 11). Participants were asked to rate to what extent each of these 58 sub-values is a guiding principle in their lives on a 9-point scale ranging from-1 (opposite to my values) to 7 (extremely important). Reliability analyses showed that the alpha values of the ten motivational value types ranged between 0.51 (tradition) and 0.87 (stimulation). The scores of the sub-values belonging to one motivational value type were averaged to create one single score per person per motivational value type.

(ii) Attitudes. Four items were used to assess participant's attitudes toward GMF and the same four items measured attitudes toward OGF. Participants were asked to rate "what do you 
generally think about GMF/OGF" on four 5-point scales varying from 1 (very unpleasant / very bad / very unfavorable / very negative) to 5 (very pleasant / very good/ very favorable / very positive). Reliabillity analyses showed that the alpha values of this scalle were 0.90 for both GMF and OGF. The mean of the four GMF-attitude ittems was computed to construct one index measuring the attitude toward GMF. A low index-score indicates a negative attitude toward GMF a high index score a positive attitude toward GMF. An attitude index toward OGF was created in a similar manner.

(iii) Beliefs. The beliefs that were used for the purpose of this study were derived from a pilot study. This study consisted of 20 interviews, taken from people of different ages and professions (students, farmers etc, with a mean age of: $24.39, S D=8.44$ ). Participants were asked questions like: "do you know what genetic modification / organical production is "which associations do you have with genetically modified food/ organically grown food" and "what do you think are the advantages and disadvantages of genetically modified food / organically grown food ${ }^{\text {th }}$. Participants' answers were recorded and categorized and served as input for constructing the beliefs used in this study. Participants in the present study were asked to rate whether they disagreed or agreed with a number of beliefs con a 5-point scale, varying from 1: disagree very much to 5: agree very much). For GMF the beliefs that were used were: "by making use of GMF our food can be improved", "GMF offers us interesting possibilities", "GMF is unnatural", "developing countries will be disadvantaged by GMF" "GMF disturbs the ecological balance", "GMF products are less healthy than not GMF products", "GMF production leads to more food allergies", "GMF could lead to problems on the long term which we cannot see right now" and "GMF is good for the environment". The beliefs that were stated negatively were changed so that the number 1 always implied that participants were negative toward GMF/OGF and the number 7 implied that participants were positive toward GMF/OGF. A reliability analysis showed that the alpha value of these 9 beliefs was 0.76 . A belief index was created by averaging the 9 belief items. A low index score indicated an overall negative belief score for GMF. For OGF the beliefs that were used were: "OGF is good for" the environment", "OGF tastes good", "OGF products are less healthy than not OGF products", "OGF products are of less quality", "OGF is unnatural", "OGF production leads to unforeseen consequences for humans and animals", and "There are risks attached to OGF production". The alpha value of these 7 beliefs was 0.72 . A belief index was created by averaging the seven belief items. A low index score indicated an overall negative belief score for OGF.

\section{Results}

\section{Intra-attitudinal structure}

To analyze which values were related to attitudes toward GMF and OGF two regression analyses were conducted. The predictors in both analyses were the ten motivational value types. In the first analysis, only the value power added significantly to the prediction of the GMF attitude $(\beta=0.32, p<0.05)$. In the second analysis, only universalism added significantly to the prediction of the OGF attitude $(\beta=0.28, p<0.05)$.

Part of our first research question was to show to what extent beliefs toward GMF mediated the influence of power on attitudes toward GMF. A mediation analysis (Baron \& Kenny, 1986) confirmed that power had a positive effect on attitudes toward GMF, but this effect was mediated by beliefs toward GMF. First, attitudes toward GMF were regressed on 
power $\left(R^{2}=0.09\right)$. Power showed to be a significant predictor of attitudes toward GMF $(\beta=0.29$, $p<0.01), F(1,98)=9.22, p<0.01$. Second, beliefs toward GMF were regressed on power Power was a significant predictor of the beliefs toward GMF $\beta=0.28, p<0.01), F(1,98)=8.42, p<$ 0.01 . Finally, attitudes toward GMF were regressed on power and on beliefs toward $G M F\left(\mathbb{R}^{2}=\right.$ $0.39 \%$. The effect of the beliefs toward GMF on the attitude toward GMF $(\beta=0.61, p<0.01)$ resulted in the disappearance of the effect of power on the attitude toward $G M F(\beta=0.13, n s)_{\text {f }}$ $F(2,97)=30.52, p<0.01$. Therefore, the relationship between the attitude toward GMF and power seemed to be completely mediated by the beliefs toward GMF.

A second mediation analysis was conducted to see if the effect of universalism on attitudes toward OGF was mediated by beliefs toward OGF. First, attitudes toward OGF were regressed on universalism $\left(R^{2}=0.08\right)$. Universafism showed to be a significant predictor of

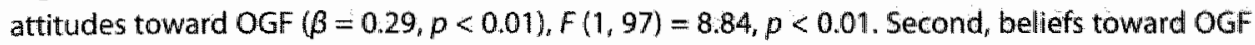
were regressed on universalism. Universalism was a significant predictor of the beliefs toward OGF $(\beta=0.22, p<0.05), F(1,98)=4.80, p<0.05$. Finally, attitudes toward OGF were regressed on universalism and on beliefs toward OGF $\left(R^{2}=0.43\right)$. The effect of the bellefs toward OGF on the attitude toward OGF $(\beta=0.60, p<0.01)$ resulted in a weakened effect of universalism on the attitude toward OGF $(\beta=0.16, p=0.05), F(2,96)=35.53, p<0.01$. A Sobel test, which tests the hypothesis that the route from values via beliefs to attitudes does not differ from zero, confirmed this partial mediation, $F(2,96)=2.14, p<0.05$ (Kenny, Kashy, \& Bolger, 1998). These results suggest that the attitude toward OGF is positively influenced by universalism and that the attitude toward GMF is positively influenced by power. These relationships between attitudes and values are mediated by beliefs and are summarized in Figure 1.1.

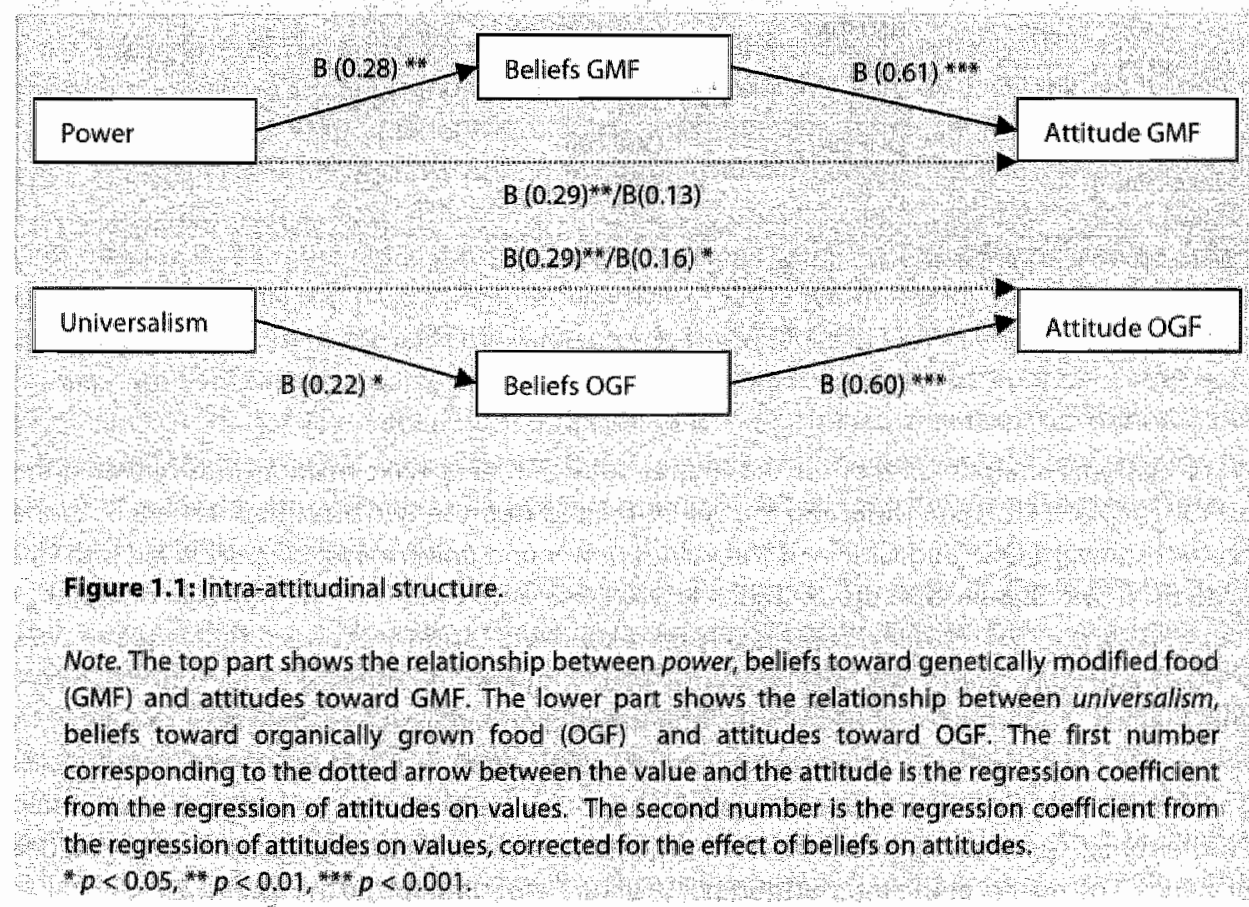


An additional analysis was conducted to see if participants who are opponents or proponents of GMF or OGF, show a different pattern in the values they adhere to. First, all participants were divided into an anti GMF group or pro GMF group (using the scale midpoint of the attitude index). Then, two separate ANOVA's were conducted. The first used power as a dependent variable (and pro versus anti GMF as independent variable); the second treated universalism as dependent wariable (and pro versus anti GMF as independent variable). The results of these analyses showed that participants who were anti GMF, scored lower on the value power than the participants who were pro GMF, $F(1,98)=9.50, p<0.01$. However, participants who scored low on GMF, did not differ in their universalism scores from participants who scored high on GMF, $F(1,98)=0.77, p=n s$.

Secondly, participants were divided into an anti OGF group or a pro OGF group fusing the midpoint of the attitude index). Then, two ANOVA's were conducted. The first had power as a dependent variable (and pro versus anti OGF as an independent variable) and the second had universalism as a dependent variable (and pro versus anti OGF as an independent variable). The results of these analyses showed that participants who scored low on OGF scored higher on the value power than the participants who scored high on OGF, $F(1,98)=5.29, p<0.05$. However, participants who scored low on OGF, did not differ in their universalism scores from participants who scored high on $\mathrm{OGF}, F(1,98)=1.25, p=n s$. In summary, people who score high on GMF or OGF differ in how much they adhere to the value power from people who score low on GMF or OGF. These results can be found in Table 1.1.

Table 1.1. The values that opponents and proponents of GMF and OGF adhere to.

\begin{tabular}{|c|c|c|c|c|}
\hline & GMF pro & GMF con & $P$ & p \\
\hline Universalism & 400 & 4.17 & 0.77 & 038 \\
\hline Power & 236 & 1,61 & 9.50 & $0,003^{\circ}$ \\
\hline & OGF pro & OGF con & f & $p$ \\
\hline Unversalism & 417 & 392 & 125 & 027 \\
\hline Power & 171 & 240 & 5.29 & $0.024^{\circ}$ \\
\hline
\end{tabular}

Nate $p<005 * p<001$

\section{Inter-attitudinal structure}

A correlational analysis was conducted to find out whether specific relationships between the attitude toward OGF and GMF, and the values related to these two attitudes existed. Both the attitudes toward OGF and GMF and the values power and universalism were inserted into this analysis. It was shown that the attitudes toward OGF and GMF were negatively correlated, $r$ $(98)=-0.29, p<0.05$. Power was positively correlated with attitudes toward GMF, $r(98)=0.29$, $p<0.01$ and universalism was positively correlated with attitudes toward $O G F, r(98)=0.29, p<$ 0.01 , which confirmed the results of the regression analysis. Furthermore, power was negatively correlated with the attitude toward OGF, $r(98)=-0.24, p<0.05$. These results propose an inter-attitudinal structure in which the two attitudes are opposed to each other. Furthermore, specific combinations of attitude patterns are reflected in specific combinations of walues. The results of the inter-attitudinal structure are summarized in Figure 1.2. 


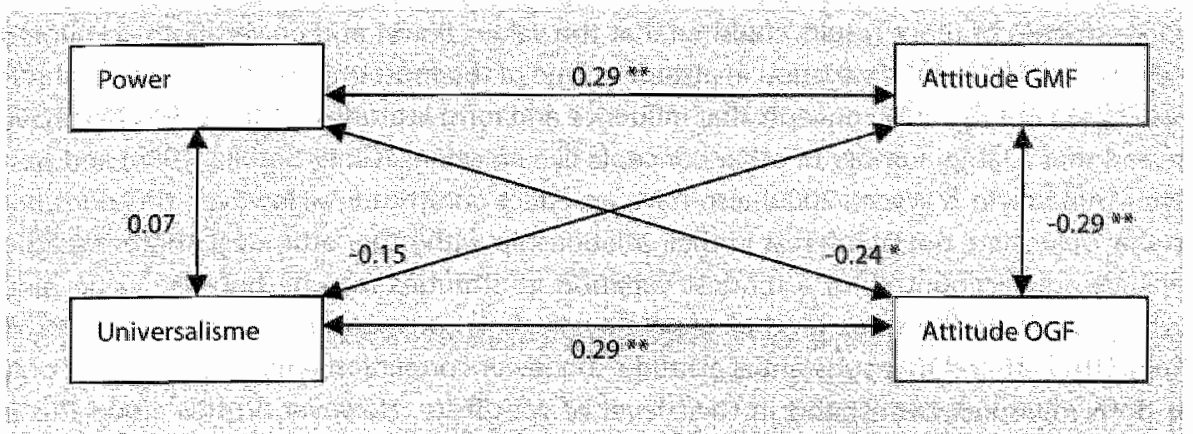

Figure 1.2: Inter-attitudinal structure.

Note The numbers represent the carrelations between the concepts:

$0 p<0.05, * 0<0.01$

\section{Discussion}

In this study, we examined the underlying inter- and intra-attitudinal structures of two, supposedly opposing attitude issues, i.e. genetically modified food (GMF) and organically grown food (OGF). A first finding was that the attitudes toward GMF and OGF were indeed negatively related. Apparently, a positive attitude toward GMF implies a negative attitude toward OGF and vice versa.

Furthermore, it was shown that OGF was related to power (negatively) as well as universalism (positively), and GMF was related to the value power (positively). This implies that the two opposing attitude positions indeed have a connection with distinctly different values, as was predicted. Respondents who agree with human domination over our natural environment, or are not against having everything under control, are also not opposed to influencing natural processes. These respondents also foster the least negative feelings toward GMF, because GMF is the ullimate way for human beings to master natural processes that they could not master in the past. A high adherence to OGF, which stands for naturalness and unaffectedness, is not in line with the value power. The essence of OGF is that in its production, human interventions are sparse and as natural as possible. Therefore, respondents being in favor of OGF show a low adherence to the value power. Although we expected the reverse relationship between GMF attitudes and the value universalism, this was not the case for our group of respondents. The value universalism could not differentiate between the respondents who scored high or low on GMF.

These results are in accordance with the predictions on the basis of the Schwartz value structure. According to this structure, the values power and universalism are two extremes on a continuum that ranges from self-transicendence (promote welfare of others) to selfenhancement (own personal interests), which implies that the two values are in conflict with each other. A possible practical implication of these findings is that, at least for $O G F$, there could be two ways to affect attitudes. On the one hand, one could focus on universalism, by emphasizing that OGF fits entirely into a universalistic state of mind. On the other hand, one could also try to focus on power, by showing that being opposed to power is compatible with a pro OGF attitude. 
One criticism of these results could be that the values power and universalism accounted for only around $10 \%$ of the variation in attitudes. One of the most irmportant reasons for this is that values are not the only concepts that influence and form attitudes. Other researchers have suggested that a large number of other concepts like emotions (Giner-Sorolla, 1999) and past behavior (Albarracin \& Wyers, 2000) also have an effect on attitudes. However, this does not mean that values are not of interest in their relationship with other attitudes. Another reason that values only accounted for a modest variation in attitudes may be because values and artitudes are not on the same level of generality. In their correspondence principle, Ajzen \& Fishbein, (1977) stated that substantial attitude -behavior correlations will be established only when both measures correspond in their level of specificity. However, in this study this is obviously not the case, because values are per definition global constructs, whereas attitudes are much more specific. Given this difference in specificity, it is quite meaningful that we were able to establish modest, but significant relationships between values and attitudes.

A further goal of this study was to specify the position of beliefs and attitudes in their relationship with values. An interesting finding was that beliefs related to GMF and $O G F$ moderated the relation between attitudes and values. Earlier studies have suggested such a relationship between values, attitudes and beliefs, but until now such relationship has not been explicitly demonstrated. The fact that beliefs are positioned between attitudes and values suggests that changing attitudes via values is probably more effective if the communication aims at the link between a person's values and relevant beliefs. However, it may be the caise that this relationship mostly holds for attitude-issues for which people show a low involvement and are not really familiar with the attitude-object. In this case, beliefs, which are more specific than the more general attitude-issue, might help people to see the attitudeobject in less abstract terms and therefore make it more down to earth and more understandable and applicable for respondents. This can result in a heightened involvement with the attitude-issue.

of course it should be noted that the specific content of relations between attitude positions and values are based on a limited sample of Dutch university students. In other words, samples such as "average consumers", "conservationists" or "technical engineers" could show a completely different attitude-value pattern. However, it was not our aim to obtain a general representation of how certain food-related attitudes relate to specific values but to demonstrate that values may add to our understanding of food-related attitude structures.

All in all, our results show that opposing attitude positions are reflected in a different structure of values. Identifying relevant values helps to understand food-related attitudes and, moreover, knowledge about specific underlying patterns of values may serve as input for developing instruments to affect or maintain existing attitudes. Therefore, research aiming at understanding or influencing food related attitudes should not limit itself to categorizing attitudes and their accompanying relevant beliefs, but should allso focus on the specific underlying values. 


\section{Chapter 2}

\section{Food and the relation between values and attitude characteristics ${ }^{2}$}

This survey showed that the values power (dominance over nature and resources) and universalism (respect for people and for nature) are related to attitudes toward genetically modified food (GMF) and organically grown food (OGF). Furthermore, these values have an influence on the centrality, commitment and ambivalence of these attitudes. Values that are positively related to an attitude influence how central this attitude is to a person. However, values that are negatively related to an attitude have a larger effect on the commitment of this attitude. No such pattern of effects was found for the relationship between ambivalence and values. These data suggest that centrality, commitment, and ambivalence are structurally different constructs that have a distinct relationship with specific values.

2 This chapter is based on the following article: Dreezens, E, Martijn, C.n Tenbült, P., Kok, G. \& de Vries, N. K. (2005). Food and the relation between values and attitude characteristics. Appetite, 45, 40-46. 
For some consumers, ideological considerations are important determinants of their food preferences. For example, for most vegetarians, their diet signifies an ideology of how life ought to be lived and not only what one is allowed to eat (Lindeman \& Sirelius, 2001). Although taste, price, availability and nutritional value are important factors, some people decide what, or what not to eat on the basis of moral considerations. Thus, in purchasing food, consumers beliefs (e.g. orgarically grown food is good for the environment), attitudes (e.g. I am very positive toward organically grown food) and values (e.g. protection of all people and nature is important to me) are impontant determinants of their behavior. However, the main focus of this chapter will be on the influence of values on food-related attitudes and attitude characteristics. Not only will we discuss the relationship between values and attitudes, but more importantly, we will emphasize that values also have an effect on specific attitudinal characteristics like attitude strength and ambivalence. Therefore, the central question of this paper is: what are the structural relations between values and three attitudinal characteristics: centrality, commitment and ambivalence. Values are important guidelines in people's lives. These three attitude characteristics not only give us information about the way an attitude is constructed, but also about how much the attitude is embedded into an underlying structure and how certain people are about their attitude. We will discuss this in the context of foodproduction technologies like genetic modification and organically grown food. These are two opposing attitude issues. Because previous research has already shown that these two attitude-issues differ in their attitude strength and ambivalence (Dreezens et al., unpublished data), they therefore provide a good means to study the influence of values on attitudes that differ in attitude characteristics.

\section{Attitudes}

An attitude is a psychological tendency that is expressed by evaluating a particular entity with some degree of favor or disfavor (Eagly \& Chaiken, 1995). An attitude is formed during the encounters a person has with an attitude-object. During these encounters, bellefs about the attitude-object are formed: An attitude consists of an organization of several bellefs focused on a specific object or situation. Beliefs are defined as "salient information relevant to the behavior" (Ajzen, 1991). An individuall may hold several beliefs toward an object, and with each of these beliefs comes an evaluation. All these beliefs and their evaluations together form an attitude.

In this chapter, we focused on two types of food products: genetically modified food (GMF) and organically grown food (OGF). The choice for these two types of products was made because of their assumed incompatibility. lt seems likely that attitudes toward OGF and GMF are negatively related because GMF is manipulated and altered by human hands, whereas the OGF is characterized by "naturalness" and "pureness" (Schifferstein \& Oude Ophuis, 1998). Therefore, they may represent an incompatibility in their underlying value structure. For some people, this incompatibility in underlying value structures is not a problem. They know very well what to think of the attitude-issue, because they for example only adhere to one of the values underlying these food-related attitudes. These people have a very strong attitude which is not ambivalent. On the contrary, other people, who see both the advantages and disadvantages of an attitude-issue have a less strong and more ambivalent attitude. Therefore, these two attitudes provide us with a broader perspective of the influences that values can have on attitudes and attitude characteristics than one attitude issue would have. 


\section{Values}

Values are assumed to be building blocks of attitudes (Eagly \& Chaiken, 1995; Verplanken \& Holland, 2002). Schwartz and Bilsky (1990) describe values as concepts or beliefs about desirable end states or behaviors, that transcend specific situations, guide the selection or evaluation of behavior, and are ordered by relative importance. Values are the most abstract of the social cognitions and serve as prototypes from which attitudes are derived (Homer \& Kahle, 1988; Luzar \& Cosse, 1998). Once a value is internalized, it becomes a standard or criterion for guiding action and for developing and maintaining attitudes toward relevant abjects and situations. A persons value system represents a learned organization of rules for making choices and for resolving conflicts (Rokeach, 1968, pp. 159-160). This means that; when people have to construct an attitude about new technolagies like genetic modification, they may be guided by the values that they find important. If the attitude-object fits with a person's values, this value will influence the attitude toward this issue.

A taxonomy of values that proved to be relatively stable among cultures was developed by Schwartz (1992; Schwartz \& Bilsky, 1990). According to this taxonomy, there are ten motivational value types that can be found in every culture and each of the ten motivational values types is subdivided into more specific values. The ten high-level values are successively: self direction, stimulation, hedonism, achievement, power, security, conformity, tradition, benevolence and universalism (Schwartz, 1992). People in all cultures acknowledige these values and the only individual and cultural differences consist of which values are found most important and guide attitudes and behavior.

\section{Values and attitudes}

One of the prominent functions of attitudes is to express personal values (Katz, 1960) and therefore, attitudes have to be influenced by or related to the values that they express. Values affect attitudes by focusing not simply on the whole attitude, but by making some specific aspects of an attitude (beliefs) more salient or important. For example, imagine a person who holds the following beliefs about eating meat: "eating meat is unethical" and "meat tastes good". If she considers the value universalism (protection for all people and for nature) as a guiding principle in her life, the first belief is probably more important and salient to her than the second belief. Because of the match between her value and a specific belief ("eating meat is unethical"), such a belief is likely to influence her overall attitudle toward eating meat to a greater extent than beliefs that do not match her important values. This would mean that when dining in a restaurant, she will think twice before ordering a large steak. Vice versa, if another person considers hedonism (pleasure, enjoying life) as a gulding principle in life, the belief about excellent taste of meat will probably influence the attitude most. This persion might then feel no guilt when eating a Big Mac for lunch.

Previous research, where the influence of the 10 values of the Schwartz Value Survey on the attitudes toward GMF an OGF was measured, showed that the attitude toward OGF was negatively related to the value power as well as positively related to the value universalism (Dreezens et al., 2005). However, GMF was positively related to the value power. This survey showed that the two opposing attitude positions have a different connection with values. Participants who did not oppose human domination over the natural environment, or favored having everything under control, were also not opposed to influencing natural processes by 
making use of GMF. A high adherence to OGF, where human interventions are sparse and as natural as possible is not in line with the value power, but in line with the value universalism. Therefore, respondents who were in favor of OGF show a low adherence to the value power and $a$ high adherence to universalism. It seemed that only the values power anid universalism had an influence on the attitude toward GMF and OGF. Therefore, the focus in this chapter will be on the relationship between these two values and the attitudes toward GMF and OGF.

\section{Attitude strength}

Some attitudes are important to us, they are central to our being. Other attitudes are trivial and do not have a large effect on us. The attitudes that are important to us and that will often come to mind or lead us in our daily behavior are called strong attitudes. People's attitudes become stronger when they have more direct experience with an attitude-object, when they are more involved with the attitude-object, or when they have expressed their attitude frequently (Krosnick, Boninger, Chuang, Berent, \& Carnot, 1993; Lord, Lepper, \& Mackie ; 1984). Strong attitudes are thought to have four characteristics (Pomerantz, Chaiken, \& Tordesillas, 1995). First, strong attitudes lead to selective cognitive processing. Second, strong attitudes are resistant to change. Third, strong attitudes are persistent over time and fourth, they are able to predict behavior. Because strong attitudes are important to a person, they easily spring to mind whenever the person encounters an attitude-object. The behavior that follows from seeing this attitude-object is therefore likely to be influenced by this particular attitude.

Additionally, there are two important strength dimensions: centrality and commitment (Holland, Verplanken, \& van Knippenberg, 2002). Centrality refers to the importance of an attitude to the self concept and personal values. Central attitudes are characterized by strong links between the attitude's core constituents (belliefs). Moreover, central attitudes are strongly embedded into the structure of personal values. Commitment refers to the certainty or conviction about the attitude. An attitude to which a person has a high commitment comes to mind very easily and therefore plays an important role in decision making. Because there seems to be a difference in how much centrality and commitment are related to personal values; these two strength dimensions will be used to uncover the influence of values on attitude strength. We predict that values will have a different influence on centrality than on commitment.

\section{Ambivallence}

Another important aspect of attitudes that is related to attitude strength is whether or not the attitude is ambivalent. Ambivalence refers to a situation in which an individual has equally strong positive and negative evaluations toward an attitude-object (Armitage \& Conner, 2000). In other words, people simultaneously see positive and negative sides of the attitude-object, and this gives them an unresolved or unpleasant feeling. There is a negative relationship between attitude strength and ambivalence. Ambivalent attitudes are less guiding for behavior and less persistent over time, whereas strong attitudes are more guiding for behavior and persistent over time. However ${ }_{z}$ since strength and ambivalence are theoretically different constructs, we wish to see if values have a differentiating role to play.

Ambivalence is associated with lower certainty of an attitude. Therefore, ambivalence might be mostly related to attitude commitment ${ }_{r}$ and less to centrality. Since the centrality of 
an attitude is expected to be influenced by related values, it is not expected that ambivalence and values are highly related.

In the present chapter, the data of 6 survey studies, all conducted between June 2002 and June 2004 were used. In every one of these studies, participants were asked about the values they adhered to, their attitudes toward GMF and OGF and their attitude strength and ambivalence toward these two attitude issues. Because all measures were the same in these 6 studies, it was possible to collapse these data into one sample, thereby improving generalizability and sample size. This overall sample consists of data of student-and consumer populations. Hereby we hoped that the data obtained in these analyses would shed a greater light on the issue than when only students would be considered.

\section{Method}

\section{Participants}

This overall sample consisted of 241 participants, both students (180) and consumers (61), of which 75 were men, with a mean age of 26.0 (ranging from 18 to 76 ).

\section{Measures}

In each of these 6 experiments we asked people about their attitudes toward genetically modified food (GMF) and organically grown food (OGF) and about their attitude strength and ambivalence toward GMF and OGF. However, the centrality and commitment measures could only be computed for some of the participants, due to the fact that the answers on the individual attitude strength questions were not allways available: Therefore, the total number of participants can vary between the different attitude characteristics.

WValues. Previous research (Dreezens et al., 2005) has shown that only the values power and universalism have an effect on the attitudes toward GMF and OGF. Therefore we only used these two values. To do so, we used the power and universalism subscales of the Schwartz Value Survey (Schwartz, 1992). People were asked how important they found each of the sub values of the power and universalism subscales (like "dominance" or "respect") on a nine-point scale ranging from - 1 (opposed to my walues) to 9 (extremely important).

ii) Attitudes. Four items were used to assess participant's attitudes toward GMF and the same four items measured attitudes toward OGF. Participants were asked to rate "what do you in general think about GMF/OGF on four 5-point scales varying from 1 (very unpleasant / very bad / very unfavorable / very negative) to 5 (very pleasant / very good / very favorable / very positive). An attitude index score was calculated for both GMF and OGF, using these four questions.

iii) Centrality. A centrallity index was composed by asking participants three questions. These were: "how much do you personally care about GMF/OGF?" (very little - very much); "how representative of your values is your attitude toward GMF/OGF?" (very unrepresentative - very representative); "how central is your attitudle toward GMF/OGF to your self-image?" (very

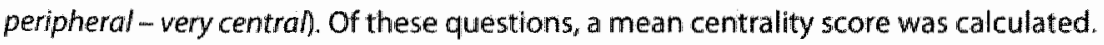


W) Commitment. A commitment index was composed by asking participants four questions. These were: "how certain are you that your opinion about GMF/OGF is correct?" (very uncertain - very certain); "how often do you think about GMF/OGF?" (very little - very much); "how interested are you in obtaining information about GMF/OGF? (very uninterested - very interested) and thow knowledgeable are you about GMF/OGF? (very unknowledgeable - very knowledgeable), of these questions, a mean commitment score was calculated. The quiestions for the centrality and commitment indexes were derived from several studies on attitude strength (Holland, Verplanken, \& van Knippenberg, 2002; Lawine, Huff, Wagner, \& Sweeney, 1998, Pomerantz, Chaiken, \& Tordesillas, 1995).

v) Ambivalence. To assess ambivalence, thiree items were used. These were: "I have doubts about my attitude toward GMF/OGF" "I cannot choose between the pros and cons of GMF/OGF" and "I have conflicting thoughts about GMF/OGF". All ambivalence questions were answered on a 5 point scale with endpoints: not at all applicable - very much applicable. This ambivalence questionnaire was composed by using items that were taken from another study on attitude ambivalence (Jamieson, 1988).

\section{Results}

\section{Attitudes}

The overall attitude toward GMF in this sample was 2.98 on a scale from 1 to 5 , which means that people were relatively neutral about GMF. Furthermore, the overall attitude toward OGF was 4.15 on a scale from 1 to 5 , which means that people were positive toward OGF. These attitudes were significantly different from each other. This implies that students and consumers are in general more positive toward DGF than toward GMF. These results are summarized in Table 2.1.

Table 2, 1 . Means, standard deviations and number of participants for the attitude, centrality, commiliment and ambivalence of both GMF and $0 G$.

\begin{tabular}{|c|c|c|c|c|c|c|c|}
\hline 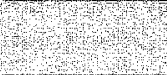 & & $\begin{array}{l}6 \mathrm{M} \\
\mathrm{sD}\end{array}$ & M & & $\mathrm{OGF}$ & $N$ & T(patred) \\
\hline Altuge & 298 & 0.08 & 237 & 415 & 0.88 & 240 & 1376 \\
\hline Centrally & 2.81 & $0.6 \%$ & 173 & 296 & 0.94 & 175 & $8.49 *$ \\
\hline Comunitment & 2.25 & 078 & 175 & 273 & 0.84 & 175 & $662 *$ \\
\hline Amblvalenee & 287 & 0,90 & 241 & 253 & 0,80 & 241 & $5.02 \pi$ \\
\hline
\end{tabular}

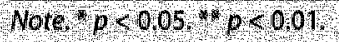

\section{Attitudes and values}

To analyze how the values power and universalism were related to the attitudes toward GMF and OGF, two regression analyses were conducted. In the first analysis, both the values power and universalism added significantly to the prediction of the GMF attitude. However, power showed a positive contribution to the GMF attitude, $\beta=0.17, p<0.01$, whereas universalism showed a negative contribution to the GMF attitude, $\beta=-0.20, p<0.01$. In the second analysis, 
both power and universalism predicted the OGF attitude in a significant way. This time, universalism was positively related to the OGF attitude $\beta=0.21, p=0.001$, and power was negatively related to the OGF attitude $\beta=0.13, p<0.05$. These results show that the attitudes toward GMF and OGF relate differently to the values power and whiversalism. This is in accordance with previous research by Dreezens et al., (2005) that showed roughly the same pattern, only then for a population that consisted entirely of students: This is summarized in Table 2.2 .

Table 2.2: The beta weights (and accompanying p-values) of the effect of the values power and universalism on the attitude, centrality, commitment and ambivalence of both GMF and OGF. The beta weights for centrality are corrected for the effect of commitment and vice versa.

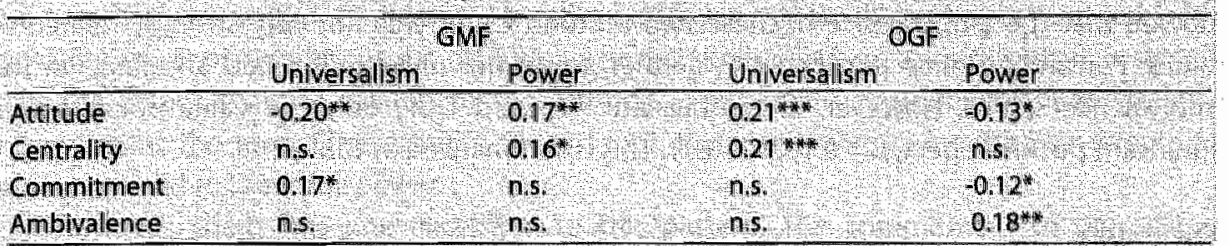

Note, $p<0.05 * p<0.01, * * 0<0.001$.

\section{Centrality, commitment and ambivalence}

Because a difference was expected in how values affected the three attitudinal characteristics, it seemed reasonable to first look at the correlations between these three concepts. Therefore, a correlational analysis was conducted in which centrality, commitment and ambivalence were used as variables. For GMF, there was a positive correllation between centrality and commitment $(r=0.45, p<0.001)$. Furthermore, there was a negative correlation between ambivalence and commitment $(r=-0.23, p<0.01)$, but no correlation between ambivalence and centrality. For OGF, the same pattern occurred. There was a positive correlation between centrality and commitment $(r=0.67, p<0.001)$, a negative correlation between ambivalence and commitment $(r=-0.23, p<0.01)$, but no correlation between ambivalence and centrality. Because of the high correlation between centrality and commitment, it was decided that when the relation between the values universalism and power on the one hand and either centrality or commitment on the other hand would be investigated, this relationship would be corrected for the influence of the other strength characteristics.

\section{Centrality, commitment and values}

Participants" attitudes toward GMF were both less central and less committed than their OGF counterparts (see also Table 2.1). When examining the relationship between power and universalism on the one hand and centrality and commitment of the attitudes toward GMF and OGF on the other hand, an interesting pattern occurred. A regression with the two values as predictor variables and centrality of the GMF attitude as dependent variable (but corrected for the effect of commitment, by adding commitment to the predictor variables) showed that only power could significantly predict the centrality of the attitude toward GMF, $\beta=0.16, p<0.05$. 
However, for commitment toward GMF (corrected for the effect of centrality), only the value unversalism was a significant contributor, $\beta=0.17, p<0.05$.

A mirrored pattern was found for the centrality and commitment toward OGF. For centrality, universallism was a positive predictor of $O G F, B=0.21, p<0.001$. This relationship between centrality and universalism was corrected for the effect of commitment. Furthermore the value power was negatively connected to the commitment toward OGF (corrected for centrality) $\beta=-0.12, p<0.05$. This is summarized in Table 2.2 .

\section{Ambivalence and values}

The overall data showed that people were significantly more ambivalent toward GMF than toward OGF (see also Table 2.1) Two regression analyses with power and universalism as predictors and the ambivalence of the attitudes toward GMF and OGF as dependent variables showed that the ambivalence of these two attitude issues was not very strongly related to values. For ambivalence toward GMF, neither power nor universalism had an effect on the ambivalence scores. However, for ambivalence toward $O G F$, only the value power had a significant positive effect, $\beta=0.18, p<0.01$. This is summarized in Table 2.2 .

\section{Discussion}

The purpose of this survey was to investigate whether values have an influence on attitudes as well as on centrality, commitment and ambivalence. Traditionally, the role of values has been researched in the light of their relationship to attitude issues, but to a lesser extent in their relationship to specific attitude characteristics. Because the attitudes toward GMF and OGF differ in their attitude strength and ambivalence, these two attitude issues were chosen to illustrate the ideas discussed in this chapter.

It was confirmed that the attitudes toward GMF and OGF indeed differed on several attitude characteristics. First of all, the attitude toward OGF was more positive than the attitude toward GMF. This was probably due to the fact that GMF is considered to be a scary development by many people and is associated with negative affect (Laros \& Steenkamp, 2004). Second of all, the attitude toward OGF was more central and more committed than the attitude toward GMF. Participants held their OGF attitude with more confidence and this attitude was more embedded into its internal structure than the attitude toward GMF. Third of all, the attitude toward OGF was less ambivalent than the attitude toward GMF. Participants experlenced more conflict regarding their attitude toward GMF than regarding their attitude toward OGF.

Furthermore, it was shown that the two attitude issues have a different relationship with the values power and universalism. Power had a positive effect on the attitude toward GMF and a negative effect on the attitude toward OGF. For universalism, this pattern was reversed. These results replicate the results of a previous survey (Dreezens et al, 2005). This implies that, although the same values underlie the two attitude issues, the underlying pattern is not the same, and it is this pattern that determines a persons' attitude.

Another interesting finding was that ambivalence, centrality and commitment seem to be different constructs (although the correlation between centrality and commitment was relatively high). Theoretically, there has been much debate about whether all attitude strength characteristics (like ambivalence, centrality and commitment) could be summarized into one variable or that these characteristics are different constructs. Our results imply that, although 
there is some overlapping between these three constructs, they are structurally different. For example, ambivalence was only slightly related to values, whereas both centrality and commitment were more related to values. Therefore, these thiree constructs each cover a part of the attitude strength construct that the other two do not.

Values have a different effect on centrality than on commitment. The results suggest that the values that have a positive effect on the attitude toward GMF and OGF are the ones influencing the level of centrality (how much is your attitude related to its underlying values). For GMF, people who adhered to power, had a more central attitude than people who did not adhere to power. The value universalism (which is negatively related to the attitude toward GMF) had no effect on centrality. However, for the attitude toward OGF, the value universalism had an effect on the centrality of the attitude (whereas the value power had none effect whatsoever). Thus, the stronger the positive relationship between an attitude and a value, the more central the attitude (influenced by that particular value) will be. For commitment (the certainty or conviction about the attitude), exactly the opposite pattern occurred. It seemed that the values that are related to the attitude in a negative way influence the level of commitment the most. The attitude toward OGF becomes more committed as people are more opposed to the value power.

However, there was one exception to this pattern. The commitment of the attitude toward GMF was indeed related to the vallue universalism, but not in a neglative way as was expected on the basis of the relationship between universalism and the attitude toward GMF. Why this was the case is not entirely clear. Perhaps the ambivalence of the attitude toward GMF had a role to play in this finding. Ambivalence means that people have conflicting thoughts about an attitude issue. This means that they could consider both power and universalism important values, and therefore were not able to make up their minds about GMF. This way, universalism could have had both a negative influence on the attitude toward GMF, and a positive influence on the commitment of the attitude toward GMF.

The pattern of results where centrallity is related to values that have a positive influence on related attitudes and commitment is related to values that have a negative influence on related attitudes is somewhat surprising. However, it is probably due to the fact that centrality is, more than commitment, related to the self concept. This means that in defining yourself, the attitudes and values most central to you will probably play a large role. However, people define themselves and the things that are important to them in a positive manner. A person holding a positive attitude toward OGF will probably see him or herself as "adhering to the value universalism" and not as "not adhering to the value power". We therefore assume that centrality is related to the values that have a positive influence on the attitude issue at hand. For commitment, which is not highly related to the self concept, this effect (describing yourself in positive terms) has a much smaller influence. However ${ }_{4}$ more generally, other research has noted a tendency for negative information to result in larger cognitive, emotional, and social responses (Ito, Larsen, Smith, \& Cacioppo, 1998; Taylor, 1991). This might mean that (when people are not motivated to use positive information like when dealing with the self) negative information gives a person more assurance and influences attitudes to a larger extent. It is therefore not surprising that values that have a negative influence on attitudes play a larger role in the commitment of an attitude.

Another issue to be considered is the fact that, although a relationship exists between attitudes, attitude characteristics and values, this is a significant but weak one. However, we did not expect to find large relationships between these concepts. Ajzen \& Fishbein (1977) 
state that attitudes and behavior must be correspondent in their level of specificity to make sure that a strong relation between the two can be found. They claim that a very specific attitude is much more able to predict a very specific behavior than a more general attitude. We expected that the same principle allso holds for the relationship between attitudes and values. Values are more abstract concepts than attitudes, and this makes it difficult for the concepts to influence each other. This however means, that finding any relationships between the two, is more meaningful than when the relationship could be easily found.

All in all, this survey showed that the values power and universalism are related to the centrality, commitment and ambivalence of the attitudes toward GMF and OGF. Centrality, commitment, and ambivalence are structurally different constructs that have a distinct relationship with walues. Therefore, we cannot simply say that strong attitudes are more related to values than weak attitudes, but attitude strength needs to be unraveled into these three components to see their autonomous influences. This way, the complicated relationships between food-related attitudes, attitude characteristics and values become more insightful and easier to interpret. 
Part 2

The missing link between values and attitudes 


$$
\frac{\tilde{1}}{\frac{1}{2 a}}
$$




\section{Chapter 3}

\section{Is priming enough? The effect of activated values on related attitudes and behavior}

In Chapter 3, two studies are described that focused on actually activating values and measuring an effect on related attitudes and behavior. Studies 3.1 and 3.2 were designed to prime both students and non-student consumers with the values power and universalism and to measure an effect of these primed values on the attitudes toward genetically modified food and organically grown food and on behavior related to these attitudes. No direct effect of the activation of the values was found on the attitudes themselves. However, the priming of the values universalism and power was somewhat reflected in the attitude strength and ambivalence toward GMF and OGF. These experiments showed that priming values does have a small result on attitude characteristics, but that it does not change attitudes themselves. 
Values are important for understanding various social psychological phenomena, like the selfconcept (Eagly \& Chaiken, 1995), personal norms (Thorgersen, 1999) choices (Verplanken \& Holland, 2002) and preferences (Feather, 1995). Theoretically, values influence attitudes (Homer \& Kahle, 1988; Maio \& Olson , 1994; Kehoe, 1975), and as a result, attitudes should be in line with their underlying values. However, although values can be considered as relatively stable and important constructs, people do not always think about their values while making everyday decislons (Verplanken \& Holland, 2002). The fact that values are not always readily available in memory when people articulate their attitudes may explain why inconsistencies between values and attitudes are often observed. Therefore, it is interesting to examine under what conditions people do use values as guiding principles in their lives. Do people live up to their values if these values are recently activated? Does activation of a value lead to attitudes and behavior in accordance with these values?

The current research used a priming paradigm to activate specific values, and then measured the effect of this activation on related attitudes and behavior. When a value is activated, for instance due to priming, the relationship between attitudes and values becomes stronger, because the attitude is seen in the light of this activated vallue, and is therefore more strongly based on this activated value. The goal of this chapter is twofold. The first goal is to investigate whether the relationship between values and attitudes can be strengthened by activating a certain value, thereby manipulating the accessibility of this specific value. The study in Chapter 1 of this dissertation demonstrated a relationship between the values power (control and dominance over people and resources) and universalism (respect and protection for all people and nature) on the one hand and the attitudes toward GMF and OGF on the other hand. The attitude toward GMF is positively related to the value power. The attitude toward OGF is negatively related to the value power and positively related to the value universalism. However, the evidence provided in Chapter 1 was only correlational. In the two experiments that will be discussed in the present chapter, the accessibility of the values power and universalism will be experimentally manipulated. Actually manipulating a relationship provides more insight in the time-course of the effect and can give more insight into the causal relationship between values and attitudes. If a value is activated before an attitude is measured, it is likely that effects that are found stem from the value influencing the attitude. With correlational data, such an influence cannot be separated from other influences. The second goal of this chapter is to measure whether activating a specific value also results in an effect on related behavior.

\section{Values, attitudes and behavior}

As discussed in the introductory chapter, values are abstract constructs that transcend specific situations and guide people's attitudes. One specific value can underlie many different attitudes, and one attitude can be influenced by a number of different values. If people adhere to a certain value, this value should be a guiding influence in their lives. Because they transcend specific situations and are guidellines or ideals, values per definition have motivational power. Values affect attitudes by focusing not on the whole attitude, but indirectly, by making specific beliefs that make up an attitude more salient or important. If these value-related beliefs were not part of the overall attitude before the value was made accessible, this activation of the specific value leads to a change in the belief-structure of the attitude, and might therefore lead to a change in the attitude itself. This was also shown in 
Chapter 1 of this dissertation, where the relationship between values and attitudes was mediated by beliefs.

The structure that encompasses values, beliefs and attitudes is called an intra-attitudinal structure. This internal structure consists of all the mental representations that underlie an attitude. An attitude that is strongly tied into its intra-attitudinal structure is called a strong or central attitude (Eagly \& Chaiken, 1995). Because of their strong links to other concepts; these attitudes are difficult to change and have a large effect on information processing. Attitudes that are more strongly embedded in their internal structure are also more predictive for behavior. Attitudes that are less strongly tied to an internal structure are called weak attitudes, and these are less difficult to change, but also less predictive for behavior. Several researchers have found evidence for a value-attitude-behavior relationship (Luzar \& Cosse, 1998; Maio \& Olsen, 1994; Thøgersen \& Ölander, 2002; Fishbein, 1963, Bemard, Malo, Olsen, 2003). It is commonly believed that the causality flows from values through attitudes to behavior. In other words, values have an impact on attitudes and behavior; but values are usually not influenced by attitudes or behavior. For instance, Homer and Kahle (1988) showed that nutrition attitudes influenced shopping behaviors and that values were associated more strongly with nutrition attitudes than with behavior (buying certain products). Thus, nutrition values did influence shopping behavior, although this influence was not direct but mediated by nutrition attitudes: Maio, Olson, Allen and Bernard (2001) demonstrated experimentally that increasing the salience of the value "equality" resulted in participants behaving in a more egalitarian manner, especially if participants reflected on their reasons to rate the value of equality high. A study by Bardi and Schwartz (2003) showed that the ten values of the Schwartz Value Survey related differently to behavior. These authors measured behavior by giving participants 80 behavioral items such as: "persuade others to go along with my preferences and options" (power) or "make sure everybody I know receives equal treatment" (universalism). In the study by Bardi \& Schwartz, the values universalism and power, which will be studied in the experiments in the present chapter as well, were found to be moderately related to behavior (correlation between universalism and the behavioral items belonging to universalism was 0.55 , the correlation between power and the behavioral items belonging to power was 0.52 ). These correlations suggest that on the one hand the relationships between the values power and universalism and behavior are strong enough to actually be found in an experiment and on the other hand that they are not too strong, so that they leave room to be strengthened by a manipulation.

So far we have discussed attitudes being related to values and that these two concepts may have an influence on the behavior that people will show. However, do attitudes related to important values also have a larger influence on behavior than attitudes related to unimportant values? This is probably so. The values that people find important are related to their self concept. By making up part of the self, walues are highly accessible and will lead an individual to be attentive to value-relevant information. This means that individuals define certain situations as either being in line with these important and accessible values or as not being consistent. As a result, important values may have a large influence on how people interpret the environment and on their attitudes and behavior. Central values elicit a motivation to act, because the self concept needs to be protected and preserved. These attitudes and values become activated every time the self is threatened, so that the person can counter these attacks to the self concept. Therefore, values that are important and accessible 
because they are related to the self concept, have a larger influence on attitudes and behavior than values that are considered not important (Verplanken \& Holland; 2002).

\section{Priming:}

Ore of the most prominent methods to manipulate the accessibility of participants attitudes or specific information used in information processing and decision making is called priming. Priming is the process by which the accessibility of specific information is increased or information is activated by recent or repeated exposure to similar information (Rotenberg et al, 2005). A simple example of priming is that if you have just heard the word "butter" (the prime), and somebody asks you to give an example of something else that you can eat for breakfast, you will probably name the word "bread" first. The idea behind this is that "bread" and "butter" are related to each other, and if the one concept is activated, the other becomes slightly activated too. On a next task, the slightly activated concept (if applicable to the task) will win from other concepts that were not activated by the previous task and that are unrelated to the prime (like cruesll or yoghurt). Priming participants, thereby making certain information more accessible, can result in the activation of certain values or attitudes or even in direct behavior change (Kawakami, Dovidio, \& Dijksterhuis, 2003): Values that are more accessible are more easily activated by a priming procedure, have a larger influence on related attitudes and behavior.

Most of the research that involves priming can be roughly divided into two categories. The first category focuses on priming in such a way that the participant remains totally unaware of the priming, also called subliminal priming or unconscious priming (Lombardi, Higgins, \& Bargh, 1987). However, the present experiments will not involve subliminal priming, but priming where participants are consciously aware of the priming stimulus. The participants consciously see or process these stimuli, but they do not know that these stimuli are expected to have an effect on later attitude formation, behavior, decision making or information processing. Recent literature shows that this approach has been used successfully. Rotenberg et al, (2005) primed women with cogntitions of control (rational, cautrous etc) or cognitions of lack of control (reckless, impulsive etc). The results of their experiment showed that women who were on a diet and were primed with lack of control words showed higher food intake on at later taste-test than women who were primed with control words. Other studies have shown that priming a very abstract concept can result in an effect on related behavior. For example, Chartrand and Bargh (1996) showed that when a goal was primed, the behavior related to this goal increased. Participants who were primed with the goal of impression formation showed a better organization of social information in memory than participants who were primed with another goal. Rassinski, Visser, Zagatsky, and Ricket (2005) primed college students with the concept of honesty. Participants had to fill in a questionnaire that was ostensibly about word meanings. They were given six words, and behind each of these words, three synonyms were written. The participants had to choose which of the synonyms resembled the target word the most. In the priming condition, four of the six target words (and their synonyms) were related to honesty. In the control condition, none of these words was related to honesty. After the priming manipulation, Rassinski et al measured how often these students reported excessive alcohol consumption. Their results showed that being primed with the concept of honesty resulted in a higher admission of past engagement in excessive drinking. Thus, increased accessibility of honesty led to more honesty about engaging in socially undesirable behavior. 
Another experiment, by Sassenberg and Moskowitz (2005) showed roughly the same pattern of results, only now the target-variable was not honesty, but creativity. These authors primed participants with the concept of creativity by asking them to describe thee situations in which they behaved creatively. Participants who were primed with creativity showed less dependence on stereotypes; supposedly because they were able or stimulated to think different ${ }^{m}$. So, priming participants with a very general concept, a goal or value like honesty or creativity, can lead to specific behavioral changes that are in line with those goals or values.

The present research uses this same procedure to prime participants with the values universalism or power and measures the effects of this priming manipulation on the attitudes toward GMF and OGF (Experiment 3.1) and related behavior (Experiment 3.2). In the first experiment, participants were students of a faculty of psychology. The second experiment however tested non-student consumers. The choice for participants in Experiment 3.2 enables us to generalize beyond the student population.

\section{Experiment 3.1}

The study described in Chapter 1 of this dissertation showed that the attitudes toward GMF and OGF were related to the values universalism and power. Power has a positive relation to the attitude toward GMF, but a negative relation to the attitude toward OGF. However, for universalism, these relationships are exactly the opposite, negative for universalism and the attitude toward GMF and positive for universalism and the attitude toward OGF. The goal of our experiment was to find out if people's attitudes toward GMF and OGF and the behavior related to these attitudes changed after participants had been primed with either the value universalism or the value power. It was predicted that because most participants do not adhere to the value power, priming them with this value would make their attitude toward GMF more positive, and their attitude toward OGF more negative. For universalism, the opposite pattern was predicted, because universalism is seen by many people as a positive value. Priming with universalism was expected to make the attitude toward OGF more positive and the attitude toward GMF more negative, because this value is positively related to OGF and negatively related to GMF. A change in attitudes (due to activating a value) was expected because participants rely more on this value, which makes the beliefs that relate to this value more important and more dominant in the attitude formation process. We expect the attitude toward GMF to change relatively easily, because this attitude has been shown to be relatively weak and therefore not very strongly embedded into an internal attitude structure. However, the attitude toward OGF is expected to change less easily, because this is a relatively strong attitude.

\section{Method}

\section{Participants}

Seventy five first year psychology students participated. The mean age of the participants 6 males and 69 females) was 20.48 years ( $S D=1.92$, ranging from 18 to 26). Participants were randomly assigned to three conditions. All participants received a small monetary reward for participating in this study. 


\section{Procedure}

Experiment 3:1 consisted of three conditions, a control condition and two priming conditions. Participants in all three conditions participated in a pretest. This took place in Session 1 . In this session, participants were asked to fill in a computerized version of a questionnaire that measured their attifudes, attitude strength and ambivalence toward both GMF and OGF. In the second session, that took place a week after the first session, participants were given a series of tasks. All participants were presented with five words. In the priming conditions, these five words were related to elther power or to universalism. In the control condition, the five words were neutral (not related to power or to universalism). Participants were asked to select three of the five words and to write down three stories (one story for every word they chose) about a situation in which the selected word could be applied to themselves. The second task, which was the same for all thiree conditions, consisted of filling out a subset of the Schwartz Value Survey and the same questionnaire as in the first session, about participants" attitudes toward GMF and OGF.

\section{Manipulation}

Priming manipulation. The stimulus materials used in this experiment were three lists of words. The first list consisted of 5 words, which were related to power. These were: "image", wealth", "powerful", "authority" and "dominate". The second list consisted of 5 words, which were related to universalism. These were: "peaceful"," sympathetic", "respecting" "just" and "tolerant". The third list consisted of 5 control words. These were: "punctual", hurried", "tactical", "diplomatic" and "energetic" 3 .

\section{Meastrres}

1) Schwartz Value Survey. The Dutch version of this survey was used (Schwartz \& Huismans, 1995) which consists of ten values (like "power"). This survey measured adherence to 58 motivational value types (like "wealth" and "authority") (see also Table 4.1). Participants were asked to rate whether they considered each of these 58 motivational value types as a guiding principle in their lives on a 9-point scale ranging from -1 (opposite to my values) to 0 (not important) to 7 (extremely important). Reliability analyses showed that the alpha values of the ten values ranged between 0.51 (tradition), 0.72 (power), 0.80 (universalism) and 0.87 (stimulation). The scores of the motivational value types belonging to one value were averaged to create one single score per value (for the original phrasing, see Table 3.1).

ii) Attitudes. Four items were used to assess participant's attitudes toward GMF and the same four items measured attitudes toward OGF. Participants were asked to rate "what do you in general think about GMF/OGF on four 5-point scales varying from 1 (very unpleasant / very bad / very unfavorable / very negative) to 5 (very pleasant / very good / very favorable / very positive). Reliability analyses showed that the alpha walues of this scale were 0.90 for both GMF and OGF.

\footnotetext{
3 These words are translated from Dutch. In the power condition, the Dutch words were "imago", "rijkdom", "machtig", "gezag" and "domineren". In the universalism condition the Dutch words were: "wredellevend", "medelevend", "respectwol", "rechtwaardig" and "tolerant". In the control condition, the words were: "punctueel", "gehaast", "tactisch", "diplomatiek" and "dloortastend".
} 
Table 3 . Defnitions of motwational yalue ypes n terns of theil goals and he sub-values that representhem:

\begin{tabular}{|c|c|}
\hline Vallue & Descitul 10 of ondivational value tupes (and sub values) \\
\hline Self direction & $\begin{array}{l}\text { Independent thought and action choosing creating exploring (reed dom, } \\
\text { oreatwity, ndependent, hoosing own goals, curlous, selfyespect) }\end{array}$ \\
\hline Stimulation & Excitement, novel by and challeage nlife lan sxcing lie a varied life, daringl \\
\hline Hedonism & Pleasure and senisuous gratification for ones af (pleasue enpylig life) \\
\hline Achievement & 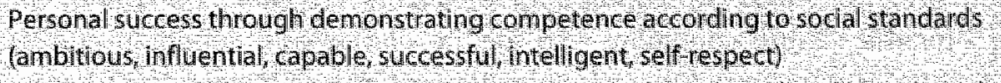 \\
\hline Power & 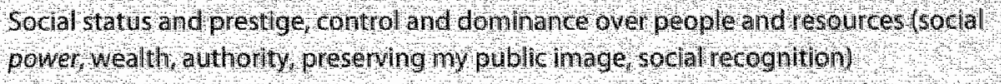 \\
\hline Secumity & 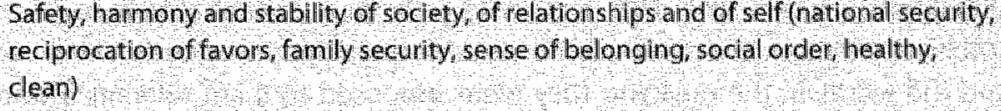 \\
\hline Conformity & 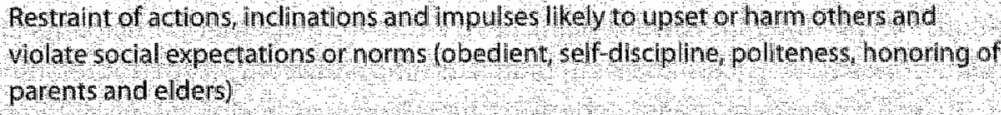 \\
\hline Tractitions? & $\begin{array}{l}\text { Respect, commitment and acceptaince of the customs and loleas that traditon in life, } \\
\text { culture or religion provide the self hespect for tradition, devout, accepting my } \\
\text { portion, humble, moderate) }\end{array}$ \\
\hline Benevolence & 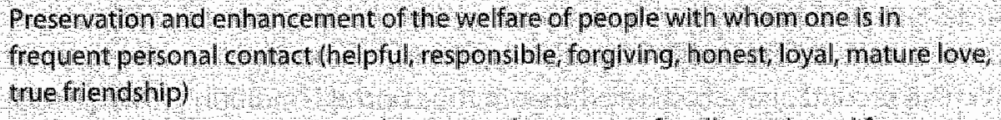 \\
\hline Universalism, & 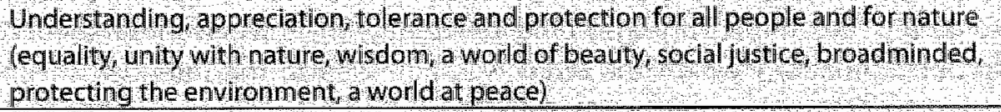 \\
\hline
\end{tabular}

Note, Adapted from the schwart Value Survey (Schwartz \& Sagle, 2000 ).

iii) Attitude strength. Seven items were used to assers attitude strength. These were: "how certain are you that your opinion about GMF/OGF is correct?" (very uncertain - very certain); "how much do you personally care about GMF/OGF?" (very unimportant - wery important); "how knowledgeable are you about GMF/OGF?" (very unknowledgeable - very knowledgeable); "how representative of your values is your attitude toward GMF/OGF?" (very unrepresentative - very representative); "how often do you think about GMF/OGF" (very little - a lat); "how interested are you in obtaining information about GMF/OGF?" (very uninterested - very interested) and "how central is your attitude toward GMF/OGF to your self-image?" (very peripheral - very centran). The strength questionnaire was composed by using items that were taken from other studies on attitude strength (Lavine et al, 1998; Pomerantz $z_{i}$ Chaiken, \& Tordesillas, 1995). The alpha values of this scale were 0.73 (GMF) and 0.85 (OGF).

iv) Ambivalence. To assess ambivalence, three items were used. These were: "I have doubts about my attitude toward GMF/OGF"; "I cannot choose between the pros and cons of GMF/OGF" and "I have conflicting thoughts about GMF/OGF". All ambivalence questions were answered on a 5 point scale with endpoints: not at all applicable - very applicable. Alpha values 
of this sciale were 0.78 (GMF) and 0.73 (OGF). This ambivalence questionnaire was composed of items that were adapted from Jamieson (1988).

\section{Results and Discussion}

\section{Manipulation check}

The first set of analyses was conducted to see whether participants had actually followed the instructions during the manipulation. Participants were asked to write three stories about themselves, where the three chosen words could actually be applied to themselves. First of all, the number of words was counted for each story. The mean number of words per story was 39.0 for the control condition, 43.6 for the universalism condition and 41.6 for the power condition. The mean number of words did not differ between the three conditions, $X^{2}(2)=$ $0.29, p=n .5$. Subsequently, all stories were scored on three aspects. First we scored whether participants wrote a story about themselves or about another person (I am tolerant vs my mother is tolerant). Then, we scored whether participants actually wrote stories where they used the words in the meaning they were supposed to (II am tolerant toward other people's options or I am tolerant toward pain). Last, we scored whether participants applied the words in an affirmative way ( 1 am tolerant) or in a disaffirmative way (I am not tolerant).

A first chi-square analysis showed that there was a significant difference between the three conditions in the amount of sttories that were not about a situation that the participants themselves had experienced, but about someone else. In the power and universalism condition, more participants wrote a story that did not concern their own experiences but of someone else ( 21 and $16 \%$ respectively) than in the control condition $(6 \%), X^{2}(2)=8.16, p<$ 0.05 . The second analysis showed that in the contral condition (10\%), participants more often interpreted the three chosen words differently than we wanted them to so that they described situations where the word was not used in the intended meaning, than in the universalism (1\%) and power (4\%) conditions, $X^{2}(2)=8.40, p<0.05$. The third chi-square analysis revealed that in the power condition (12\%), participants used the words more often in a negative way ("I don't think wealth is important" "compared to "I do think wealth is important" $)$ than in the control condition $(3 \%)$ and the universalism condition $(1 \%), X^{2}(2)=$ $13.80, p<0.001$. This means that this part of the participants was in one of the three stories not primed with the value power, but with the opposite of this value. However, because all participants wrote three stories, and these particular participants still wrote two stories in an affirmative way, we did use these participants in the analysis. Leaving them out would have resulted in a decrease in sample size.

\section{Values}

First of all, a one-way ANOVA tested whether the manipulation resulted in a difference between conditions in adherence to the values power and universalism. It was expected that participants primed with power would be more power-minded than participants in the other two conditions, and that participants primed with universalism would be more universalismminded than the participants in the other two conditions. The results of this analysis (condition as factor and the means for the values power and universalism as dependent variables) showed that there was no difference between the three conditions in how much participants adhered to power, $F(2,72)=0.98, p=n .5$, or universalism, $F(2,72)=0.68, p=n$. $\mathrm{s}_{f}$ after the manipulation. 
This means that the manipulation did not result in an effect on values. Results are summarized in Table 3.2 .

Table 3.2 The means and standard deviations of the post nanipulation measure of the values pomer and unversolism for the three conditions and the $\mathrm{p}$ value of the difference between the three conditions in Experiment 3.1 .

\begin{tabular}{|c|c|c|c|c|c|c|c|}
\hline & \multicolumn{2}{|c|}{ Power condition } & \multicolumn{2}{|c|}{$\begin{array}{l}\text { Unversalism } \\
\text { condition }\end{array}$} & \multicolumn{2}{|c|}{ Controlsondition } & $\begin{array}{l}p \text { value (between } \\
\text { conditions) }\end{array}$ \\
\hline & $N$ & SD & NS & SD & $M$ & SB & 4 \\
\hline Power & 294 & 131 & 248 & 100 & 263 & 125 & n.s. \\
\hline Universalism & 4,43 & 1.25 & 4.72 & 0.86 & 473 & 0,93 & ns: \\
\hline
\end{tabular}

Note: the scores can range from -1 to?

\section{Attitudes}

Repeated measures analysis were conducted with the pretest and the posttest of the attitudes as within subjects variables and the three conditions as the between subjects variable. The first analysis, on the attitude toward GMF showed that there was no difference between the three conditions when comparing the pre- and posttest of the attitude toward $G M F, F(2,72)=0.66$, $p=n . s$. The second analysis, on the difference between the pre-and posttest of the attitude strength toward GMF showed a significant interaction effect between attitude strength and condition, $F(2,72)=3.39, p<0.05$. The attitude strength of the participants in the power condition became higher, whereas the attitude strength of the participants in the universalism condition became lower. The participants in the power condition showed more attitude strength toward GMF than participants in the universalism condition. The third analysis, on difference between the pre- and posttest of the ambivalence toward GMF showed that there was no difference between the three conditions on the ambivalence toward $G M F, F(2,72)=$ $0.87, p=n .5$. These results are summarized in Table 3.3 .

The same three repeated measures analysis were conducted for the attitude, attitude strength and ambivallence toward OGF. The first analysis, on the difference between the preand posttest of the attitude toward OGF showed that there was no difference between the three conditions on the change in attitude toward $\operatorname{OGF}_{n} F(2,72)=0.76, p=n$.s. The second analysis, on the difference between the pre- and posttest of the attitude strength toward OGF aglain showed no difference between the three conditions on changes in attitude strength toward OGF, $F(2,72)=1.79, p=n .5$. The third analysis, on the difference between the pre and posttest of the ambivalence toward OGF showed that there was no difference between the three conditions on changes in ambivalence toward $O G F, F(2,72)=1.22, p=n .5$. These results are summarized in Table 3.3.

Priming participants with power or universalism did not affect attitudes related to these values. Thus, the prediction that attitudes would change when their underlying values are temporarily made more accessible was not confirmed by our data. This absence of results is inconsistent with earlier findings of Homer and Kahle (1988), Maio and Olson (1994) or Kehoe (1975), who did observe that priming a particular value leads to changes in related attitudes. 
However, we did observe a change in attitude strength. Participants who were primed with universalism subsequently became less certain about their attitude toward GM.

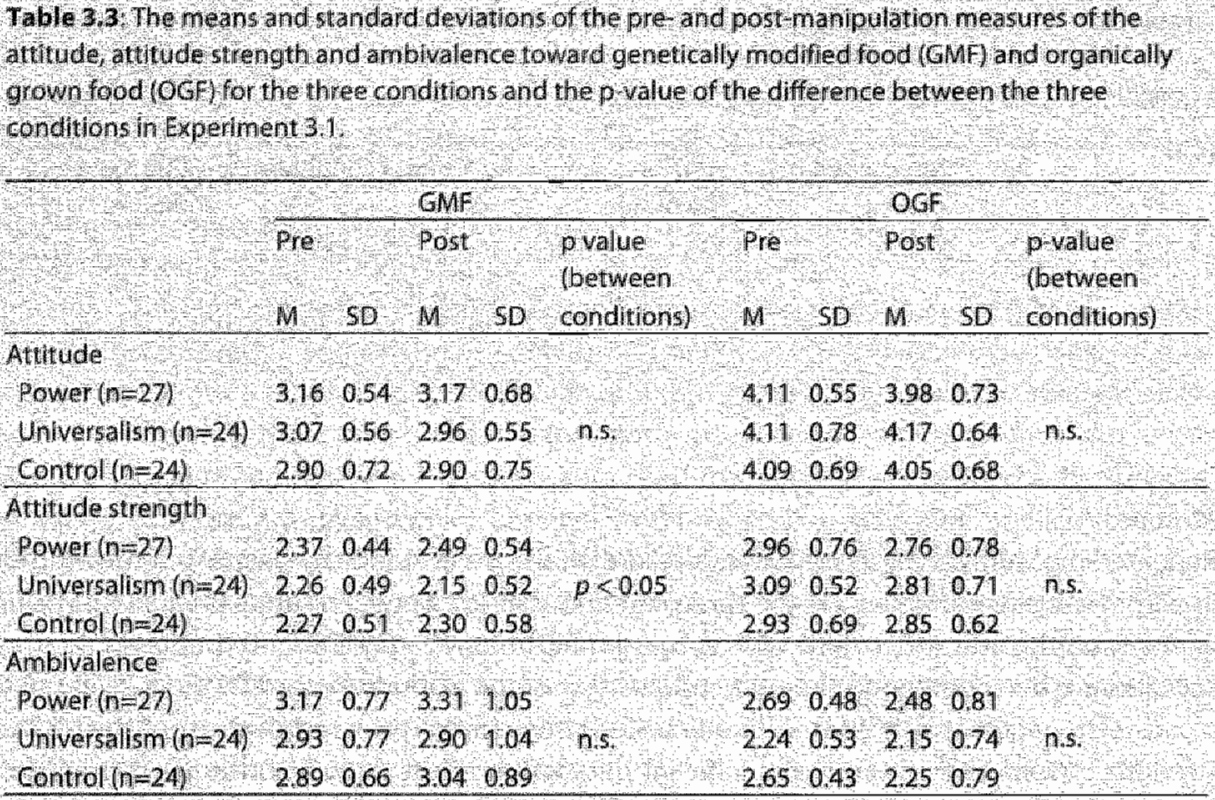

\section{Correlations between values and attitudes}

To test whether the correlations that were found in Chapter 1 of this dissertation could also be found in Experiment 3.1, we conducted a correlational analysis with the values power and universalism and the attitudes toward GMF and OGF as variables. However, we only measured both attitudes and values after the manipulation. Because the manipulation did not work as we intended, we think it is possible to interpret these correlations as if no manipulation was applied. Still, conclusions from these data need to be drawn with caution. The results showed that roughly the same pattern between values and attitudes could be identified. This is shown in Figure 3.1 . 


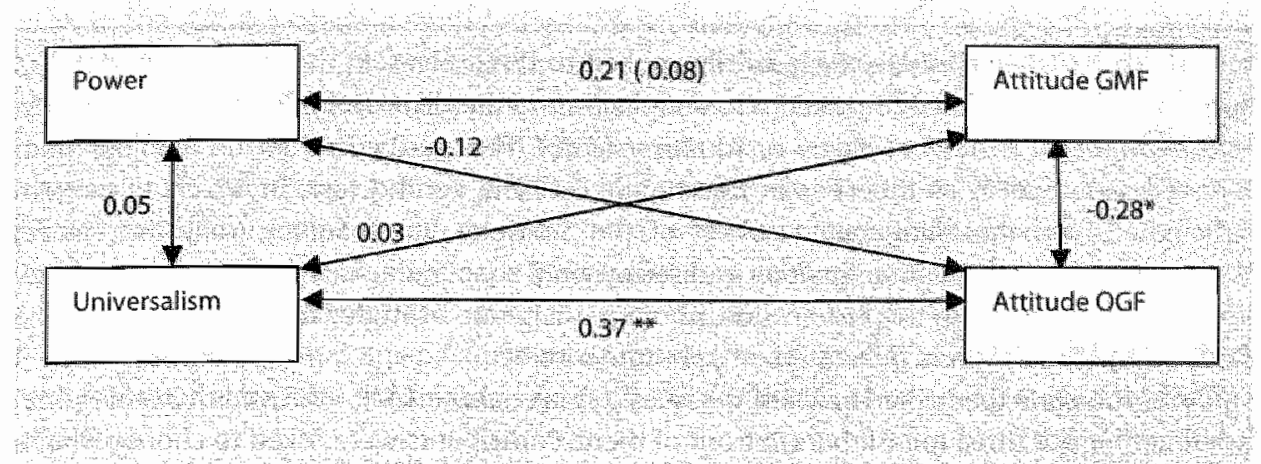

Figure 3.1 Correlations between the values power and unversalism on the one hand, and the attitudes toward GMF and OGF on the other hand.

Note, $p<0,05 * 0<001$

\section{Experiment 3.2}

This experiment tested not only whether people's attitudes toward genetically modified food and organically grown food change after they have been primed with either the value universalism or the value power, but also whether the activation of the values had an influence on subsequent behavior. The procedure was roughly the same as in Experiment 3.1 ithe differences in the procedure will be described below). In addition, people were asked to make choices between several muesli bars which were genetically modified, organically produced or regullarly produced.

\section{Method}

\section{Participants}

Sixty non student consumers participated in this experiment. These participants reacted to ar advertisement that was placed in the local newspaper, or they were recruted in a sports facility. The mean age of the participants ( 24 males and 36 females) was 42.73 years $(\mathrm{SD}=$ 16.70 , ranging from 18 to 76 ). They were randamly divided over three conditions. All participants received a small monetary reward for participating in this study.

\section{Procedure}

The experiment consisted of the same three conditions as Experiment 3.1, two priming conditions, and a control condition. However, this time, a measure of values was incorporated into the pretest of the experiment to allow for a better detection of small effects than in the first experiment. The pretest also enabled us to detect whether participants on the posttest adhered more to the values they were primed with than before the manipulation. The pretest consisted of a questionnaire that had to be filled out at home. This questionnaire contained the Schwartz Value Survey and the questionnaire about genetically modified food (GMF) and organically grown food (OGF). In the second session, that took place approximately a week after the first session, participants were asked to come to the university and were given a number of tasks. The priming procedure was the same as in the first experiment, where all 
participants were shown 5 words. They were asked to select three of the five words and write a story about a situation where these words applied to themselves. In the priming conditions, these 5 words were related to power or to universalism. In the control condition, the five words. were neutral (not related to power or to universalism). The words used in the manipulation were the same words as the ones in Experiment 3.1. The second taisk in which all people participated, was the filling out a subset of the Schwartz Value Survey (only the values universalism, power, hedonism, tradition and stimulation, again on a scale from -1 to 7 ) and the same questionnaire as in the first session, about participants attitudes toward GMF and OGF. These questionnaires were presented on a computer screen.

After the participants had finished the questionnaire about GMF, OGF and the values, the experimenter put three muesli-bars in front of them. Participants were asked to choose which of these three bars they would like to take home. The bars were selected for their taste and appearance and a sticker with the ingredients was placed on each bar. These stickers were manipulated so that some bars appeared to hawe genetically madified ingredients, some appeared to have organically produced ingredients and some appeared to be regular mueslibars. This was done by adding the words "organically grown" or "genetically modified" in the ingredients (for example: "genetically modified nuts" or "organically grown cacao beans"). The brands, tastes and ingredients of the bars were counterbalanced, so that a muesli bar of a certain taste or brand was sometimes genetically modified, sometimes organically produced and sometimes regularly produced. Participants were asked to look at the ingredients of the bars, before deciding which bar to choose.

\section{Measures}

\section{i) values}

Both the pre- and posttest of the values were measured with the regular Schwartz Value Survey, which asks people to decide how important 58 values are as a guideline in their lives, on a scale from - 1 (opposite to my values) to 0 (not important), to 7 (extremely important).

ii) attitudes, attitude strength and ambivalence

The attitudes, attitude strength and ambivalence were measured in exactly the same way as in Experiment 3.1.

\section{Results and Discussion}

\section{Manipulation check}

During the manipulation, participants were asked to write three stories about themselves, where the three chosen words could actually be applied to themselves. The mean number of words per story was 21.7 for the control condition, 22.8 for the universalism condition and 27.0 for the power condition. The mean number of words did not differ between the three conditions, $X^{2}(2)=0.66, p=n . s$. Then, all stories were scored on three aspects. First we scored whether the participants wrote a story about themselves or about someone eise (I am tolerant versus my best friend is tolerant). The first chi-square analysis showed that there was no difference between the three conditions in the number of stories that about a situation that the participants themselves had experienced (control, 96\%; universalism, $97 \%$ and power, $95 \%), X^{2}(2)=0.50, p=n$.s. Then, we scored whether participants actually wrote stories where they used the words in the meaning we intended (tolerant toward others) or in another meaning (tolerant toward pain). The second analysis showed that the three conditions did not 
differ in the number of words that were interpreted differently lcontiol $10 \%$, universalism, $5 \%$ and power, $8 \%, \mathrm{X}^{2}(2)=1.63, p=\mathrm{ns}$. Last, we scored whether the participants used the words affirmatively (I am tolerant) or disaffirmatively (I am not tollerant). The third chi-square analysis revealed that in the power condition (35\%), participants used the words more often in a disaffirmative way ("I don't think wealth is important", compared to "I do think wealth is important") than in the control condition (18\%) and the universalism condition $(6 \%), X^{2}(2)=$ $21.66, p<0.001$. This means that in the power condition, more participants were in some of the stories not primed with the value power, but with the opposite of this value. However, because it was never the case that one person wrote more than one disaffirmative story (and therefore always wrote at least two affirmative stories), these participants were not taken out of the analysis.

\section{Correlations between values and attitudes}

To test whether the correlations that were found in Chapter 1 of this dissertation could also be found in Experiment 3.2, we conducted a correlational analysis with the pretest of the values power and universalism and the attitudes toward GMF and OGF as variables. The results showed that the same pattern between values and attitudes could be identified. This is shown in Figure 3.2 .

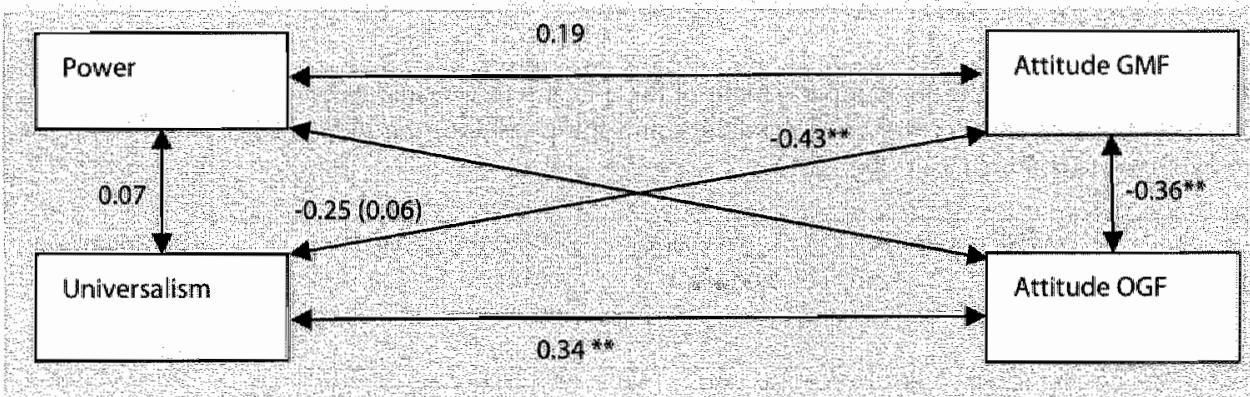

Figure 3.2: Correlations between the values power and universollsm on the one thand and the attitudes toward GMF and OGF on the other hand:

Note ** $p<0.01$.

\section{Values}

Two repeated measures analyses were conducted with the pretest and the posttest of the values universalism (analysis 1) and power (analysis 2) as within subjects variables and the three conditions as the between subjects variable. The first analysis, showed a significant main effect for universalism, $F(1,56)=12.87, p<0.01$. All participants became more universalism minded on the posttest, irrespective of the condition. Furthermore, a significant difference between the three conditions on the value universalism on the difference between the pre- and posttest was shown, $F(2,56)=3.73, p<0.05$. The universalism condition was different from the power and control conditions, in that these participants became more universalistic after the manipulation. The second analysis, showed a significant main effect for power, $F(1,56)=23.30$, $p<0.001$. All participants became more power minded after the manipulation. Additionally, this analysis showed a significant interaction effect between the value power and condition, $F$ 
$(2,56)=3,35, p<0,05$. Participants in the unversalism condition became less power-minded after the manlipulation than the participants in the other two conditions. This is summarized in Table $3,4^{4}$.

A somewhat surprising finding was that participants in every condition became more positive toward both power and universalism after the priming procedure. However, because our hypothesis that participants who were primed with universalism would become more universalism minded, and less power minded (and vice versa for the participants primed with power) was also confirmed, we do not consider this a crucial problem. We think that the explanation for the higher adherence to values in general rests in the fact that we used the same value questionnaire twice, once on the pretest and one week later on the posttest. We believe that participants, in recognizing the questionnaire, in general scored higher the second time they filled in the questionnaire. In designing Experiment 3.2 , we assumed that the time-lag of one week between the two measures would be enough to ensure that this kind of effect would not occur. To make sure that in further experiments this would not occur again, we decided to tuse wo different value measures from now on, with different answering scales. A side effect of this choice is that it is then difficult to compare the two value measures over time, because the two scales cannot be compared. Howewer, because we are mostly interested in the difference between conditions on the posttest, and we are still able to test for that effect, we choose to use two different walue measures from this point onwards.

Table 3.4: The means and standard deviations of the pre and post manipulation measures of the values power and universalsm for the three canditions and the p-value of the difference between the three conditons in Experiment 32.

\begin{tabular}{|c|c|c|c|c|c|c|c|c|c|c|c|c|c|}
\hline & \multicolumn{4}{|c|}{ Power condition } & \multicolumn{3}{|c|}{$\begin{array}{l}\text { Unnversalism } \\
\text { condition }\end{array}$} & & \multicolumn{4}{|c|}{ Control condition } & \multirow{2}{*}{$\begin{array}{l}p \text {-value } \\
\text { (between } \\
\text { conditions) }\end{array}$} \\
\hline & Pre & & Post & & Pre & & Post & & Pre & & Post & & \\
\hline & $M$ & SD & M & SD & $\mathrm{M}$ & SD & M & SD & $M$ & 50 & $M$ & SD & \\
\hline & & & 2.6 & 130 & & & 177 & 1,03 & & 1.0 & 3 & 8 & \\
\hline Dniversal|sm & 3.95 & 1.07 & 4,68 & 0.91 & 493 & 0.86 & 5,25 & 0,76 & 4,27 & 111 & 431 & 123 & $p<0,05$ \\
\hline
\end{tabular}

Note the values were measured on a scale from 1 to 7

\section{Attitudes}

Six repeated measures analysis were conducted with the pretest and the posttest of the attitudes as within subjects variables and the three conditions as the between subjects variable. The first analysis showed that there was no difference between the three conditions on the attitude toward $G M F, F(2,53)=1,35, p=n$.s. The second analysis showed no significant interaction effect between attitude strength toward GMF and condition, $F(2,54)=0.05, p=$

\footnotetext{
4 These analyses were repeated using an ANCOVA with the posttest of the value as dependent variable, the pre-test as covariate and condition as fixed factor. These ANCOVA analyses showed the same pattern of results as the repeated measures analyses.
} 
n.s. The third analysis, on the ambivalence toward GMF showed that there was no difference between the three conditions ${ }_{i} F(2,55)=1.79, p=$ n.s.

The same three repeated measures analysis were conducted for the attitude, attitude strength and ambivalence toward OGF. The first analysis showed that there wais no difference between the three conditions on the attitude toward OGF, $F(2,54)=1.70, p=$ n.s. The second analysis, on the attitude strength toward OGF, again showed no difference between the three conditions, $F(2,53)=0.86, p=n$.s. The third analysis showed that there was marginally significant difference between the three conditions on the ambivalence toward $O G F, F(2,53)$ $=2.88, p=0.07$. The ambivalence in the universalism condition decreased more than in the other conditions due to the manipulation. This can be seen in Table $3.5^{5}$

Table 3.5. The means and standard deviations of the pre and postmanipulation measures of the attitude, attitude strength and ambivallence toward genetically madifled food (GMF) and organically. grown food (OGF) for the three conditions and the p-value of the difference between the three conditions in Experiment 3.2

\begin{tabular}{|c|c|c|c|c|c|c|}
\hline & \multicolumn{4}{|c|}{ GMF } & \multicolumn{2}{|l|}{ OGF } \\
\hline & $\begin{array}{l}\text { Pre } \\
\mathrm{N}(\mathrm{SD})\end{array}$ & $\begin{array}{l}\text { Post } \\
\text { M (SD) }\end{array}$ & $\begin{array}{l}\text { p-value } \\
\text { (between } \\
\text { conditions) }\end{array}$ & $\begin{array}{l}\text { Pre } \\
\mathrm{M}(\mathrm{SB})\end{array}$ & $\begin{array}{l}\text { Post } \\
\text { M(sD) }\end{array}$ & $\begin{array}{l}\text { p-value } \\
\text { (between } \\
\text { conditions) }\end{array}$ \\
\hline Attifude & मिलि' & बक्ष & & & n? & \\
\hline Power $(n=21)$ & $2.95(0.86)$ & $282(1.11)$ & & $385(0.57)$ & $3.76(0.55)$ & +1 \\
\hline Universalism $(n=20)$ & $2,42(1,95)$ & $2.61(0.85)$ & n.s. & $4.42(0.60)$ & $4.45(0.62)$ & nis: \\
\hline Control $(n=15)$ & $267(0.92)$ & $2.76(0.86)$ & & $3.79(0.60)$ & $4.72(3.12)$ & \\
\hline \multicolumn{7}{|l|}{ Attitude strength } \\
\hline Power $(n-27)$ & $244(0,73)$ & $2.47(0,93)$ & & $276(0.84)$ & $258(073)$ & \\
\hline Unversalism (n $=24$ ) & $2,37(0.77)$ & $2.35(0,49)$ & n.s. & $345(0.67)$ & $3.3(0.92)$ & n.s. \\
\hline Control $(n=24)$ & $2.08(0.59)$ & $2.13(0.49)$ & & $2,67(0,78)$ & $272(0.94)$ & \\
\hline \multicolumn{7}{|l|}{ Ambivalence } \\
\hline Power $(n=27)$ & $233(0.52)$ & $2.58(0.59)$ & & $2.44(0.63)$ & $2.35(0.99)$ & \\
\hline Universalism $(n=24)$ & $267(0.50)$ & $2.59(0.55)$ & 10.5 & $248(0.34)$ & $1.89(0,99)$ & $p=0,0 \%$ \\
\hline Control $(n=24)$ & $2.68(0,58)$ & $2.71(0.62)$ & & $2.34(0.45)$ & $220(0,98)$ & 8 \\
\hline
\end{tabular}

\section{Behovior}

At the end of the experiment, participants were offered a choice between three muesli bars: a regular bar, an organically produced bar (OGF bar) and a bar with genetically modified ingredients (GMF bar). In the universalism condition, 8 regular bars, 13 OGF bars and 0 GMF bars were chosen. In the power condition, 8 regular bars, 10 OGF bars and 3 GMF bars were chosen. Participants in the control condition chose 5 regular bars, 9 OGF bars and 3 GMF bars. A chi square analysis revealed that although participants in the universalism condition chose less GMF bars than the participants in the other conditions, but more OGF bars than in the

5 These analyses were repeated using an ANCOVA with the posttest of the attitude for attitude strength ambivalencel as dependent variable, the pre-test as cowaliate and condition as fixed factor. These ANCOVA analyses showed the same pattern of results as the repeated measures analyses. 
other two conditions, the choice for type of bar by condition was not significant; $X^{2}(6)=6.012$, $p=n . s_{.}$These results are summarized in Table 3.6 .

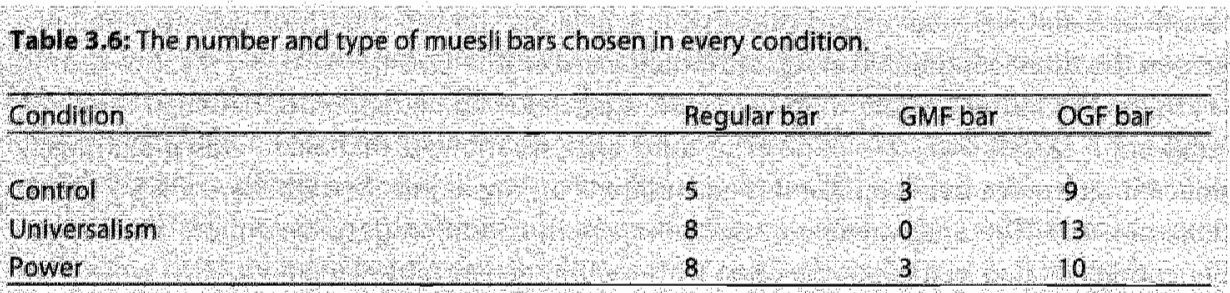

\section{General Discussion}

The experiments presented did not show that priming a value resulted in a change in attitudes. On attitude level, we found only results on attitude strength and ambivalence, but these effects were clearly not strong enough to change attitudes. However, a considerable body of research has shown that this relationship between values and attitudes exists and even more that priming a value does lead to changes in attitudes (Homer \& Kahle, 1988; Maio \& Olson, 1994; Kehoe, 1975). What are the possible explanations for the lack of effects in the present research?

A first possible explanation for not finding the predicted results on the attitudes toward GMF and OGF could be the way that participants were primed. Maybe letting people choose between 3 out of 5 words and applying these words to themselves and their lives did not result in enough activation of the value. However, other researchers have used simillar manipulations (asking people to describe three situations in which they behaved creatively) and found that priming people with creativity resulted in less stereotyping, which can be seen as being creative (Sassenberg \& Moskowitz, 2005). A difference between our manipulation and the one of Sassenberg and Moskowitz was that in their experiment, participants were free to choose whichever part of the concept of creativity they liked, although in the present experiments, participants had to pick three concepts rellated to power ar universalism out of 5 given ones. Maybe this "lack of freedom" in the situations that participants reported can explain the lack of results. It could have made the participants feel that they did not have a choice and could therefore not pick those parts of the value that they adhered to most. This lack of choice could have resulted in resistance to the manipulation, which could have decreased the effect of the manipulation.

A second possible explanation is the fact that in the power conditions, a number of stories (12\% in Experiment 3.1 and $35 \%$ in Experiment 3.2) was written in a way that the word that was described was used negatively (I don't like wealth) instead of positively (I like wealth). Hereby, participants could have failed to activate the value power or could even have activated the value opposed to power (universalism). However, there were only a few participants that wrote negative stories for more than one of the situations they described. Therefore, we do not think that the power manipulation did not work all together, but only that some 
participants were less primed with power than they could have been, had they followed the instructions. Also, this can only explain why the expected results were not found in the power conditions, and not the lack of results in the universalism condition. Therefore, it is not seen as the most important explanation for the lack of results.

A further possible explanation is the fact that in the experiments of Sassenberg and Moskowitz (2005) and Rassinski, Visser, Zagatsky, and Ricket (2005), the values that were primed (creativity or honesty) have behavioral counterparts that are quite obviously" connected to these values. For example, honesty (value) is logically related to not lying (behavior) or telling the truth (behavior). Even a more abstract concept such as creativity, for most people is closely related to things like: creating new things, letting go of conventions etc. However, abstract values like power and universalism, and even the five words that were used in the manipulations (e.g. wealth, tolerance) are different in the sense that their behavioral counterparts are much less obvious and clear-cut. The fact that being power-minded usually leads to a positive attitude toward GMF is something that does not follow a straight logical path, but a pathway with some twists and turns. Therefore, it may be that correlational data show a relationship between power and universalism on the one hand, and OGF and GMF attitudes on the other hand, but that participants are unaware of this relationship. Priming a value does then not necessarily lead to a change in attitudes. Maybe, this relationship between values and attitudes can be strengthened if participants were somehow made aware of this rellationship between power / universalism and OGF / GMF. This possible explanation for the absence of an effect will be tested in Chapter 4. 
$\overline{60}$ 


\section{The missing link: On strengthening the relation between values and attitudes ${ }^{6}$}

Two experiments are discussed that test whether the activation of values may result in a change in the relationship between the activated value and connected attitudes. Participants were primed with the value universalism and asked for their attitudes toward organically grown food and genetically modified food. Our results strongly suggest that values do seem to affect attitudes if the relevant value is activated AND the link between the activated value and attitude is activated as well. However, merely activating a specific value is not sufficient to instigate a change in the relationship between a value and its related attitudes. Also, the attitudes and values themselves does not change, but the relation between values and attitudes consolidates.

6 This chapter is an adjusted version of the following article: Dreezens, E, Martijn, C., Tenbult, P., Kok, G. \& De Vries, N. K. (2005). The missing link: On strengthening the relation between attitudes and values. (submitted for publication). 
Suppose you are in your car on your way to the local supermarket. You are listening to the radio and are tuned in to a program about the outcomes of al recent environmental study. The most important result of this study is that modern agriculture endangers the ecological balance because of the overuse of pesticides and the intense cultivation of the soil. These kind of research outcomes always worry you because you are certainly the kind of person that cares for nature and a sound ecological balance. You arrive at the supermarket and do your shopping. Suppose someone would examine your purchases and judge them against some ecological standard. Would they infer that the radio message changed your attitude toward products that are produced in an environmentally friendly way? for instance, would it make you consider buying free range eggs, or organic wegetables, or perhaps vegetarian products instead of meat?

There is no one-to-one relationship between walues and the attitudes that are connected to them. If people consider the value "nature" an important guideline in their lives, this does not necessarily mean that they have a positive attitude toward recycling and a negative attitude toward driving a car, or that they always buy ecological food. Even when values are activated at a certain moment in time, e.g. by listening to a radio message, this does not necessarily lead people to think about, or reconsider, their attitudes that relate to this value. What are the reasons for this lack of correspondence between the values that people adhere to and their attitudes? In this paper we focus on the relation between values and attitudes and try to contribute to an explanation for the often observed absence of correspondence between them. Furthermore, we discuss a precondition that might contribute to a stronger correspondence between values and attitudes.

Values are often seen as the building blocks of attitudes and preferences, and as cognitive structures that represent important motivations (Verplanken \& Holland, 2002). One of the prominent functions of attitudes is to express personal values (Katz, 1960; Maio \& Olson, 2000) and attitudes can be influenced by or related to the values that they express. One value can be the basis of many attitudes and one attitude can be based on multiple values. Especially values that are important to a person, and are activated by a certain situation and therefore made salient can affect someone's attitudes and behavior. Obviously, attitudes are not only determined by their underlying values. Other important determinants of atuitudes are, for instance, affective reactions (Eagly \& Chaiken, 1995). Although there are many similarities between values and attitudes, it seems important to stress the differences between them for a better understanding of the two concepts. Values are more generall than attitudes and therefore transcend specific situations and objects, whereas attitudes do not. This means that those values, because they exceed specific situations and are guidelines or ideals, are important motivators in people"s lives. However, an attitude only motivates a person to act when the attitude is strongly pelated to a value and therefore important for this persons" self concept, but not generally speaking. Also, values are assumed not to change radically (Bernard, Maio, \& Olson, 2003), whereas attitudes, especially weak ones can under certain circumstances be construed on the basis of temporarily accessible information (Wilson \& Hodges, 1992) and can therefore vary from time to time.

Some attitudes are more consistent with their underlying walues than others. High attitude strength seems to be a consequence of a strong correspondence between attitudes and their underlying values. Research by Holland, Verplanken, and Van Knippenberg (2002) has shown that there are two underlying attitude strength dimensions: centrality (the degree to which an attitude is personally important and perceived as central to the self or personal 
values) and commitment (the certainty with which an attitude is held). lt is the centrality of an attitude that determines how much the attitude is related to its underlying values. Central attitudes are thought to energize behavior, because they may help us to achieve important goals and serve as motivations in our lives:

Another characteristic of strong attitudes is that they are more accessible to a person and that they may come to mind more frequently (Krosnick, 1989). High accessibility is associated with more attitude-consistent behavior, because accessible attitudes are more likely to be activated upon exposure to the attitude-object (Fazio, Sambonmatsu, Powell, \& Kardes, 1986). A study by Bassili (1996) showed that people who had a highly accessible attitude changed their attitude less quickly than people with a less accessible attitude. Kokkinaki and Lunt (1997) showed that more accessible product attitudes were more predictive of subsequent behavior than less accessible product attitudes. These findings point to the fact that accessible attitudes are generally strong attitudes that are not easily changed and have a strong relationship with behavior. It seems likely that the same kind of relationship may hold for accessible values and their related attitudes. An accessible value comes to mind more frequently, which results in the activation of attitudes connected to this value. The simultaneous activation of a value and its related attitudes strengthens the relationship between them.

However, not all research findings support the suggestion that highly accessible values affect related attitudes. One reason why this relationship is often so difficult to establish was identified by Ajzen and Fishbein (1977). They state that when two concepts are not equal in their level of specificity, it is difficult to find a strong relation between these concepts. Attitudes and behavior must be measured on an equally specific level to ensure that a strong relation between the two can be found. If the same reasoning applies not only to the relation between attitudes and behavior, but also to the relationship between values and attitudes, this means that it will be equally difficult to establish a relationship between walues and attitudes. Values are by definition far more abstract concepts than attitudes and the gap between the two concepts with respect to their level of specificity is quite large. Moreover, because several values can be related to a single attitude, and several attitudes can be influenced by a single value, there is no one to one relationship between attitudes and values. Therefore, it is not surprising that it is difficult to predict a specific attitude on the basis of one single and general walue.

A first attempt to close the gap between attitudes and values was made by Verplanken and Holland (2002, Experiments 2 and 3). They showed that even when a value is retrieved from memory and has implications for an attitude or a behavior, this is not enough to ensure that the value influences related behavior. Values also have to be a part of participants' self concept before they can influence behavior. In their experiments, Verplanken and Holland first measured whether a certain value (environment) was a part of a participants' self concept. Then, half of the participants were subjected to a priming procedure, in which the environmental value was activated. Afterwards, all participants had to choose between several television-sets. Participants whose environmental value was activated chose television-sets that scored higher on environmental aspects than participants in the control condition, but this was only true for the participants for whom the value environment value was part of their self concept.

Another experiment worthwhile to consider in this respect is the one of Snyder and Kendzierski (1982). This experiment illustrates that two concepts can only influence each other when they are relevant to one another. Snyder and Kendzierski asked their participants to take 
on the role of a juror in a sex discrimination case in court in the first condition the relewance condition) participants were told that how they thought about affimative action was relevant for the sex discrimination case. Participants in the second condition the accessibility condition) were only instructed to articulate their affirmative action thoughts. Thus, both groups of participants were asked to think about their attitude toward affirmative action, but only the relevance group was told that this attitude was thought to have implications for their Judgments: The results of this experiment showed that participants in the relevance condition displayed a stronger relationship between their thoughts about affirmative action and their judgments as a juron. In other words, their attitude behavior consistency was much higher than that of participants in the accessibility condition. This experiment suggests that making an attitude more accessible by retrieving it from memory is not sufficient to influence related behavior. The attitude must also be regarded as being applicable to behavior. The implications of this experiment perhaps may be translated to the relationship between attitudes and values. Would it not be likely that a walue only has an influence on an attitude if the value is perceived as relevant for that specific attitude?

Taken together, the work of Snyder and Kendzierski (1982) and Verplanken and Holland (2002) suggests that three (interrelated) conditions should be met in order to find a relation between values on the one hand and attitudes and/or behavior on the other hand. Values should be (1) accessible, (2) part of the self concept, and (3) people should perceive that their commitment to a certain value implicates the specific attitude and/or behavior at hand.

The present chapter focuses on identifying under what conditions values may relate to attitudes. More specifically, the experiments were designed to test the hypothesis that values must not only be activated to have an effect on attitudes, but people need to see the relevance or link between a certain value and a related attitude. The hypothesized underlying process is as follows: first, a value needs to be activated (made more accessible). Subsequentlly, if people perceive the relevance between the activated value and the attitude issue at hand, the relation between their value and their attitude judgment will become stronger. In these experiments we focus on the value universalism (protection and respect for nature and all people) and the attitudes toward organically grown food (OGF) and genetically modified food (GMF). Most of the Dutch students have shown to find universalism relatively important (Dreezens, Martijn, Tenbült, Kok, \& De Vries, 2005). Therefore, it was expected that this value is part of their self concept and, when activated, gains temporary importance.

In the first experiment described in this paper, the first manipulation aimed at activating the value universalism, by letting participants engage in a mock "personality test" and then telling them that the value universalism could be applied to themselves. Then, some participants were subtly informed that the value universalism had something to do with their attitude toward organically grown food (OGF), whereas other participants did not receive such information. Research by Dreezens et al (2005) has shown that the value universalism is positively related to the attitude toward OGF and negatively related to the attitude toward GMF. Then, all participants had to express their attitudes toward OGF and GMF. We expected that only the participants whose value was activated and who received information about the limk between the value and the attitude would show ai strong value-attitude correspondence. Participants whose value was activated without suggesting the link between the value and the attitude toward OGF, were not expected to show a stronger value-attitude correspondence. Furthermore, this design enabled us to study how the experimental manipulations influence 
the attitude toward GMF that is negatively related to both universalism and the attitude toward OGF.

\section{Experiment 4.1}

This experiment was designed to test the hypothesis that activating the value universalism and suggesting a link between universalism and OGF will result in a strong value-attitude correspondence. However, only activating the value universalism will not have a large and immediate effect on the attitude toward organically grown food (OGF) because participants do not automatically detect the link between the universalism and OGF. Therefore, we designed an experiment with three conditions. In the first condition, the activation condition, the value universalism was activated, but no link between universalism and OGF was suggested. In the second condition, the link condition, the value universalism was activated, and a subtle link between universalism and OGF was alluded to. In the third condition, the contral condition, the value universalism was not activated, nor was a link between universalism and OGF suggested.

\section{Method}

\section{Participants}

In this study, 51 students participated in return of a monetary reward. The mean age of the participants ( 6 males and 45 females) was 20.26 years $(S D=2.12$, ranging from 18 to 28 ). The respondents were randomly allocated to the three experimental conditions.

\section{Procedure}

Participants were tested individually in 30 minute sessions. When entering the laboratory, participants were seated. The experimenter explained the procedure and participants filled out an informed consent form if they agreed to continue with the experiment. Participants were told that they had to fill in a personality questionnaire which resembled the kind that can be found in women's magazines. These personality questionnaires are often about "how good is your relationship?", "are you in for a career?" or "are you assertive enough?". This manipulation was chosen because we did not want the participants to take the feedback they" would receive later in the experiment too seriously (because this could result in answers that are influenced by unwanted demand characteristics). The experimenter told the participants that she wanted to compare their scores on this "nonscientific" version of a personality" questionnaire to a more "scientific" version that they would receive later in the experiment. The first task was to fill out the Schwartz Value Survey. Thereafter, the personality questionnaire was presented to the participants, consisting of 17 questions. All participaints were led to believe that the computer then calculated their "personal result" which was shown on the screen. After this manipulation, participants were again asked to fill out a subset of the Schwartz Value Survey (only the values universalism, power, hedonism, tradition and stimulation). We were only interested in their scores on universalism and the other four values served as distraction items. The last part of the experiment consisted of two filler questionnaires (to disguise that we were only interested in their attitude toward OGF and' 
GMF) and a questionnalre about OGF and GMF. Then, participants were thanked, debriefed and paid.

\section{Manipulation}

The personallty questionnaire consisted of 17 questions. To activate the value universalism, in six of the questions, the answers that participants could choose from were different for the control condition than for the activation and link conditions. For example, all participants received the question. "Which organization would you like to be a member of?". In the control condition, the possible answering alternatives were a) Be sparing with style b) SOS sexism c) Union against cursing. Thus, in the control condition none of the answering alternatives had anything to do with universalism. In the activation and link conditions however the alternatives were: a) Greenpeace b) 505 sexism c) Union against cursing. The idea behind this manipulation was that, the first answer in the activation and the link conditions was related to universalism, whereas the one in the control condition was not. By choosing the most appealing (universalistic) alternative (and the same idea was repeated for five more questions of the personality questionnaire), people would get the idea that the universalistic character of their "personal result" was based on their answers on the test. Moreover, these questions also served to activate uniwersalism in the relevant conditions. A manipulation check showed that $77 \%$ of the participants chose the universalistic answer alternative four times or more (of the total of six possible times).

The "personal results" were the second part of the activation manipulation. Participants in the control condition received the following "personal result":

You appreciate rules, but you think that they are usually too strict. On the one hand, you like to follow your own destiny, but on the other hand you feel the pressure of people around you to fit in. You try to find your own way in all this, by keeping the rules in the back of your mind, but not giving them too much attention. You like a beer and enjoy eating out with your friends. Words that describe you are: enjoying, sociability and loyal.

In this "personal result" universalism or the link between universalism and OGF were not mentioned. However, in the activation condition, the "personal result" did allude to the value universalism:

You are someone who thinks about himself and your surroundings a lot. Things like recycling, respect for others and politics are not unfamiliar to you. You are open to other people and you respect their viewpoints. Your prionity is to live a happy life, but at the same time take into account your surroundings. Words that describe you are: interested, recycling, involved and enjoying.

In this condition, participants were told that they were a universalistic person. However, nothing suggested a link between universalism and OGF. This link was added in the link condition. The only difference between the activation and the link condition was the replacement of the two italic words by "honest (ecologicall) food" and "honest food". In the original materials, these words were of course not printed in italics. 
Measures

Pretest

1) Schwartz Value Survey (Personal Profile NM version). The Schwartz Value Survey was used to measure which values participants find important in their lives (Schwartz, 1992). It consists of ten general values that are divided into 40 sub values. Participants were given the following instruction: "Here we briefly describe some people. Please read each description and think about how much each person is or is not like you". An example of one of the questions is: "Thinking up new ideas and being creative is important to him. He likes to do things in his own original way". Participants could answer 40 of these questions on a six point scale ranging from 1 (very much like me) to 6 (not like me at all). The scores of the sub values belonging to one general value were averaged to create one single score per general value. In the posttest, the same measure was taken, but limited to the values universalism, power, hedonism, tradition and stimulation.

\section{Posttest}

ii) Schwartz Value Survey. The Dutch version of this survey (Schwartz \& Huismans, 1995) consists of ten motivational value types (like "tradition $n^{m}$ ), which are tested by asking people to rate how important they find 58 sub-values (like "respect for tradition" and "humble"). Participants were asked to rate to what extent each of these 58 sub-values was a guliding principle in their lives on a 9-point scale ranging from -1 (opposite to my values) to 7 (extremely important).

iii) Attitudes. Four items were used to assess participant's attitudes toward GMF and four identical items measured attitudes toward OGF. Participants were asked to rate "what do you in general think about GMF/OGF" on four five-point scales varying from 1 (very umpleasant / very bad / very unfavorable / very negative) to 5 (very pleasant / very good / very favorable / very positive).

iv) Attitude strength. Seven items were used to assess attitude strength for OGF and GMF separately. These were: "how certain are you that your opinion about GMF/OGF is correct?" (very uncertain - very certain): "how much do you personally care about GMF/OGF?" (very little very much); "how knowledgeable are you about GMF/OGF?" (very unknowledgeable - very knowledgeable): "how representative of your values is your attitude toward GMF/OGF?" (very unrepresentative - very representative): "how often do you think about GMF/OGF?" (very little very much); "how interested are you in obtaining information about GMF/OGF?" (very uninterested - wery interested) and "how central is your attitude toward GMF/OGF to your selfimage?" (wery peripheral - very central). All strength questions were answered on a five-point scale. This questionnaife was composed by using items from other studies on attitude strength (Lavine, Huff, Wagner, \& Sweeney, 1998; Pomerantz, Chaiken, \& Tordesillas, 1995).

v) Ambivalence. To assess ambivalence, three items were used for OGF and GMF. These were: "I have doubts about my attitude toward GMF/OGF" "I cannot choose between the pros and cons of GMF/OGF" and "I have conflicting thoughts about GMF/OGF". All ambivalence questions were answered on a five-point scale with endpoints: not at all applicable - very much applicable. This ambivalence questionnaire was composed by using items that were adapted from Jamieson (1988). 


\section{Results and Discussion}

\section{Attitudes, attitude strength and ambivalence}

The first series of analyses tested whether a difference between the three conditions existed with respect to attitudes, attitude strength and ambivallence toward both GMF and OGF. A MANOVA using the GMF attitude, attitude strength and ambivalence as dependent variables and condition as fixed factor showed no difference between the three conditions, $F(2,48)<$ 1. A second MANOVA using the OGF attitude, attitude strength and ambivalence as dependent variables and condition as a fixed factor also indicated no difference between the three conditions, $F(1,48)=1.25$, n.s. These results showed that the manipulation did not result in a difference in attitudes, attitude strength or ambivalence between the three conditions. The means and standard deviations of the attitudes toward GMF and OGF are reported in Table 4.1 .

Table 4,1. The means and standard deviations of the attitudes toward organleally grown food $106 \mathrm{~F}$ ) and genetically modified food (GMF), the means and standard deviations of the value unversalism (pre-and posttest) and the correlations between OGF-universalism and GMF universalism for each of the three conditions of Experiment 4. 1. Correlations in columns with different subscripts are different

\begin{tabular}{|c|c|c|c|c|c|c|c|c|c|c|}
\hline Condition & Altits & $\begin{aligned} & \\
& 50\end{aligned}$ & $\mathrm{Atiit}$ & $\begin{array}{l}\mathrm{eGME} \\
\mathrm{sD}\end{array}$ & 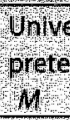 & $\mathrm{sallsm}$ & $\begin{array}{l}\text { Unviv } \\
\text { postt } \\
\text { Nu }\end{array}$ & SD & $\begin{array}{l}\text { Gorrelation } \\
\text { OGF. } \\
\text { unversalsm }\end{array}$ & $\begin{array}{l}\text { Correlatlon } \\
\text { GMF } \\
\text { unversalism }\end{array}$ \\
\hline $010=16)$ & 377 & 95 & 292 & 0.51 & 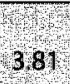 & 0,83 & 430 & 104 & 00 & \\
\hline ( $(n=18)$ & 408 & & 289 & 074 & 4,03 & 0.82 & 438 & 0.74 & 0220 & 0,194a \\
\hline$\left.k k^{\prime}(1)=17\right)$ & 30 & 0.4 & 278 & 0.68 & 399 & 080 & 461 & 107 & $0.573 \%$ & $0.662 \% *$ \\
\hline
\end{tabular}

Note: The pretest universalism scores were measured on a seale from 1 to 6 , whereas the posttest universalism scores were measured on a scale from 1 to $7, p<, 05, * p<01$.

\section{Values}

A second analysis tested for a difference between the three conditions on their universalism scores on the posttest, corrected for differences in universalism on the pretest. We tested this with a Univariate GLM with the posttest of universolism as dependent variable, condition as fixed factor and the pre-measure of universalism as a covariate. This analysis showed that there was no difference between the three conditions on their post universalism scores, $F(2,47)<1$. Therefore, we cannot conclude that activation of universalism leads to higher adherence to this value. The means and standard deviations of the value universalism (pre- and posttest) are reported in Table 4.1 .

\section{Attitudes and values}

For the third and fourth analyses, which were meant to test if there was a difference in the relationship between the value universalism and the attitudes toward OGF and GMF between the three conditions, we constructed two GLMs with parameters representing the attitudes 
toward OGF and GMF respectively as dependent variables, the three conditions as fixed factor: the value universalism as a covariate and containing the interaction between unversolism and condition. For OGF, this analysis showed that there was a marginally significant difference in the relation between universalism and OGF between the three conditions, $F(2,45)=2.61, p<$ 08. For GMF, the analysis showed a significant effect $F(2,45)=4.17, p<0.0$. Although the first effect is only marginally significant, it is still interpreted since there was a clear prediction of the direction of the effect. To investigate which conditions differed from each other, three tests for the difference between two correlations were done, for both OGF and GMF. The raw correlations between universalism and both attitudes (toward OGF and GMF) can be found in Table 4.1. For analysis, first the correlations were Fisher-transformed to Z-scores. Then, the correlations were compared pairwise. The positive relationship between universalism and OGF was (marginally) significantly stronger in the link condition than in the control condition, $Z=$ $1.58, p=.056$, and significantly stronger in the link condition than in the activation condition, $Z$ $=2.50, p<.01$. The control- and activation conditions did not differ from each other.

A similar but inversed pattern of results was found for the attitude toward GMF. The neglative relationship between GMF and universalism was stronger in the link condition than in the control condition, $Z=2.41, p<.01$ or the activation condition, $Z=2.67, p<.01$. The control condition did not differ from the activation condition. These results showed that for both OGF and GMF, the relationship with the value universalism became stronger when a link between the attitude and the value was suggested.

The results of the first experiment showed that only if the value universalism is activated and if a link between universalism and food preference was suggested, participants showed a strong value-attitude correspondence. Supposedly, participants have actively related the value universalism to their attitude toward OGF. If they felt that they had a universalistic personality, participants became more positive toward OGF. However, if they did consider themselves less universalistic, they became more negative toward OGF. This may have resulted in the strengthened relation between the value universalism and the attitude toward OGF, without

affecting the mean adherence to this value or attitude. Furthermore, the same pattern of results was shown for the value universalism and the attitude toward GMF. This is an intriguing finding, because participants were never explicitly toid about the link between universalism and GMF. Earlier research by Dreezens et al. (2005) has shown that OGF and GMF are negatively interrelated and that the value universalism is negatively related to GMF. We therefore assume that linking the value universalism with one connected attitude resulted in the strengthening of the relationship between the value universalism and other connected attitudes. This means that the effect of stating a link between a value and a related attitude might carry over to other attitudes that are also connected to the attitude linked to the value.

\section{Experiment 4.2}

The results found in the first experiment are even more remarkable when considering that participants received a personality result that was based on a test that was explicitly described as "nonscientific". After telling them that a nonscientific personality questionnaire showed that they had a universalistic personality, and that this value had a link with OGF, the value became more predictive of related attitudes. To replicate this finding, we decided to use a manipulation that was rather bizarre, which should enable participants to discount the result that was the outcome of the test. Instead of filling out a personality test, participants were now 
told that they had to choose a cookle and that their choice reflected their personality. In a pretest, participants rated this cookie-personality test as untrustworthy (on a scale from 1, very unbelievable to 10 , very believable, they rated the manipulation a 3.6 on average). This means that participants in general do not believe that their personality can be predicted on the basis of the cookie they choose. It was anticipated that because participants did not believe the manipulation of the second experiment, they were not forced to give answers in line with their universalism value, but were able to discount the manipulation. This way, the second experiment tested how much of the effect found in the first experiment was due to participants' responsiveness to demand characteristics:

\section{Method}

\section{Participants}

In this study, 63 undergraduate students participated and received a monetary reward. The mean aige of the participants ( 25 males and 38 females) was 21.64 years ( $S D=2.32$, ranging from 19 to 29). The respondents were randomly allocated to the three experimental conditions.

\section{Procedure}

Participants were seated. The experimenter explained the procedure and participants filled out an informed consent form if they agreed to continue with the experiment. The first task was to complete the Schwartz Value Survey. Thereafter, the participants had to choose one of the five cookies that were placed on the table before them. Then, they were given a "personal result". After this manipulation, participants were asked to fill out a subset of the Schwartz Value Survey, two filler questionnaires and the questionnaire about GMF and OGF. Finally, participants were thanked, debriefed and paid.

\section{Manipulations}

Participants were presented with five cookies. Their task was to choose the cookie that they wanted to eat most. They were told that the cookie they chose reflected their personality. After choosing a cookie, participants were given a "personal result". The personal result was only dependent on the experimental condition and not on which cookie the participant had chosen. The personal results in the different conditions were exactly the same as the personal results in Experiment 4.1. In the activation condition, the value universalism was activated, but participants did not receive information linking universalism to OGF. However, in the link condition, both the value universalism and the link to OGF were suggested in the text. In the control condition, the value universalism was not activated, nor was the link between universalism and OGF stated.

\section{Measures}

The measures that were used in Experiment 4.2 were the same as the ones in Experiment 4.1. except for two alterations. In this experiment, values on the posttest were measured with a shontened version of the regular Schwartz Value Survey (translated into Dutch) (Schwartz \& 
Huismans, 1995). Because we were primarily interested in participants' scores on the value universalism, we only asked participants to rate the value universalism and four other values as. fillers (power, stimulation, hedonism, tradition).

Furthermore, the questionnaire about the attitudes, attitude strength and ambivalence toward both GMF and OGF was different from the questionnaire in the first experiment. The second experiment made use of seven-point scales instead of five-point scales for all the answers in these questionnaires. This gave us the opportunity to detect more differentiation in participants' answers.

After the manipulation, subjects were asked two questions: How credible did you think the "personal result was?", and "How credible did you find the idea that we could predict your personality on the basis of the cookie that you chose", with answering alternatives being: very implausible (-3), implausible $(-2)$, somewhat implausible (-1), neutral (0), somewhat plausible (1), plausible (2) and very plausible (3).

\section{Results and Discussion}

\section{Credibility of the manipulation}

The mean score of the participants on the first manipulation check (credibility of the personal result) was $1.06(S D=1.69)$, which means that the participants rated the personal result somewhat plausible. The mean score of the participant on the second manipulation check was $-1.56(\mathrm{SD}=1.45)$, which means that the participants rated the link between choosing a cookie and personality implausible. In other words, participants slightly agreed with their personality result, but did not believe that their result could be predicted by means of choice of a cookie.

\section{Attitudes, attitude strength and ambivalence}

The first set of analyses tested possible differences between the three conditions in attitudes, attitude strength and ambivalence toward both GMF and OGF. A MANOVA using the GMF attitude $e_{s}$ attitude strength and ambivalence as dependent variables and condition as a fixed factor showed no difference between the three conditions, $F(2,60)<1, n$, s. A similar MANOVA using the OGF attitude, attitude strength and ambivalence as dependent variables also revealed no difference between the three conditions, $F(2,60)=1.10, n .5$. This means that there were no differences in attitudes, attitude strength or ambivalence between the three conditions. The means and standard deviations of the attitudes toward GMF and OGF are depicted in Table 4.2 .

\section{Values}

A second analysis tested for a difference between the three conditions on their universalism scores on the posttest, corrected for differences in universalism on the pretest. We analyzed this with a Univariate GLM with the posttest of universalism as dependent variable, condition as fixed factor and the pre-measure of universalism as a covariate. This analysis showed that there was no difference between the three conditions on their post universalism scores, $F(2$, $59)<1$. The means and standard deviations of the value universalism (pre-and posttest) are shown in Table 4.2. 
Table 4.2. The means and standard deviations of the atritudes toward organically grown food (OGF) and genetically modified food (GMF), the means and standard deviationis of the value universalism (pre- and posttest) and the correlations between OGF universalism and GMF universalism for each of the three conditions of Experinent 42 . Correlations in columns with different subscripts are different:

\begin{tabular}{|c|c|c|c|c|c|c|c|c|c|c|}
\hline Condition & $\begin{array}{l}\text { Atiti } \\
\text { ogf } \\
\text { M }\end{array}$ & & $\begin{array}{l}\text { Attin } \\
\text { GMF } \\
\text { M }\end{array}$ & & $\begin{array}{c}\text { Unive } \\
\text { prete } \\
M\end{array}$ & salism & $\begin{array}{l}\text { Unive } \\
\text { postte } \\
\text { NA: }\end{array}$ & $\begin{array}{l}\mathrm{sal} \\
\mathrm{st}\end{array}$ & $\begin{array}{l}\text { Correlation } \\
\text { OGF } \\
\text { universalism }\end{array}$ & $\begin{array}{l}\text { Conrelation } \\
\text { GMF } \\
\text { universalism }\end{array}$ \\
\hline Control (n-2) & 5,26 & 0.89 & 385 & 134 & 429 & 0.62 & 4.86 & 1.01 & 0.108 & 0088 \\
\hline Actin $(n=22)$ & 5,76 & 0.69 & 374 & 118 & 410 & 0.61 & 465 & 0,75 & 0170 & 0292 \\
\hline$(n-20)$ & 535 & 105 & 3,31 & 131 & 413 & 0.77 & 4,48 & 0,91 & 0.640 * & 0,147 \\
\hline
\end{tabular}

Note. The pretest universalism scores were measured on a scale from 1 to 6 , whereas the posttest unversallsm scores were measured on a scalle from 1 to $7 \% \mathrm{p}<.05$.

\section{Attitudes and values}

For the third and fourth analyses, which were meant to test if there was a difference in the relationship between the value universalism and the attitudes toward OGF and GMF between the three conditions, we constructed two GLMs with parameters representing the attitudes toward OGF and GMF respectively as dependent variables, the three conditions as fixed factor, the value universalism as a covariate and containing the interaction between universalism and condition. For $O G F$, this analysis showed that the three conditions differed in the relation between universalism and $\mathrm{OGF}, F(2,57)=5.93, p<.01$. For $\mathrm{GMF}_{\text {s }}$ the analysis showed the same effect, $F(2,57)=3.64, p<.05$. To investigate which conditions differed from each other, three tests for the difference between two correlations were dlone, both for OGF and GMF. The raw correlations between universalism and both the attitudes toward GMF and OGF can be found in Table 4.2.

The raw correlations were Fisher-transformed to $z$-scores. Then, the correlations were subjected to pair wise comparisons. The relationship between universalism and OGF was significantly stronger in the link condition than in the control condition, $Z=2.56, p<.01$ and also significantly stronger in the link condition than in the activation condition, $Z=2.79, p<$ .01. The control- and activation conditions did not differ from each other. A different pattern of results was found for the attitude toward GMF. The relationship between universalism and GMF was not stronger in any of the three conditions. These results show that only for $O G F$, the relationship with the value universolism is stronger when the link between the attitude and the value is stated. However, for GMF, this relationship was not found.

The second experiment roughly replicated the results of Experiment 4.1 , but only for the relationship between universalism and OGF. Again, the hypothesis that values only are clearly related to connected attitudes when the link between the two is referred to was confirmed. However, in Experiment 4.2, it was shown that a rather minimal manipulation still resulted in the same pattern of results as in Experiment 4.1. Furthermore, in both Experiments 4.1 and 4.2, the scores that participants gave on the universalism scale and on their attitudes toward OGF did not change. Only the correlation between these two concepts changed. This suggests that it is unlikely that the results of Experiments 4.1 and 4.2 are totally due to demand characteristics. 


\section{General Discussion}

In attitude theory it is generally assumed that attitudes are related to values, most often through evaluations of outcomes of behavior or characteristics of attitude-objects (Eagly \& Chaiken, 1995). Our studies provide an empirical demonstration that values can indeed be related to attitudes, but only when the link between the value and the attitude is clear or made accessible. Taken together, the results of the two experiments reported in this paper suggest that activating a value and specifying the link between a general value and a more specific attitude results in a high correlation between this value and this attitude. This means that by suggesting that a value and an attitude are related, the value becomes an important predictor for the attitude, or in other words, attitudes come to reflect their underlying values: Even though values are abstract and unchangeable constructs, it seems possible to activate them in certain situations. This activation might result in people using value-relevant information in decision making, judgments, and evaluations, on the precondition that they are also aware of the link between values and those judgments. Linking an attitude to a value could make this: value more in line with the attitude in terms of specificity.

These effects are even more meaningful when the minimalistic nature of the manipulation is taken into account. By just reminding people in a very subtle way that universalism has something to do with OGF, a strong relationship between universalism and OGF is established. Furthermore, the effect persists even when an untrustworthy test was introduced to tell participants that they were universalistic persons (as was the case in Experiment 5.2). Even when participants found their test results implausible, the linking of an attitude to a value thad an effect on the relationship between the two concepts. This sheds new light on the literature on value-attitude relationships. As Ajzen (1977) has argued values are much less specific than attitudes, and it is therefore difficult to influence attitudes via values. Suggesting a link between these two could have resulted in the bridging of the specificity-gap between values and attitudes. In the literature, this link effect has already been reported concerning the relationship between attitudes and behavior. However, the finding that this reasoning also applies to the connection between values and attitudes is new.

One of the criticisms of these studies could be the possible influence of demand characteristics. One could argue that the fact that the correspondence between values and attitudes is higher in the link condition is due to demand characteristics, because participants. think that they are assumed to become more positive toward both universalism and OGF. However, we do not think that the data support this assumption. First, especially in the second experiment, participants reported that they did not believe that it is possible to predict their personality on the basis of the cookie they chose. If participants do not believe this manipulation, they were able to discount the manipulation and therefore give answers which were not in line with their universalism value. Second, if participants would have thought that they were expected to become more positive toward universalism, this would show in the scores on the post measure of universalism. However in both Experiments 4.1 and 4.2 , there was no difference between the control condition, where the value universalism was not activated, and the activation and link conditions, where the value uriversalism was activated, on the posttest of universalism. The fact that the universalism scores did not differ between the three conditions counters the explanation that the effects were due to demand characteristics, caused by activation of the value universalism. The same reasoning holds for the attitudes toward OGF and GMF. These attitudes also did not differ between the three conditionis. If 
people would have seen through our manipulation, the most obvious way to show demand characteristics was to change their attitude and universalism scores in a positive way in the activation and link conditions. However, since the average of the scores per condition did not change (only the strength of the relationship between the attitude and the value), we consider it relatively umlikely that the effect found in these two experiments were influenced by demand characteristics.

Linking universalism and OGF, by using them in the same context, resulted in a carryover effect of uniwersalism on GMF in the Experiment 4.1. The activation of the value universalism and suggesting the link between universalism and the attitude toward OGF did not only strengthen the relationship between universalism and OGF, but also strengthened the negative relationship between universalism and GMF. We suppose that participants, through the negative relations of universalism and OGF with GMF must have sensed that if there is a link between universalism and OGF, there must also be allink between universalism and GMF. By making this connection themselves, the relationship between GMF and universalism might have been strengthened in the same way as the relationship between OGF and universalism was. This could mean that the effect of suggesting a link between a value and a related attitude might carry over to other attitudes. This effect was not replicated in the second experiment. However, the reason for this could be that the second experiment used a different manipulation. Perhaps the choice of a cookie resulted in less comparison of the value universalism to the self (and therefore less activation of the self) than the personality questionnaire where participants repeatedly had to choose between several (universalistic) answers. If self activation is a factor in the effects that were found in these two experiments, the lack of self activation in the second experiment could have resulted in the disappearance of the carryover effect. Since self activation effects were not measured or manipulated explicitly in these experiments, this will remain an issue for further study.

One could argue that to efficiently test the effect of activating a value on the one hand, and linking a value to an attitude on the other hand, a $2 \times 2$ design would be better suited. However, the reported experiments were carried out with a $3 \times 1$ design. This is due to the fact that it seems very difficult to suggest a link between a value and an attitude, without also activating this value. Suggesting that universalism and OGF are connected automatically results in the activation of the value universalism. Further research should aim at unraveling these assumed components to see whether the effect is an interaction between activating a value and a suggested link between a value and an attitude. This could be investigated by taking apart the activation of a value and the linking of a value to an attitude. Linking a value to an attitude on time 1 , and then activating the value on time two, which could be an hour, a day or a week later could provide more insight into whether activation and linking are both necessary for a strong value-attitude correspondence to occur. 
Chapter 5

Unraveling the link effect: The role of demand characteristics and self awareness 
The study discusised in Chapter 5 aimed to investigate whether the link-effect could be explained by self-activation or demand characteristics. The manipulations that were used in Chapter 5 made use of self referent words, which could have activated the self. Activation of the self results in a higher correspondence between attitudes and values. Therefore, activation of the self could have confounded the results found in Chapter 4 . Furthermore, by informing participants that they have a universalistic personality, and that this has something to do with OGF, participants could have felt the inclination to state that they evaluated OGF positively, when they actually did not. If this was the case, the higher correlation between universalism and $O G F$ in the link conditions did not occur because suggesting the link made participants realize that universalism and OGF have something in common, but because participants felt forced to report a more consistent attitude toward OGF. However, the experiment described in this chapter showed that self activation or demand characteristics were not the main underlying mechanism of the link effect. There was no difference between the conditions where self referent words were used and the conditions where no self referent words were used.

In Chapter 1 of this dissertation, it was shown that the attitudes toward organically grown food (OGF) and genetically modified food (GMF) are influenced by the values universalism (respect for all people and for nature) and power (control and dominance ower others and resources). Furthermore; the two experiments in Chapter 3 showed that merely activating a value through a priming manipulation did not result in an effect of the activated value on related attitudes. However, the two experiments in Chapter 4 portrayed that a stranger relationship between values and attitudes emerged when the value was activated AND the value and attitude were implicitly linked to each other. These experiments suggest that a stronger value-attitude relationship will occur when people recognize that their values are connected to the attitude issue at hand. In the two experiments of Chapter 4 , this connection between the value universalism and the attitude toward OGF was suggested by providing participants with a (fake) personality questionnaire that described the value universalism and also mentioned the words "honest, ecological food". This minimal and implicit connection between universalism and OGF that was introduced in the link conditions resulted in significantly higher correlations between universalism and the attitude toward OGF than in the activation conditions, where this relation was not suggested. This means that if the words "honest, ecological food" are mentioned in the context of universalism, participants subsequently seem to use their underlying value universalism as a guide to decide what to think of OGF.

However, two possible confounders could have arisen in the manipulations used in Chapter 5 . These experiments were designed to activate values and provide participants with a link between values and attitudes. However, the manipulation that was chosen to activate values could at the same time also have made participants self-aware. By telling participants "you are someone who thinks about himself and your surroundings a lot" the value universalism was activated, but using self referent words could also have activated the self concept (Smallwood, 2004; Van Der Meulen, 2001) and therefore made participants self-aware (Stapel \& Tesser, 2001 1. It can be argued that activation of the self or a heightened self-awaremess has an effect on the relationship between values, attitudes and behavior. When the self is activated, people attend more to their own attitudes, feelings and values (Hutton \& Baumeister, 1992; Pryor, Gibbons, Wicklund, Fazio, \& Hood, 1977), and this is shown to instigate a thorough consideration of antecedents and consequences of behavior (Gibbons, 1983). Higgins (1996) 
also argues that the aspects of the self that are most relevant or applicable to one's current goals and activities are most likely to come to the fore when the people are aware of themselves. This means that when the self is activated, people rely more on their own values, attitudes and feelings, automatically select and activate the things that are most relevant for the task at hand and think more thoroughly about how to behave and why to do so. This way, the relationship between their attitudes, values and behavior becomes stronger, because people are more conscious about what is important to themselves and act accordingly. In Chapter 4, activation of the self by using self referent words could therefore have resulted in the selection and activation of the value universalism as the most relevant concept for deciding what to think about OGF, thereby strengthening the relationship between universalism and OGF. If this was the case, the strengthened correspondence between universalism and OGF in the link conditions did not result from linking universalism and OGF, but from activating the self:

A second confounder that could have been elicited by the manipulation used in the experiments of Chapter 4 is the effect of demand characteristics. By informing participants that they have a universalistic personality, and that this has something to do with OGF, Just because they thought that this was expected of them, participants could have felt the inclination to state that they evaluated OGF positively, when they actually did not. This could then have resulted in a more consistent attitude toward OGF of the participants in the link conditions, compared to the participants in the activation conditions. If this was the case, the higher correlation between universalism and OGF in the link conditions did not occur because suggesting the link made participants realize that universalism and OGF have something in common, but because telling participants that they are a universalistic person and then suggesting the link between universalism and OGF forced participants to report a more consistent attitude toward OGF than they would have done otherwise.

In sum, there are two competing explanations for the link effect that was found in Chapter 4. The first explanation describes that the manipulation resulted in activation of the specific value. Then in the link condition, suggesting the link resulted in participants using the activated value to determine their attitude toward the linked subject. $A$ second explanation is the fact that using words that refer to the self (I, me, you, your) could have resulted in either an effect of demand characteristics or an effect of self activation. Because both self activation and demand characteristics could have resulted from telling participants that they themselves had a universalistic personality, it is difficult to disentangle the effects of these two possible confounders. Therefore, the purpose of the experiment discussed in this chapter was to investigate whether self activation and/or demand characteristics had an effect on the results by manipulating reference to the self and reference to the link between attitudes and values independently in a $2 \times 2$ design. Finding of either a main effect of self referencing or an interaction between self referencing and linking would identify self activation as confounder for the link effect. By taking the self referent words out of the manipulation and making participants believe that the personality characteristic they had to read was not necessarily related to themselves, we hoped that the possible influence of demand characteristics on the results was undone. 


\section{The present research}

The purpose of Experiment 5 was to investigate whether the manipulation that was used in the three experiments in Chapter 4 resulted (together with a linkeffect) in the activation of the self. Therefore, this experiment consisted of four conditions, which together formed a $2 \times 2$ design (self reference versus non self reference and activation versus link). The first condition, where the manipulation was self referring, and the value universalism was activated but not linked to OGF was called the self-referring-activation condition (SRA). The second condition, where the manipulation was seff referring and the link between universalism and OGF was stated was called the self referring-link condition (SRL). The third condition, where the manipulation was not self referring and the link was not stated was called the non self referring activation condition (NSRA). Consequently, the fourth condition, where the manipulation was non self referring, but the link was stated, was called the non self referringlink condition (NSRL). The manipulations that were used in the two self referring conditions were exactly the same as the manipulations that were used in the experiments in Chapter 4. However, the manipulations that were used in the non self referring conditions were newly designed for this experiment. By making use of this $2 \times 2$ setup, we wanted to investigate whether for a link effect to occur, both the link manipulation and the self reference manipulation are needed, or whether one of these two manipulations is enough to strengthen the relationship between attitudes and values. Furthermore, we wanted to see whether the link effect also occurred when the possible effect of demand characteristics was diminished.

\section{Method}

\section{Participants}

In this study, 74 undergraduate psychology students participated and received a monetary reward. The mean age of the participants $(16$ males and 58 females) was 20.00 years (SD $=$ 3.94, ranging from 17 to 47 ). The respondents were randomly allocated to the four experimental conditions.

\section{Procedure}

The experiment consisted of two sessions, Session 2 being approximately 3 months apart from Session 1. In Session 1, all participants were asked to fill in a large number of questionnaires. Amongst these questionnaires were two questionnaires that were of importance to this particular research, one that measured the values that participants adhered to (Schwartz Value Surwey), and another one that measured their attitudes toward OGF and GMF. Three months after filling in these questionnaires, participants of the first session were asked to participate in the second session. This long period between Session 1 and 2 was created to ensure that participants would not remember their answers in Session 1, and would therefore not answer in exactly the same way in Session 2. The first task in the second session was the manipulation task. This experiment consisted of four conditions. In each condition, we tried to activate the value of universalism. The way in which this was done, was in essence similar to the manipulation of the two experiments reported in Chapter 4 . However, for the present experiments, we looked for a procedure that could be presented as personality feedback in the self-reference conditions and as a simple description of, not necessarily participants" own personality, in the non self-referent conditions. Therefore, we designed a "dice-throwing" 
personality description procedure. In all four conditions, participants were presented with a collection of eight different dice. In the two self-referent conditions, participarits were asked to select two of these dice, to throw them and to add the numbers. Then, the experimenter presented a stack of 11 envelopes. She explained to the participants that they took part in a numerology-personality study and that each of the eleven envelopes corresponded with the 11 possible outcomes of rolling two dice. All envelopes were marked with a number between 2 and 12 . In reality, each envelope contained the same universalistic personality description. Then, she selected and opened the envelope that corresponded with the number of the eves that the participant had thrown and gave the description to the participant. This manipulation was developed to give participants the fllusion that they still had a little control over the number they threw although they knew that throwing dice depends on chance only (Langer \& Roth, 1975). In the two non self-referent conditions, participants were neither allowed to select nor to throw the dice themselves. These participants had no illusion of control, and therefore expected the outcome of the numerology-personality study only to be based on chance. This way, participants were not forced to believe that the personality description was necessarily in accordance with their true personality, which was assumed to result in a smaller effect of demand characteristics. In the activation conditions (both self reference and non self reference), the personality result told participants that they had a universalistic personality, thereby activating the value universalism, but the link between universalism and OGF was not mentioned. In the link conditions (both self reference and non self reference) however, the value universalism was activated through the personality result, and the link between universalism and OGF was subtly suggested. The personal result in the non self reference conditions is described below. Note that the words between brackets are the only words that were different for the link condition, compared to the activation conditions.

A universalistic person is someone who thinks about himself and the surroundings a lot. Things like recycling, respect for others (honest, ecological food) and pollitics are not unfamiliar to universalists. They are open to other people and respect other people's viewpoints. Their priority is to lead a happy life, but at the same time take into account their surroundingss. Words that describe universalistic people are: interested, recycling (honest food), involved and enjoying.

In the non-self referent conditions, we made sure that the text did not refer to the participants themselves, but described the value universalism in very general terms. In the self referent conditions however, the personality description was exactly the same as the one in the non self referent conditions only were participants told that they themselves were universalistic people and that the keywords applied to them (for the original phrasing, see the procedure section of Experiments 1 and 2, Chapter 4).

After reading the text, participants in the non self reference conditions were asked four questions: "Which occupational group do you think contains the most universalistic people?", "Which age group do you think contains the most universalistic people?" "Which sex do you think contains the most universalistic people?" and "In which country in Europe do you think the largest percentage of universalistic people live?". These questions were intended to make sure that participants did elaborate on the concept of universalism, but did not necessarily apply this concept to themseives. Participants in the self reference conditions had to answer five questions after the manipulation. These were: "How applicable is the personality 
description to yourself?" "How plausible did you think the personality description was?" "How positive / negative was this personality description?". "How much did this personality description fit in with your norms and values?" and "How well do you think we are able to predict your personality on the basis of rolling dice?". All five questions could be answered on 7 point scales. These questions were designed to explicitly let participants apply the concept of universalism to themselves.

\section{Measures}

1) Schwartz Value Survey (Personal Profile INM version): The Schwartz Value Survey was used to measure which values participants find important in their lives (Schwartz, 1992). It consists of ten general values that are divided into 40 sub values. Participants were given the following instruction: "Here we briefly describe some people. Please read each description and think about how much each person is or is not like you". An example of one of the questions is: "Thinking up new ideas and being creative is important to him. He likes to do things in his own original way". Participants could answer 40 of these questions on a six point scale ranging from 1 (very much like me) to 6 (not like me at all). The scores of the sub values belonging to one general value were averaged to create one single score per general value:

iil Regular Schwartz Value Survey. In the second session, values were again measured; but this time with the sthortened version of the regular Schwartz Value Survey. The Dutch version of this survey (Schwartz \& Huismans, 1995) consists of 58 sub-values which are tested by asking to rate to what extent each of these 58 sub-values is a guiding principle in their lives on a 9 point scale ranging from -1 (opposite to my values) to 7 (extremely important). Only the subvalues that belong to the general vallues universalism, power, hedonism, tradition and stimulation were used in the second session.

iii) Attitudes toward OGF and GMF. Four items were used to assess participants' attitude toward OGF and the same four items were used to measure participants' attitudes toward GMF. Participants were asked to rate "what do you in general think about OGF/GMF" on four fivepoint scales varying from 1 (very unpleasant / very bad / very unfovorable / very negative) to 5 (very pleasant / very good / very favorable / very positive).

\section{Results and Discussion}

\section{Attitudes}

To test for a difference in attitude toward GMF on the posttest, a univariate GLM analysis was conducted with the post GMF attitude measure as dependent variable, the pre GMF attitude measure as covariate and condition as fixed factor. This analysis showed that there was no difference between the conditions in their attitude scores toward GMF on the posttest, corrected for the pretest, $F(3,69)=0.432, p=$ n.s.

A second univariate GLM tested for a difference between the conditions in their attitude toward OGF. This analysis; with the post OGF attitude measure as dependent variable, the pre OGF attitude measure as covariate and condition as fixed factor, showed that there was no 
difference between the conditions on their post $O G F$ attitude, $F(3,69)=1.47, p=17.5$. This is summarized in Table 5.1.

\section{Walues}

To test for a difference in the value unwersalism on the posstest, a univariate GLM analysis was conducted with the post universalism measure as dependent wariable, the pre universalism measure as covariate and condition as fixed factor. This analysis showed that there was no difference between the conditions in their scores on the walue universolism on the posttest, corrected for the pre test $t_{*} F(3,69)=0.557, p=n . s_{\text {. }}$

A second univariate GLM tested for a difference between the conditions in their power value. This analysis, with the post power measure as dependent vanable, the pre power measure as covariate and condition as fixed factor, showed that there was no difference between the conditions on their post power measure, $F(3,69)=0.18, p=n .5$. This can be seen in Table 5.1.

\section{Attitudes and values}

Three tests were conducted to investigate whether self reference had an effect on the results. Therefore we computed the correlations between GMF-universalism and OGF-universalism on the pre- and the posttest. These can be found in Table 5.2. Finding of either a main effect of self referencing or and interaction between self referencing and linking would identify self activation as confounder for the link effect.

To test whether there was a main effect of linking, the two activation conditions were taken together and they were compared to the two link conditions. The relationship between umiversalism and OGF was (marginally) significantly stronger in the link conditions $(r=0.689)$ than in the activation conditions $(r=0.445), Z=-1.52, p=.06$. These results suggest that the correlation between universalism and OGF in both link conditions was stionger than the correlations between unversalism and OGF in both the activation conditions. The same test was conducted for the relationship between GMF and universalism. The difference between the two link conditions $(-0.155)$ and the two activation conditions $(-0.334)$ proved not to be significant, $Z=-1.79$, $p=n, s_{*}$ 
Table 5.1. The means and standard deviation of the pre and post measures of the attitude toward genetically modified food (GMF) the attitude toward organically grown food (OGF) and the means and standard deviations of the value unversalism (pre and postrest).

\begin{tabular}{|c|c|c|c|c|c|c|}
\hline Condition & $\begin{array}{l}\text { Pre Atitude } \\
\text { GMF }\end{array}$ & $\begin{array}{l}\text { Post Attitude } \\
\text { GMF }\end{array}$ & $\begin{array}{l}\text { Pre Atituide } \\
\text { ogf }\end{array}$ & $\begin{array}{l}\text { post Attitud } \\
\text { oGF }\end{array}$ & $\begin{array}{l}\text { epre measure } \\
\text { universalism }\end{array}$ & $\begin{array}{l}\text { Postmeasure } \\
\text { universalism }\end{array}$ \\
\hline $\mathrm{Su}^{+}$ & $M(S D)$ & $M(S D)$ & $M(s D)$ & $M(S \mathrm{D})$ & $\mathrm{M}(\mathrm{SO})$ & $M(S D)$ \\
\hline $\begin{array}{l}\text { Self ref activ } \\
(n=18)\end{array}$ & $4.48(1,39)$ & $393(120)$ & $502,1,64)$ & $532(1.05)$ & $2.89(0.86)$ & $6.68(0.79)$ \\
\hline $\begin{array}{l}\text { Seff reflonk } \\
(n=19)\end{array}$ & $393(0.95)$ & $3.83(1.21)$ & $526(1,19)$ & $491(1.05)$ & $2,22(074)$ & $680(0.86)$ \\
\hline $\begin{array}{l}\text { Non self ref activ } \\
(n=19)\end{array}$ & $3.56(1,52)$ & $3.43(1.48)$ & $588(0.89)$ & $525(0.87)$ & $303(098)$ & $6.34(1.01)$ \\
\hline $\begin{array}{l}\text { Mon self ref link } \\
(n=18)\end{array}$ & $3.01(094)$ & $353(0.91)$ & $5.85(1,08)$ & $532(0.84)$ & $2.64(0.84)$ & $6.64(1.10)$ \\
\hline
\end{tabular}

Mote The pretest of the value universalism was measured on a scale from 1 to 6 , whereas the post test was neasured on a scale from 1 to 7

To test whether there was a main effect of self referencing, both the self reference conditions were taken together, and these were compared to the mean of the non self reference conditions. This analysis showed that there was no difference between the mean correlation (universalism and OGF) in the self reference conditions $(r=0.547)$ and in the non self reference conditions $(r=0.587), Z=0.24, p=n .5$. This means that no main effect of seif referencing could be found. For GMF however, there was a main effect of self referencing. The two self-referent conditions showed a stronger correlation between universalism and GMF than the two non self-referent conditions $s_{n} Z=2.14, p<0.05$.

To test for an interaction effect between self reference and linking, the mean of the self reference-activation condition and the non self reference-link condition $(r=0.570)$ was compared to the mean of the self reference-link condition and the non self reference activation condition $(r=0.564)$. This analysis did not show a significant interaction effect, $Z=-$ $0.03, p=n$.s. The same test with the relationship between universalism and GMF as dependent variable showed that there was no interaction between self-reference and linking, $Z=0.28, p=$ n.s. This can be seen in Table 5.2 .

Table 5.2 The correlations between GMF unversalisin and OGF unversalisin on the pres and posttest for each of the four conditions * $p<0.05, * p<0.01$.

\begin{tabular}{|c|c|c|c|c|}
\hline Condition & $\begin{array}{l}\text { Correlation GMF } \\
\text { universalism } \\
\text { pretest }\end{array}$ & $\begin{array}{l}\text { Comrelation GMF } \\
\text { universalism } \\
\text { posttest }\end{array}$ & $\begin{array}{l}\text { Correlation OGF } \\
\text { unversalism } \\
\text { pretest }\end{array}$ & $\begin{array}{l}\text { Correlation OGF. } \\
\text { universalism } \\
\text { posttest }\end{array}$ \\
\hline Selfref activation & 0.316 & $0.501^{\circ}$ & 0.121 & 0.428 \\
\hline Self reflink & 0.075 & $-0,386$ & 0.180 & $0.665^{*}$ \\
\hline Nonself ref activation & 0238 & 0.167 & 0.030 & $0.462^{\circ}$ \\
\hline Non self reflink & 0,025 & 0.076 & $0.489^{*}$ & $0.712 * *$ \\
\hline
\end{tabular}




\section{Discussion}

In the present experiment, we tried to reduce the possible effect of demand characteristics and self awareness, by not referring to the self in the personal test result but rather to universalists in general. We argue that the use of self referent words could have made participants rate their attitudes in fine with the value universalism, because they felt we forced them to do so. By taking out the self referent words, we reduced the amount of demand characteristics induced by the manipulation. Furthermore, eliminating the self referent words also changed the self activating nature of the manipulation. To summarize, the results of this experiment suggest that for GMF, there was no link-effect, but an effect of self referencing. Participants who received a personality description where self referent: words were used, showed a stronger negative link between universalism and GMF than the participants who were not confronted with self referent words. These results however do not suggest that the effect of linking as it was found in Chapter 4 is influenced by self referencing, or can be disaffirmed. However ${ }_{r}$ they do show that self activation (due to self referencing) does play a role in these kind of manipulations and that self activation can make values, and the relationship between values and attitudes more strongly present.

For OGF, there was no effect of self referencing and no interaction between linking and self referencing. The only main effect that was (marginally) significant was the effect of linking. Therefore, we believe that his experiment showed that the link effect that was found in Chapter 4 and again in this chapter was not only due to an effect of demand characteristics or self activation. The results of the present experiment shows that it did not matter whether the personal result, which was used as a manipulation, activated the self ("you are a universalistic

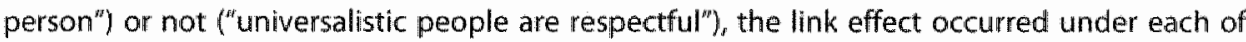
these conditions. This does not necessarily mean that the link effect has nothing to do with self-activation or demand characteristics. However, it does mean that self activation and demand characteristics are not the onlly, or main, cause of the link effect. It also does not mean that participants showed no effect of self activation whatsoever, only that there was no difference between the conditions in their amount of self activation, and therefore that self activation or demand characteristics do not cause the link effect.

However, the reason for the relatively high correlations between universalism and OGF in the activation conditions (compared to Experiment 1 and 2 of Chapter 4), resulting in a marginally-significant difference between the activation conditions and the link conditions remains unclear. It could be that the manipulation that was chosen in this experiment (rolling dice) had some kind of side effect that resulted in this lack of significant differences between these correlations. Another possibility is that the questions that were given to the participants after they read the personal result lead to participants thinking more about the concept of universalism than in the experiments in the Chapter 4 , where participants were not given these questions.

One possible effect that self activation/demand characteristics could have had, and that we could not rule out by this study, is the fact that the effect of self activation could have been different for the link condition compared to the control- and activation conditions. If suggesting the link (mentioning the words "honest, ecological food") created more self activation than mentioning words like "recycling" and "respect for others", than the link effect as it was found in Chapter 4 and the present chapter, could have been purely due to an effect of self activation instead an effect of linking. However, we suspect that this explanation is 
unlikely, because it is very difficult to come up with an underlying mechanism that explains why "honest, ecological food" would activate the self more than "recycling" or "respect for others". Therefore, we consider this explanation mplausible:

A matter forconsideration is the fact that in future experiments it can be advantageous to make sure that the values on the pretest and the posttest are measured by making use of the same scales In most experiments described in these chapters, the scale on the pretest was different from the scale on the posttest. We decided to do this, because in most of the experiments, the pretest inmediately preceded the experimental phase, which was immediately followed by the posttest. Therefore, we wanted to make sure that there was a very small chance of consistency motives, which could have caused participants to answer the same way on the posttest as on the pretest. Rather than relying on randomization, we decided to measure the values in different ways, preventing obvious consistency tendencies but enabling us to investigate whether there was an interaction between the three conditions and the moment that the value universalism was measured (pre-or post-measure).

Because self activation and demand characteristics can now be ruled out as an explanation for the link-fiect, we need to tum in a different direction to find the underlying mechanism of the link effect. One such mechanism could be the lact that suggesting the link between a value and an attitude puts the abstract value in a different light. Maybe, linking an abstract value to a more concrete attitude makes the value seem more concrete, thereby bridging the gap in specificity between attitudes and values. However, this possible explanation needs to be tested thoroughly, before any conclusions can be drawn. 
The purpose of the present dissertation was to conduct a thorough investigation of the relationship between values and attitudes. Our main goal was to examine whether values influence attitudes and how and when they do so. We hawe focused on food innovations as an angle to study the relationsihip between attitudes and their underlying values. The studies presented in this dissertation employed both correlational and experimental research designs. We selected a variety of manipulations to activate values and study their connection with attitudes. In this final chapter, the main empirical findings presented in Chapters 1 to 5 will be summarized. Subsequently, these findings will be discussed in a broader context. Then, some suggestions for further research will be discussed.

\section{Overview of the main findings}

The first central question in this dissertation was whether values play a role in forming and expressing attitudes. One of the main conclusions of Chapter 1 , the first empirical chapter is that specific attitudes are indeed related to specific values. In this chapter, we examined the underlying inter- and intra-attitudinal structures of two attitude issues, i.e. genetically modified food (GMF) and organically grown food (OGF). A first finding was that the attitude toward OGF was related to the value universalism (positively) as well as to the value power (negatively). In addition, the attitude toward GMF was related to the value powver (positively). Furthermore, the attitudes toward GMF and OGF were negatively related. A positive attitude toward GMF is associated with a negative attitude toward OGF and vice versa. Together, this implies that the relation to values is different for these two opposing attitude issues. Furthermore, we have shown that values do play a role in the prediction of attitudes.

A further goal of Chapter 1 was to study the position of bellefs in their relationship with values and attitudes. An interesting finding was that beliefs related to GMF and OGF mediated the relation between attitudes and values. If a value is activated, it might influence some of the beliefs that an attitude is made up of. The beliefs that are in line with this activated value become more important, and influence the generall attitude more than other, unimportant beliefs. This can result in attitudes being more in line with their underlying values. Taken together, the results of Chapter 1 show that attitudes are related to value endorsement, that opposing attitude positions are reflected in different values structures and that beliefs mediate the relationship between values and attitudes. Identifying relevant values improves our understanding of food-related attitudes and how they are constructed and therefore helps to gain more insight into the possible ways to reinforce or change attitudes.

The second central question of this dissertation was examined in Chapter 2. The study presented in this chapter focused on the structural relations between vallues and three important attitude characteristics: centrality, commitment and ambivalence. These three attitude characteristics determine the embeddedness of an attitude in its underlying structure. Centrality refers to the importance of an attitude to the self concept and personal values. Commitment refers to the certainty or conviction about the attitude. Ambivalence refers to a situation in which an individual has both strong positive and strong negative ideas about an attitude-object. Chapter 2 showed that values have a different effect on centrality than on commitment. The values that were positively associated with the attitude toward GMF and OGF influenced the level of centrality of an attitude. For GMF, people who adhered to power. had a more central attitude than people who did not adhere to power. Adherence to the value universalism had no effect on the centrality of the GMF attitude. However, for the attitude 
toward OGF, the value universalism, to which it is positively related; did have a positue association with the centrality of the attitude. Thus, the stronger the positive relationship between an attitude and a value, the more central the attitude was. This is probably due to the fact that centrality is, more than commitment, related to the self concept. People define themselves and the things that are important to them in a positive manner. Therefore, centrality is related to the values that people do find important. For commitment exactly the opposite pattern occurred. It seemed that endorsement of the values that were related to the attitude in a negative way was associated with the level of commitment. For example, people who were not attached to the value power had a committed attitude toward OGF. Commitment is highly related to the certainty or conviction with which an attitude is held. In general, there seems to be a tendency for negative information to result in larger cognitive, emotional, and social responses than positive information (lto, Larsen, Smith, \& Cacioppo, 1998; Taylor, 1991). This leads to negative attitudes and vallues having more effect on their environment than positive ones. Therefore, people are more certain about the values they consider to be negative than about positive values. There was no relation between values and the ambivalence of an attitude. Taken together, Chapters 1 and 2 shed light on how exactly values are associated to attitudes and how other variables; like beliefs and attitude strength characteristics fit in with this reiationship.

In the second part of this dissertation, we shifted our focus from examining the underlying structure of values and attitudes to actually influencing this relationship experimentally. The two experiments in Chapter 3 demonstrated that merely activating a value is not enough to strengthen the relationship between attitudes and values. The answer to our third general question: does activation of a value lead to a reaction in its related attitudes, was therefore negative. Mere activation of the values power and universalism did not result in a change in the attitudes toward GMF and OGF, or in a stronger relationship between values and attitudes. We argued that one reason for this lack of influence of values on attitudes could be that participants did not realize that there is a relationship between a value and specific attitudes.

In Chapter 4 , we argued that a precondition for a strong value-attitude relationship should be met before the relationship between values and attitudes can be strengthened. If a value is activated and a small and minimal link between a value and an attitude is suggested, the usually absent to weak relationship between values and attitudes can be strengthened. By merely suggesting an attitude issue in the context of a value, people realize that this relationship exists. We have called this the "link effect". We argue that, because this link suggests to participants that the abstract value can be applied to very concrete things such as food, participants come to see this value with different eyes. This way, the implications of the value are extended to a domain that participants before had never thought of as being related to this value. However, we think that this link effect does not occur because participants. actively and consciously connected the two concepts that are linked through the manipulation. The manipulations that were used in Chapter 4 were designed to be minimal and unobtrusive. We merely mentioned the words "ecological food" in the context of the walue universalism, and we never explicitly told participants to think more positively about OGF. We argue that this link effect is a relatively simple manner to remind people of the fact that the attitudes they endorse have something to do with values that we all find important and vice versa. By doing this in an unobtrusive way, we also decreased the possible influence of demand characteristics. Had we told participants how universalism and OGF are related and that considering universalism an important value is associated with a positive attitude toward 
OGF, we could have created the impression that we wanted participants to evaluate both OGF and whersalism more positively. The minimal nature of our manipulation however ensured that the link effect was as litte as possible influenced by unwanted effects. However, the manipulations that were used in Chapter 4 could not entirely rulle out important alternative explanations.

The experiment in Chapter 5 was designed to rule out an effect of demand characteristics and Gelf awareness. The manipulationis as they were used in Chapter 4 were changed, so that they were less prone to demand characteristics. We did this by eliminating all references to the self. By informing participants that they have a universalistic personality, and that this has something to do with $O G F$, participants could have felt the inclination to state that they evaluated $O G F$ positively, when they actually did not, just because they thought that this was expected of them: Moreover, a heightened self awareness is known to result in a larger congruence between values and attitudes. The effect that we interpreted as being an effect of activating a value and linking it to an attitude could therefore also have resulted from activation of the self. By taking all references to the self out of the manipulation, we made sure that the effect that was found could only result from the link effect; and not from an effect of self activation or demand characteristics. The experiment in Chapter 5 showed that both the self awareness explanation and the demand characteristics explanation are implausible.

Taken together, we have shown that the values power and universalism underlie the attitudes toward GMF and OGF and that only when the link between these values and attitudes is suggested, there is a strong relationship between them. One possible limitation of the research described in this dissertation is the fact that we used only two values and two attitudle issues to show these effects. This could limit our ability to generalize these findings to other attitude issues and values. However, we think that food attitudes do not differ very much from most other attitudes. When looking at the characteristics of the attitudes toward GMF and $O G F$, they were moderate to high in strength and their valence varied from neutral / negative to positive. We therefore argue that by choosing these two attitude issues, we covered a substantial part of the possible variations in valence and attitude strength. Hereby we improved the chance that the results of our studies can be generalized to other attitudes which fall within the same attitude strength and valence ranges. This reasoning also holds for the two values that were repeatedly used in our studies. By choosing the values universalism and power, we used two values that differ on all possible variables. As Schwartz (1992) argued, there are two continuums on which values can differ: self transcendence versus self anhancement and openness to change versus conservation. Universalism is a value that belongs to the self-transcendence part of the value circle, whereas power belongs to the selfenhancement part. Furthermore, power is related to conservation, whereas universalism is related to openness to change. Using these two values in our research enables us to generalize more than using one value would have. Apart from limitations, the research presented in this dissertation also had particular strengths. We replicated the correlational patterns that were found in many ways, both by measuring correlations and after experimentally manipulating accessibility and links. By using both correlational studies and experimental studies to examine the same phenomenon, we ensured that the effects that we found are not merely an artifact of some kind. Furthermore, we repeatedly showed that values and attitudes can be or are related to each other and that this relationship can be strengthened by subtly suggesting the link between an attitude and a specific value. We showed that this linking could be induced by a so-called personality questionnaire and, more minimally, by letting participant choose one out 
of 5 cookies. Moreover, we replicated these results with students as well as non student consumers: This way, we hope to have convinced the critical reader of the potential of our findings:

\section{Conclusions, implications and future research}

\section{Conclusions and implications}

The first conclusion that can be drawn from our findings is the fact that values do contribute to the explanation and prediction of attitudes. We have shown in several experiments, with both student-and consumer-populations, that values help to understand why some attitudes are positive and others are negative. Furthermore, we have shown that there is a systematic relationship between specific values and attitudes. However, we argue that merely activating values in order to understand or influence specific attitudes is not enough. There are certain preconditions that need to be taken into account. It is not so that activating a value that people find important, will automatically lead people to judge situations or attitude issues more in line with the activated value. It has to be (however subtly) suggested how this activated value relates to a concrete opinion or attitude issue. We have shown that this can be accomplished by presenting an attitude issue in the context of a specific value. This can be done by adding the words secological food" to a description of the value universalism, without further explaining what the exact relationship between the two is. This minimal manipulation leads to a larger value-attitude correspondence. Without this manipulation; the relationship between values and attitudes is small or absent. With this added link, the relationship increases to a substantial level. This is probably mostly true for value-attitude relations that are weak in the first place. If a value is evidently related to an attitude (like for instance the walue health and the attitude toward smoking), this link effect might have a much smaller impact, because people already realize that the two are connected. Attitudes that are important to a person are very strongly embedded into their underlying attitudinal structure. Because people often think about their strong attitudes, and apply them to a large variety of situations, a strong attitude probably already has been used in all situations to which it could be applied. All the possible connections between this attitude and other concepts have most likely already been made. In this case, linking an attitude and a value does not have a large influence, because participants already realized that there is a connection between a value and an attitude. For weak attitudes, which are held with less conviction, the whole spectrum of possible relations to other concepts has not been explored in so much detail, because people not often think about these attitudes, or apply them in their daily lives. Only the very obvious connections will be clear to the person that holds the attitude. In these cases, linking a value and an attitude can sugglest unknown connections to people and linking cain still have an effect.

However, it is not the case that activating a specific walue and linking it to an attitude leads to an immediate change in related attitudes or behavior. This could be due to the fact that the manipulation made some participants more positive toward OGF and universalism and others more negative. Participants who did not adhere to universalism in the first place, will probably find this value even less important after the manipulation, and will become more negative toward OGF. However, participants who did adhere to universalism before the manipulation, come to find universolism even more important and probably rate OGF as more 
positive. These wo effects can cancel each other out when looking at the mean attitude score, but are reflected in the strength of the association between universalism and OGF. Thus, activation of a value may only strengthen the relationiship between values and attitudes. Another reason for this lack of effect on the levell of attitudes could be due to the fact that attitudes are resistant to change. All elements in an attitude structure are connected to each other and are in balance with each other. A change in one attitude leads to an imbalance in its underlying attitude structure. This imbalance can onlly be corrected if other attitudes, values or beliefs also change (Heider, 1946), which results in the fundamental restructuring of the elements in the attitudinal structure Eagly \& Chaiken, 1995; Judd \& Krosnick, 1982; Johnson \& Eagly, 1989\%. It seems that a change in the total structure of an attitude, which is needed to instigate attitude change, is hard to achieve. However, our results suggest that it is possible to strengthen specific relationships within this attitude structure.

This important role of values in attitude formation is not widely recognized. Many social psychological theories, although they describe attitudes in detail, consider values as distant influences, too abstract to actually have a meaningful effect on attitudes. The Theory of Planned Behavior for instance, regards values as distal determinants, which do not have a direct effect on attitudes. Ajzen (1988) has set a trend to investigate attitudes and related concepts with an increasing level of specificity. He argued that onlly if participants are asked what their behavior will be a) in a specific situation, b) on a specific time and c) at a specific location, it is possible to predict their behavior in that specific situation, time and location. He calls this the principle of correspondence. However, we would like to argue that it is possible to use an abstract construct such as a value to predict more concrete constructs such as attitudes from it. One advantage of the use of values in the explanation of attitudies is that if you know which values certain people find most important, this can be a useful predictor of how they would think about many specific attitude issues. Thus, examining people's values can serve as a quick scan to determine how people think about specific attitude issues.

\section{Further research on the time course and sensitivity of the link effect}

A possible constraint of the studies described in this dissertation is that the activation of a value and the suggestion of a link between wallue and attitude were always induced within the same manipulation. First, a value was activated, and directly afterwards, a link between the value and a specific attituide issue was suggested. Also, the activation was always presented first, followed by suggesting a link. It is not yet evident whether taking apart these two elements of our manipulation would result in the same pattern of effects that was found so far. This could be tested in an experiment where the link between universalism and OGF is suggested on time 1, and the value universalism is activated some time la day, a week or a month) later or vice versa. The time-lag between linking and activation could be gradually increased so that it becomes clear how much the two can be separated in time, without decreasing the link effect. This taking apart of activation and linking would also decrease the effect that demand characteristics have on the manipulation. If it turns out that activation and linking can be separated in time, this may provide us with a useful procedure to implement the link effect in real life settings.

A second question relating to the two main elements of our manipulation is whether a value needs to be activated and linked to an attitude or whether linking is enough to ensure an effect of values on attitudes. It is possible that linking a value to an attitude only has an 
influence when the value is activated If walue is not activated, the relations whth its related concepts are also not active, and it could be that in these cases, people do not recoginize the link between a value and an attitude. However, it could also be the case that by referring to an attitude that is related to a value, the value becomes activated automatically. Then, activation is not necessary for a link-effect to occur. This might also depend on the centrality of the attitude or the centrality of the value, so that activation is not necessary for strong/central attitudes, but would be necessary for weak ones. Further research should aim at unraveling these assumed components to see whether the effect is an interaction between activating a value and a suggested link between a value and an attitude.

Furthermore, in daily life, participants usually do not first encounter a situation where a value is activated and linked to an attitude-object and then immediately move on to the next: situation where they have to rate or act upon this attitude-object. In between this activation / linking, and the expression of an attitude, there is always interference (time or stimulation) of some kind. For example, in a supermarket, you rarely see an advertisement where OGF is linked to universalism, and right after that have the choice between all the products that you wanted to buy in a regular form and an organically grown version. It always takes at least time and sometimes effort to be able to apply a freshly activated and linked value on attitudes. Up until now, we have only measured whether linking on time 1 results in an effect on attitudes on time 2, which was 5 minutes later. Further research should therefare test the link effect in a situation that is comparable to the real life. This could be done by imitating a supermarket environment in the laboratory, or on a computer. Even better would be to conduct the experiment in a real supermarket. The manipulation could then be given before participants enter the supermarket (for example through putting up posters at the entrance that activate universalism and link OGF to universalism) and the dependent variable coulld be the mean number of OGF food products that participants buy. This experimental setup will largely increase the ecological validity of the results.

\section{Further research on the structural relations between values and attitudes}

Because values and attitudes are part of an encompassing inter-and intra attitudinal structure, activation of one value and linking it to a specific attitude issue could lead to activation of another value-attitude relation. In Experiment 4.1, an effect of linking was found on other attitudes than the attitude that was linked to the activated value. If the vallue universalism was activated and linked to the attitude toward $O G F_{n}$ the attitude toward $G M F_{i}$ which was not linked to the value universalism, became more negatively related to universalism. We called this a carry-over effect. It seems possible to influence a number of related attitudes by activating only one value and linking it to one of these attitudes. This handling of several related attitudes simultaneouslly can be necessary to influence al specific attitude if it is strongly embedded into its underlying internal attitude structure. In these cases, changing only one attitude does not work, because this attitude then does not fit within its underlying structure anymore. Only if all attitudes in a structure are changed and hence the balance is restored, such a manipulation will have an effect. Further research on the value-attitude relationship should therefore focus on explaining and predicting when and how this carry-over effect occurs, thereby making it a tool to influence more than one attitude by manipulating only one value. 
Another matter related to attitude structure is whether it is necessary that people actually adhere to a value for the relationship between values and attitudes to be influenced by the link effect In our experiments, we always activated the value universalism and linked ht to OGF. In these cases, where most participants adhered to a value, we found that the link effect occurred. However, what would happen if we activated the value power and linked it to the attitude toward GMF? The first plausible option is that activating the value power and linking it to GMF results in a stronger positive relationship between the two. However power is a value that most people do not find important in their lives. The literature on "attitude bolstering" predicts an effect opposite to the link-effect that we found. Sherman and Gorkin (1980) define attitude bolstering as follows: "threats to one's selfilmage caused by one's own counterattitudinal actions, lead to attempts to re-establish those threatened attitudes." This means that when a person has done something that is opposed to their attitudes, they try to "neutralize" this action by doing something that strengthens their attitudes. We reasoned that, because power is opposite to participants' values, activating this value in response to participants' answers on a personality questionnaire could threaten their self concept. This could lead to the activation of values that restore the self concept (in this case, the value universalism). It is therefore possible that activating and linking the value power results in activation of the value universalism instead. In this case, adherence to a value is a necessary condition for the link effect to occur.

The last issue that we wish to discuss is the finding that activating a target value does not always result in the expected relation with attitudes or behavior. Next to the activated target value, another value can be intentionally or unintentionally activated. This other value can be in conflict with the target value, which results in an uncertain outcome on attitudes or behavior. This was shown by the experiment by Darley and Batson (1973), on the parable of the Good Samaritan ${ }_{i}$ which was also discussed in the introduction section of this dissertation. These researchers showed that even when the value "benevolence" was activated, people did not help a stranger, because another value, "punctuality", was made even more accessible by telling participants that they were in a hurry. Darley \& Batson confronted a sample of theological students with an emergency situation that obviously demanded their help. All students were sent on their way to another building to give a presentation. Half of the students were told to give a presentation on the parable of the goad Samaritan, whereas others were tolld to give a presentation about their career. Furthermore, the experimenter told some of the students that they were in a hurry, and tolid others that they had enough time to go from building $A$ to building $B$. All students encountered a man in need in between the two buildings. The results of this experiment showed that independent of the topic of their presentation, students who were not in a hurry stopped to help more often than students who were in a hurry. Activation of the value benevolence (by letting students think about the parable of the good Samaritan) did not work if another value, punctuality was also activated. This experiment is an illustration of the dilemmas that people come to face in their daily lives. it is never the case that a person finds only one value important in life, or that only one value is activated at a certain moment. Even if a value is experimentally actiwated, as we have done, it could be that other values, which are of great importance to the person, or that are activated because of the situation, interfere with the experimentally activated value. Since different walues can have different consequences, it is therefore difficult to predict which attitudes or behavior will occur in such a situation. Therefore, further research should focus on 
investigating whether the link effect cam help in applying one walue more than another to a related attitude in the situation where two or more values are important for an attitude issue.

We hope to have contributed to the general understanding of how values infuence attitudes and how the relationship between these two concepts can be strengthened. Writh the findings of the present dissertation in mind, we wish to emphasize that values should again be taken seriously as predictors of attitudes, and that it is possible to manipulate values so that they have an effect on attitudes. We therefore would like to conclude with the device that research should again place more value on values. 
94 
Although taste, prize, avallability and mutrition value are important factors, some people decide what or what not to eat on the basis of moral considerations. These moral considerations, or values, are therefore important determinants of participant's attitudes toward food. For instance, people who walue innovation and technique, usially have a positive attitude toward the new food production technique called genetically modification. However, others, who like to keep things as they have always been, do not like this new food production technique. An attutude can be seen as a disposition to evaluate attitude-objects with some degree of favor or disfawor (Eagly \& Chaiken, 1993). Anything that can be discriminated or evaluated can serve as an attitude-object. An attitude is comprised of severall belliefs or cognitive components. The attitude toward organically grown food can for instance be comprised of beliefs like "organically grown food is healthy" or "organically grown food is produced without pesticides". Values determine which attitudes people feel strongly about and how to react to certain objects or situations. The attitude toward organically grown food can for instance be influenced by the walues "power" (control and dominance over people and resources) and "universalism" (respect for all people and for nature). In this dissertation, we systematically examine the relationship between values and attitudes. The first goal of this dissertation is to inwestigate if and how wallues exert their influence on (food-related) attitudes. The second goal is to determine the preconditions that might contribute to a stronger correspondence between values and attitudes and to understand their underlying mechanisms. Seven studies are discussed that reveal when and how values are related to attitudes, the effects of a strong value-attitude coherence and the mechanism underlying a strong relationship between values and attitudes.

In Part 1, which consists of two chapters, we describe two studies that on the one hand aimed at investigating the attitudes toward food-innovations and on the other hand at revealing the values that underlie these attitudes. In Chapter 1 , the selection of two, presumably opposing food-issues enabled us to study whether specific attitude positions are linked to specific patterns of values. Thus, study 1 addressed which specific values play a role in predicting participants' attitudes toward genetically modified food (GMF) and organically grown food (OGF). These two attitude issues, have a presumed incompatibility, because their underlying ideas are opposed to each other. OGF stands for producing products in the most natural and pure way, whereas GMF stands for manipulation and human interference. These two attitude issues and their underlying values were investigated in a survey with 100 participants, where we first asked participants to determine how important they found 10 values, and then asked them to rate how they thought about OGF and GMF. The results of Study 1 showed that when respondents scored high on the value power (control and dominance over people and natural resources), they rated GMF positively and OGF more negatively. Participants who rated the value universalism (welfare for all people and protection of nature) high, rated OGF as positive. Furthermore, the relationship between attitudes and values was mediated by beliefs. The effect that values have on attitudes flows through the specific beliefs, or cognitive components, that the attitude is comprised of. These findings imply a meaningful relationship between specific values, beliefs, and these food-related attitudes, and suggest that values play a role in explaining attitudes toward GMF and OGF. Chapter 1 therefore provides correlational evidence of the relationship between specific values, beliefs and attitudes.

The next central question in this dissertation is related to how exactly values influence attitudes. Usually, a change in attitudes is coincided by a change in attitude characteristics like 
attitude strength and ambivalence. Since values influence attitudes and therefore also their characteristics, Chapter 2 focuses on the relation between walues and three important attitude characteristics. For Study 2, the data of several experiments were combined and included 241 students and non student consumers. We measured the importance that participants placed on 10 values, and their attitudes, centrality, commitment and ambivalence toward GMF and OGF. Study 2 again showed that the values power and universalism were related to the attitudes toward GMF and OGF. Furthermore, these values had an influence on the centrality, commitment and ambivalence of these attitudes. Values that were positively irelated to an attitude influenced how central this attitude was to a person. Universalism determined the centrality of the attitude toward OGF, whereas power determined the centrality of the attitude toward GMF. This is probably due to the fact that centrality is related to the self concept. People define themselves and the things that are important to them in a positive manner. Therefore, centrality is related to the values that people do find important. However, values that were negatively related to an attitude had a larger effect on the commitment of this attitude. Power determined the commitment of the attitude toward OGF, whereas universalism determined the commitment of the attitude toward GMF. Commitment is highly related to the certainty or conviction with which an attitude is held. In general, there seems to be a tendency for negative information to result in larger cognitive, emotional ${ }_{n}$ and social responses than positive information (Ito, Larsen, Smith \& Cacioppo, 1998; Taylor, 1991). This leads to negative attitudes and values having more effect on their environment than positive ones. Therefore, people are more certain about the values they consider to be negative than about positive values. No such pattern of effects was found for the relationship between ambivalence and values. To sum up, in Chapter 2, it was shown that the three important attitude strength characteristics, centrality, commitment and ambivalence have different relationships with values.

In Part 2, which consisted of three chapters, we aimed at finding a way to strengthen the relationship between values and attitudes, since it is often considered to be present ${ }_{\text {b }}$ but weak. We discuss a solution to this often missing value-attitude correspondence. Five studies show that only when people are aware that there is a connection between a value and its related attitudes, they show a high value-attitude correspondence. This connection or "link" between values and attitudes is considered a precondition for a strong relation between attitudes and their underlying values. In Chapter 3, two studies are described that focus on activating values and measuring their effect on related attitudes and behavior. Studies $\mathbf{3 . 1}$ and $\mathbf{3 . 2}$ were designed to prime both students and non-student consumers with the values power and universalism and to measure an effect of these primed values on the attitudes toward GMF and OGF. Participants could choose three out of 5 words that were related to power (in the power condition) or to universalism (in the universalism condition). They had to use each of these three words to describe a situation where their attitudes or behavior were guided by this word (i.e. were guided by the value power or universalism). The idea behind this manipulation was that applying three words to the self results in the temporary activation of this value. Then, participants were asked to rate their attitudes toward GMF and OGF. No effect of the activation of these values was found on the attitudes. The attitudes toward GMF and OGF did not differ between the conditions. In study 3.2. where behavior was also measured by letting participants choose between a regular muesli bar, a genetically modified muesli bar and an organically grown muesli bar, activation of the value power or universalism did not have an effect on related behavior. These experiments show that merely priming values does not 
necessanily change attitudes or behavior. This signifies that activating values is not enough to ensure an effect of walues on attitudes:

In Chapter 4, an explanation for the missing results in Chapter 3 was discussed.

Two experiments are discussed that test whether the activation of values results in a change in the relationship between the activated valuie and connected attitudes. Participants were given mock personality test through which the value universalism was activated (activation condition) or not (control condition). This activation of the value universalism was realized by telling participants that their personality corresponded with a universalistic personality, which was described as being respectful, open to ather people and glood to nature, In the third condition, the link condition, the value universalism was also activated but furthermore, participants were alluded to the relationship that the value universalism has with the attitude toward OGF, by merely mentioning the words "ecological food" in the description of a universalistic person. Our results strongly suggest that universalism does seem to affect the attitude toward OGF if universalism is activated AND the link between universialism and OGF is suggested as well. However, merely activating the value universalism is not sufficient to instigate a change in the relationship between universalism and OGF, as was also shown in Experiments 3.1 and 3.2. Thus, the correspondence between universalism and OGF only becomes stronger in the link condition, and not in the activation and control conditions. Moreover, the attitudes and values themselves do not change, only the relation between values and attitudes consolidates. The link effect is shown with several manipulations. in Study 4.1, a personality questionnaire was, uised to activate the value universalism and to link universalism to OGF, whereas in Study 4.2, participants were asked to choose between several cookies. Furthermore, in the first experiment, not only the relationship between universalism and OGF consolicdated in the link condition, but also the link between universalism and GMF, although this link was not alluded to. We arglue that this could be due to the fact that the value universalism and the attitudes toward GMF and OGF are embedded into an underlying structure. The connections within this structure may have activated the link between universalism and GMF by making use of the experimentally activated link between universalism and $\mathrm{OGF}$.

The study discussed in Chapter 5 aims at investigating whether the link-effect is caused by self-activation or demand characteristics. The manipulations used in Chapter 4 made use of self referent words, which could have activated the self. The personality test told participants that they had a universalistic personality and that they were open to other people and cared for nature. Activation of the self usually results in a higher correspondence between value and attitudes. Therefore, activation of the self could have confounded the results found in Chapter 4. Moreover, by informing participants that they have a universalistic personality and that this has something to do with OGF, participaints could have felt the inclination to evaluate OGF in line with their values, when they actually did not share this evaluation. If the effect of demand characteristics would have played a role, the higher correlation between universalism and OGF in the link conditions did not occur because suggesting the link made participants realize that universalism and OGF have something in common, but because participants felt forced to report a more consistent attitude toward OGF. Therefore, we designed two new conditions where the self referent words were removed. Participants were now told that a universalist is someone who cares for nature and for other people. Hereby, we tried to still activate the value universalism, but reduce the effect of self activation or demand characteristics. Study $\mathbf{5}$ showed that self activation or demand characteristics are not the main underlying mechanism 
of the Hink effect. There was no difference between the conditions where sellf referent words were used (and the self could have been activated) and the conditions where no self referent words were used (and the self could not have been activated).

The present dissertation offers a systematic analysis of the relationship between values and attitudes. As was shown in Part 1, values do have an influence on food related attitudes and exert this infuence by changing the beliefs that the attitude is made of, and by changing the strength of an attitude. Part I of this dissertation therefore provides us with a better understanding of how attitudes are influenced and which role values can play in this process. Furthermore, in Part 1 it is shown that the relationship between values and attitudes generally is weak when it comes to food-innovations. However, the experiments in Part 2 show that this relationship can be strengthened a great deal by merely suggesting the link between $a$ value and an attitude. This linking does not have to be very explicit or apparent, but even works when used relatively implicitly. Only mentioning the words "ecological food" in a description of a universalistic person results in strong and significant correlations between universalism and OGF land sometimes even between universalism and GMF), whereas not mentioning these two words results in weak correlations between the value and the attitude. These findings provide a way to bring attitudes in line with respected values, but only if the value and the attitude are related in the first place.

All in all, the data presented in this dissertation all point to the fact that values do contribute to the explanation and prediction of attitudes. We have shown that there is a systematic relationship between specific values and attitudes. However, we argue that merely activating values in order to understand or influence specific attitudes is not enough. A strong relationship between attitudes and values can be accomplished by presenting an attitude issue in the context of a specific value e.g. by suggesting the link between an attitude and a value. It is however not the case that activating a specific value and linking it to an attitude leads to an immediate change in related attitudes or behavior. Activation of a value only strengthens the relationship between values and attitudes. This effect of linking attitudes and values is probably mostly useful for value-attitude relations that are weak, because in these cases, only the very obvious connections will be clear to the person that holds the attitude. Linking a value and an attitude then can suggest unknown connections to people. However, if a value is evidiently related to an attitude (like for instance the value health and the attitude toward smoking), this link effect might have a much smaller impact, because people already realize that the two are connected. This important role of values in attitude formation is not widely recognized. Many social psychological theories, although they describe attitudes in detail, consider values as distant influences, too abstract to actually have a meaningful effect on attitudes. However, we would like to argue that it is possible to use an abstract construct such as a value to predict more concrete constructs such as attitudes from it. With the findings of the present dissertation in mind, we wish to emphasize that values should again be taken seriously as predictors of attitudes, and that it is possible to manipulate values so that they have an effect on attitudes. This in turn can lead to attitudes and behavior that are more in line with the norms and values of society. It could help in making people realize that the attitudes and behaviors that they endorse are actually opposite to the values that they find important, and that they therefore need to be changed in order to act in line with their moral guidelines. 
100 
Nederlandse samenvatting 
Ook al zilin smaak, prijs en woedingswaarde belanigrijke factoren, sommige mensen beslissen wat ze wel en niet willen eten op grond wan morele overwegingen. Deze morele overwegingen, ook wel waarden genoemd, zijn daarom belangrijke determinanten van de attitude die mensen ten opzichte van voeding hebben. Bijwoorbeeld, mensen die innovatie en techniek belangijik vinden, hebben over het algemeen een positieve houding tegenover nleuwe voedingsinnovaties zoals genetische modificatie. Anderen, die de dingen het liefste bij het oude houden, zullen deze innovatie minder interessant winden. Een attitude kan worden gezien als een dispositie om een attitude-object positief of negatief te evalueren (Eagly \& Chaiken, 1993). Een attitude is opgebouwd uit verschillende cognitieve componenten ${ }_{r}$ ook wel beliefs genoemd. De attitude tegenover biologisch voedsel kan bijwoorbeeld bestaan uit beliefs als: "biologisch voedsel is gezond" of "biologisch voedsel wordt geproduceerd zonder gebruilk te maken van pesticiden". Waarden bepalen welke attitude-onderwerpen belangrijk zijn voor lemand en hoe te reageren in bepaalde situaties. Zo zou de attitude tegenover biologisch voedsel beinvloed kunnen worden door de waarden universalisme (respect voor alle mensen en de natuur) en de warde macht (contrale en dominantie over mensen en bronnen). In dit proefschrift onderzoeken we op systematische wijze de relatie tussen waarden en attitudes. Het eerste doel is te onderzoeken of en zo ja hoe waarden een invloed hebben op attitudes. Het tweede doel is het in kaart brengen van de voorwaarden die bijdragen aan een sterke relatie tussen waarden en attitudes en het onderliggende mechanisme van deze relatie te begrijpen en te werklaren. Zeven studies worden besproken die onthullen wanneer en hoe waarden gerellateerd zijn aan attitudes, en hoe deze relatie verstevigd kan worden.

In Deel 1, dat bestaat uit twee hoofdstukken, beschrijven we twee studies die aan de ene kant gericht zijn op het onderzoeken van de attitudes tegenover voedingsinnovaties, en aan de andere kant op het ontdekken van de waarden die aan deze attitudes ten grondslag liggen. In Hoofdstuk 1 biedt de selectie van twee tegengestelde voedingsinnovaties ons de kans am te bestuderen of specifieke attitudes zijn gerelateerd aan een specifiek patroon van waarden. Studie 1 onderzoekt welke specifieke waarden een rol spelen in het voorspellen van iemands attitude tegenover genetisch gemodificeerd voedsel (GGV) en biologisch voedsel (BV). Deze twee attitude onderwerpen zijn tegengesteld aan elkaar omdat hun onderliggende ideeeen moeilijk met elkaar te verenigen zijn. Biologisch voedsel staat voor een productiewijze die zo natuurlijk en puur mogelijk is. Genetisch gemodificeerd voedsel is echter het product van manipulatie en menselijke interventie. Deze twee attitude onderwerpen en hun onderliggende waarden worden onderzocht in een survey met 100 deelnemers, die gevraagd werden om aan te geven hoe belangrijk ze 10 waarden wonden, en daama hun attitudes tegenover GGV en BV te rapporteren. De resultaten van Studie 1 laten zien dat wanneer deelnemers hoog scoren op de waarde macht (controle en dominantie aver mensen en bronnen), ze GGV positief vinden, maar BV negatiever. Deelnemers die de waarde universalisme (respect voor de natuur en de medemens) belangrijk vinden, zijn echter positief tegenover BV. Verder blijkt de relatie tussen waarden en attitudes gemedieerd te worden door beliefs. Waarden kunnen een attitude beinvloeden door bepaalde beliefs te activeren. Deze resultaten impliceren een betekenisvolle relatie tussen waarden, beliefs en deze voedingsgerelateerde attitudes en ze suggereren dat waarden een rol spelen in het verklaren van attitudes tegenover GGV en BV.

De tweede centrale vraagstelling wan dit proefschrift is gerelateerd aan hoe waarden attitudes precies beinnvloeden. Over thet algemeen gaat een verandering in attitude gepaard met een verandering in attitudekarakteristieken zoals attitudesterkte en ambivalentie. Omdat 
waarden attitudes beïnloeden; en daarom ook hun karakteristieken, vicht Hoofdstuk 2 zich op de relatie tussen waarden en drie belangrijke attitudekarakteristieken, centraliteit, overtuiging en ambivalentie. Voor Studie 2 werden de data van verscheidene experimenten gecombineerd tot een groep van 241 personen die wit zowel studenten als consumenten bestond. Alle deelnemers werden gevraagd aan te geven hoe belangrijk ze 10 algemene waarden vonden en wat hun attitudes, centraliteit, overtuiging en ambivalentie tegenover zowel GGV als BV waren. Studie 2 liet wederom zien dat de waarden macht en universalisme gerelateerd zijn aan de attitudes tegenover GGV en BV. Daarmaast hadden deze waarden ook een invloed op de centrailteit en mate van overtuiging van deze attitudes: Waarden die positief gerelateerd waren aan een attitude hadden een invloed op de centraliteit van deze attitude. Universalisme beïnvloedde de centraliteit van de attitude tegenover $B V_{*}$ waar macht de centraliteit van de attitude tegenover GGV beïnvloedde. Dit hangt samen met het feit dat centraliteit sterk is gerelateerd aan het zelfconcept. Mensen definiëren zichzelf en de dingen die belangrijk woor zichzelf zijn in positieve termen. Daarom is centraliteit gerelateerd aan de waarden die mensen belangrijk vinden. Met name de waarden die negatief gerelateerd waren aan een attitude hadden een effect op de overtuiging van de attitude. De waarde macht beinvloedde de overtuiging van de attitude tegenover $B V$, en de waarde universalisme beïnvloede de overtuiging van de attitude tegenover GGV. Overtuiging is gerelateerd aan de zekerheid waarmee een attitude gehouden wordt. Over het algemeen lijkt er een tendens te zijn dat negatieve informatie grotere cognitieve, emotionele en sociale effecten teweegbrengt dan positieve informatie (Ito, Larsen, Smith, \& Cacioppo, 1998; Taylor, 1991). Dit leidt ertoe dat negatieve attitudes en waarden een groter effect hebben op hun omgeving dan positieve attitudes en waarden. Daarom zijn mensen zekerder over de waarden die ze negatief vinden dan over de waarden die ze posiltief vinden. Eenzelfde soort patroon werd niet gevonden voor de relatie tussen waarden en ambivalentie. De studie in Hoofdstuk 2 toonde dus aan dat drie belangrijke attitudekarakteristieken, centraliteit, overtuiging en ambivalentie alledrie een andere relatie met waarden hebben.

In Deel 2, dat uit drie hoofdstukken bestaat, richten we ons op het vinden van een manier om de relatie tussen waarden en attitudes te wersterken, aangezien deze relatie vaak wel aanwezig is, maar niet zelden zwak is. Vijf studies laten zlen dat alleen wanneer mensen zich ervan bewust zijn dat er een connectie bestaat tussen waarden en hun gerelateerde attitudes; er een sterke correspondentie tussen de twee te vinden is. Deze connectie, of het ervaren van een "link" tussen waarden en attitudes wordt gezien als een voorwaarde voor een sterke relatie tussen attitudes en hun onderliggende waarden. In Hoofdstuk 3 worden twee studies beschreven die zich richten op het activeren van waarden en het meten van een mogelijk effect van deze geactiveerde waarden op gerelateerde attitudes en gedrag. Studies 3.1 en 3.2 werdien ontworpen om bij zowel studenten als consumenten de waarden macht en universalisme te activeren, en om het effect van deze geactiveerde waarden op de attitudes tegenover GGV en BV te meten. Deelnemers konden kiezen tussen drie woorden die gerelateerd waren aan macht (in de macht conditie), of aan universalisme (in de universalisme conditie). Ze moesten elk van deze drie woorden gebruiken om een situatie te beschriven waarin hun attitudes of gedrag gedreven werden door dit woord (gedreven werden door macht of universalisme). Het idee achter deze manipulatie was dat het toepassen van deze drie woorden zou resulteren in een tijdelijke activatie van de waarde universalisme of macht. Daarna werden alle deelnemers gevraagd om aan te geven wat hun attitudes tegenover GGV en BV waren. Er werd geen effect gevonden wan het activeren van de waarden macht en 
universalisine op de gemeten attítudes. De attitudes tegenover GGV en BV verschilden niet tussien de condities. In studie 3:2, waar ook een gedragsmaat werd meegenomen door deelnemers te laten klezen tussen een genetisch gemodificeerde mueslireep, een biologische mueslireep en een reguliere mueslireep, had de activatie van de waarden macht en universalisme ook geen effect op de keuze voor de mueslirepen. Deze experimenten laten zien dat alleen het activeren van een waarde niet genoeg is om een effect op attitudes en gedrag te bewerkstelligen.

In Hoofdstuk 4 wordt een verklaring voor de ontbrekende resultaten in Hoofdstuk 3 beschreven. Twee experimenten worden beschreven die testen of de activatie van een waarde resulteert in een verandering in de relatie tussen de geactiveerde waarde en gerelateerde attitudes: Deelnemers kregen een (nep) persoonlijkheidstest woorgelegd waarmee de waarde universalisme werd geactiveerd (activatie conditie) of niet werd geactiveerd (controle conditie). De activatie van de waarde universalisme werd gerealiseerd door deelnemers te vertellen dat hun persoonlijkheid volgens de test overeen kwam met een universalistische persoonlijkheid. Deze werd beschreven als zijnde respectvol, open naar anderen en goed voor de natuur. In de derde conditie, de link conditie, werd ook de waarde universalisme geactiveerd, maar werd daarnaast de link tussen universalisme en biologisch voedsel gesuggereerd, door het noemen van de woorden "eerlijke, biologische voeding" in de beschrijving van de universalistische persoonlijkheid. Onze resultaten suggereren dat universalisme geen invloed lijkt te hebben op de attitude tegenover BV wanneer de waarde alleen geactiveerd wordt, maar wel invloed lijkt te hebben wanneer ook de link tussen BV en universalisme gesuggereerd wordt. De relatie tussen universalisme en BV werd dus alleen sterker in de link conditie, en niet in de controle en activatie condities. Daarnaast bleken de attitudes en waarden zelf niet te veranderen door de manipulatie, maar alleen de relatie tussen deze twee. Dit link effect werd aangetoond door middel van meerdere manipulaties. In studie 4.1 werd de bovengenoemde persoonlijkheidstest gebruikt om de waarde universalisme te activeren en te linken aan BV. deze studie liet zien dat door het suggereren van een link, de positieve relatie tussen de waarde universalisme en BV sterker werd. Dit link effect werd ook aangetoond in studie 4.2. Hier werden deelnemers gevraagd om een keuze te maken tussen 5 koekjes, waaraan een persoonlijkheidskenmerk gekoppeld werd. In het eerste experiment werd niet alleen de positieve relatie tussen universalisme en BV sterker, maar ook de negatieve relatie tussen universalisme en GGV, hoewel deze link niet gesuggereerd werd. Wij veronderstellen dat dit komt door het feit dat de waarde universalisme en de attitudes tegenover BV en GGV geintegreerd zijn in een onderliggende structuur. De connecties binnen deze structuur kunnen de link tussen universalisme en GGV geactiveerd hebben via de experimenteel geactiveerde link tussen universalisme en BV.

De studie die in Hoofdstuk 5 beschreven wordt richt zich op het onderzoeken van de vraag of het link effect wordt veroorzaakt door zelfactivatie of door zogenaamde "demand characteristics". De persoónlijkheidstest vertelde mensen dat zij een universalistische persoonlijkheid hadden en dat zij daarom open staan voor anderen. De manipulaties in hoofdstuk 4, maakten dus gebruik wan woorden die refereerden aan het zelf, die ervoor gezorgd kunnen hebben dat het zelf werd geactiveerd. Activatie van het zelf resulteert gewoonlijk in een hogere correspondentie tussen waarden en attitudes. Daarom kan zelfactivatie de sterkere relatie tussen waarden en attitudes (zoals gevonden in Hoofdstuk 4) veroorzaakt hebben. Daarnaast kunnen deelnemers zich gedwongen gevoeld hebben om hun attitude tegenover BV in lijn te stellen met de geactiveerde universalistische waarde, omdat ze 
persoonlijk op deze waarde werden aangesproken. Als dit effect van zogenaamde "denand characteristics" een rol heeft gespeeld, dan is de hogere colrelatie tussen waarden en attitudes in hoofdstuk 4 niet veroorzaakt door het link effect, maar omdat deelnemers zich gedwongen voelden om een hoge relatie te rapporteren. Daarom werden in Hoofdstuk 5 twee nieuwe condities ontwikkeld waar alle woorden die aan het zelf gerelateerd waren verwijderd werden. Deelnemers werden nu verteld dat een universalist iemand is die respect heeft voor de natuur en de medemens. Hierdoor werd nog steeds de walarde universalisme geactiveerd, maar niet meer het zelf en/of demand characteristics. Studie $\mathbf{5}$ toonde aan dat zelfactivatie en demand characteristics niet het link effect kunnen verklaren. Er bestond geen verschil tussen de condities waar de woorden die aan het zelf refereerden afwezig waren en de originele condities. Het link effect bleef echter wel bestaan.

Dit proefschrift biedt een systematische analyse van de relatie tussen waarden en attitudes. In Deel 1 werd aangetoond dat waarden een invloed hebben op voedingsgerelateerde attitudes en dat waarden deze invloed uitoefenen door het veranderen van attitude sterkte en de beliefs waaruit een attitude is opgebouwd. Deel I van dit proefschrift geeft ons daarom een beter begrip van hoe attitudes beïnvloed kunnen worden en de rol die waarden in dit proces spelen. Daarnaast laat Deel 1 zien dat de relatie tussen waarden en attitudes over thet algemeen zwak is wanneer het gaat over voedingsinnovaties. De experimenten in Deel 2 van dit proefschrift laten zien dat deze relatie versterlkt kan worden door een waarde te activeren en de link tussen een waarde en een attitude te suggereren. Deze link hoeft niet heel expliciet of overduidelijk aanwezig te zijn, maar kan redelijk impliciet gehouden worden. Alleen het noemen van de woorden "eerlijke, biologische voeding" in een beschrijving van een universalistische persoonlijkheid resulteert in sterke en significante correlaties tussen waarden en attitudes. Deze bevindingen leiden naar een manier om attitudes in lijn te brengen met hun onderliggende waarden, maar alleen wanneer de waarde en attitude aan elkaar gerelateerd zijn.

Alles bij elkaar laten de data zoals ze in dit proefschrift gepresenteerd zijn zien dat waarden iets kunnen toevoegen aan het begrijpen en voorspellen van attitudes. We hebben laten zien dat er een systematische relatie bestaat tussen specifieke walarden en attitudes. We beargumenteren dat alleen het activeren van waarden niet genoeg is om specifieke attitudes te beïnvloeden. Een sterke relatie tussen waarden en attitudes kan worden veroorzaakt door een attitude onderwerp in de context wan een waarde te presenteren. Het is echter niet zo dat het activeren en linken van een waarde leidt tot een onmiddellijke verandering in attitudes of gedrag. Activatie van een waarde versterkt alleen de relatie tussen waarden en attitudes. Dit effect van het linken van een waarde en een attitude is waarschijnlijk het meest invloedrijk wanneer de relatie tussen een waarde en een attitude zwak is. In dat geval zal een persoon zich alleen bewust zijn van de meest voor de hand liggende relaties tussen deze waarde en attitude. Het linken van de waarde met de attitude kan echter de tot dan toe onbekende connecties blootleggen. Echter, wanneer een waarde overduidelijk is gerelateerd aan een attitude (zoals de waarde gezondheid en de attitude tegenover roken) zal het effect van het leggen van de link niet zoveel meer toevoegen. De belangrijke roll die waarden innemen in attitude formatie wordt niet overal erkend. Veel sociaal psychologische theorieen beschrijven attitudes in detail, maar zien waarden als werre inwloeden die te abstract zijn om werkelijk een groot effect op attitudes te hebben. Wij willen echter angeven dat het mogelijk is om een abstract construct zoals waarden te gebruiken om meer concrete constructen te woorspellen. Met de bevindingen van dit proefschrift in ons achterhoofd willen we benadrukken dat 
waarden weer serieus genomen moeten worden als voorspellers van attitudes en dat het mogelijk is om waarden te manipuleren en hiermee een effect op gerelateerde attitudes te veroorzaken. Dit kan vervolgens leiden tot attitudes en gedrag die in overeenkomst zijn met de belangrijke waarden en normen binnen de maatschappij: Hierdoor zouden mensen zich kunnen realiseren dat het gedrag en de attitudes waaraan zij vasthouden eigenlijk niet in overeenkomst zjon met de waarden die ze belangrijk vinden, en dat deze attitudes en gedrag veranderd moeten worden om in lijn met hum morele overwegingen te leven. 


\section{Dankwoord}

Ik ben een gelukkig mens. Met zoveel mensen om je heen die je dierbaar ziljn en die je bijstaan in leuke en moeilijke tijden kun je ook bijna niet anders. Maar dat betekent natuurlijk niet dat je ieders hulp en toewijding maar voor lief moet nemen. Vandaar dit dankwoord. Om bepaalde soorten bedankjes bij bepaalde soorten mensen te plaatsen, zoals dit nou eenmaal hoort bij een dankwoord, heb ik nog een laatste wetenschappelijke opmerking: Zle Tabel D. 1 (zoz). 


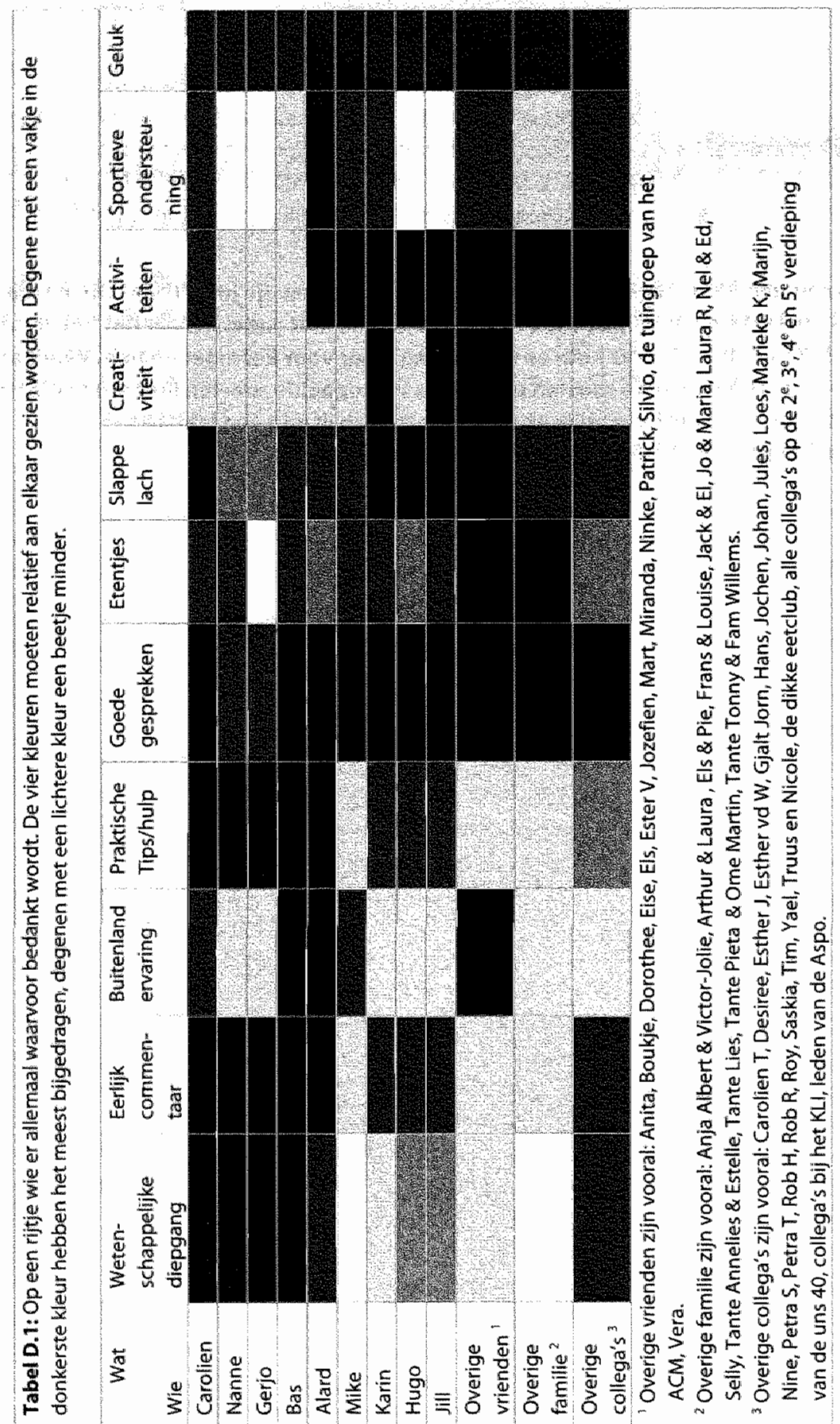




\section{Curriculum Vitae}

Ellen Dreezens werd op 2 oktober 1979 te Brunssum geboren. Na 6 jaar voorstudie aan de basisschool de Kastanjehof en openbare basisschool de Regenboog behaalde ze in 1997 het Atheneum diploma aan het Jeanne d'Arc college te Maastricht. In datzelfde jaar begon ze haar studie Psychologie, afstudeerrichting cognitieve ergonomie, aan de Universiteit Mastricht. Deze studie werd in 2001 afgerond met het behalen van het doctoraal diploma. Van 2001 tot 2005 was zij werkzaam als Assistent in Opleiding bij de capaciteitsgroep Experimentele Psychologie van de Universiteit Maastricht. Het onderzoek in het kader van dit project werd uitgevoerd aan de Universiteit Maastricht en aan de University of Troms te Noorwegen. 
110 
References 
Ajzen, $1 .$, \& Fishbein, $M_{1}(1977)$. Attitude-behavior relations: A theoretical analysis and review of empirical research. Psychological Bulletin $84,888-918$.

Ajzen, I. (1988). Attitudes, personality and behaviour. Chicago: Dorsey.

Ajzen, 1. (1991). The theory of planned behavior. Organizational behavior and human decision processes, $50,179-211$.

Albarraclin, D., \& Wyers, R. S., Jr. (2000). The cognitive impact of past behavior: Influences on beliefs, attitudes and future behavooral decisions. Journal of Personality and Social Psychology, 79, 5-22.

Allen, M. W. Baines, S. (2002) Manipulating the symbolic meaning of meat to encourage greater acceptance of fruits and vegetables and less proclivity for red and white meat. Appetite, 38, 118-130.

Allport, G. W. (1935). Attitudes. In C. Murchison (Ed.), A handbook of social psychology (pp. 798-844). Worcester, MA: Clark University Press.

Armitage, $C_{.}$\& Conner ${ }_{f}$ M. (2000). Attitudinal ambivalence: A test of three key hypotheses. Personality and Social Psychology Bulletin, 26, 1421-1432.

Austin, $J_{1} T_{*} \&$ Vancouver, J. B. (1996). Goal constructs in psychology: Structure, process, and content. Psychological Bulletin, 120, 338-375.

Bagozzi, R. P., Lee, K. H., \& Van Loo, M. F. (2001). Decisions to donate bone marrow: The role of attitudes and subjective norms across cultures. Psychology and Health, 16, 29-56.

Bardi, A., \& Schwartz, S. H. (2003). Values and behavior: Strength and structure of relations. Personality and Social Psychology Bulletin, 29, 1207-1220.

Baran, R. M., \& Kenny, D. A. (1986). The moderator-mediator variable distinction in social psychological

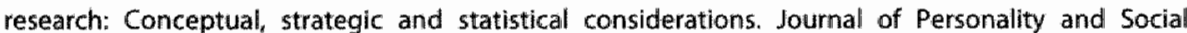
Psychology, 51, 1173-1182.

Bassili, J. N. (1996). Meta-judgmental versus operative indexes of psychological attributes: The case of measures of attitude strength. Journal of Personality and Social Psychology, 71, 637-653.

Bem. A. P. (1970). Demonstrations in attitude change and persuasive communication. Psychological Reports, 27, 703-706.

Bem, D. J. (1972). Self-perception theory. In L. Berkowitz (Ed.), Advances in Experimental Sacial Psychology (vol. 6, pp.1-62). San Diego, CA: Academic Press.

Bernard, M. M., Malo, G. R., \& Olson, J. M. (2003). The vulnerability of values to attack: Inoculation of values and walue-relevant attitudes. Personality and Social Psychology Bulletin, 29, 63-75.

Biek, M., Wood, W., Chaiken, S. (1996). Working knowledge, cognitive processing and attitudes: On the determinants of bias. Personality and Social Psychology Bulletin, 22, 547-556.

Birkeland, R., Thompson, J. K., Herbozo, S., Roehrig, M., Cafri, G., \& van den Berg, P. (2005). Body image, 2, 53-61.

Breckler, 5. J., \& Wiggins, E. C. (1989). Affect versus evaluation in the structure of attitudes. Journal of Experimental Social Psychology, 25, 253-271.

Bredahl, L. (1999). Consumers" cognitions with regard to genetically modified foods: Results of a qualitative study in four countries. Appetite, 33, 343-360.

Bredahl, L. (2001). Determinants of consumer attitudes and purchase intentions with regard to genetically modified foods: Results of a cross-national survey. Journal of Consumer Policy, 24, 23-61.

Brunso, $K_{*}$, Scholderer, $J_{2}$ \& Grunert, $K$. (2004). Testing relationships between values and food-related lifestyle: Results from two European countries. Appetite، 43, 195-205.

Cacioppo, J. T., Gardner, W. L., \& Berntson, G. G. (1997). Beyond bipolar conceptualizations and measures: The case of attitudes and evaluative space. Personally and Social Psychology Review, 1, 3-25.

Chalken, S., Pomerantz, E. M. \& Giner-Sorolla, R. (1995). Structural consistency and attitude strength. In R. E. Petty \& J. A. Krosnick (Eds.). Attitude strength: Antecedents and consequences (pp. 387-412). Hillsdale, NJ: Eribaum.

Chartrand; T. L., \& Bargh, J. A. (1996). Automatic activation of umpression formation and memorization goals: Nonconscious goal priming reproduces effects of explicit task instructions. Journal of Personality and Social Psychology, 71, 464-478.

Cook, T. D., Flay, B. R. (1978). The persistence of experimentally induced attitude change. In L. Berkowitz (Ed.), Advances in experimental social psychology (Vol 11, pp. 1-57). New York: Academic Press. 
Cook, A. J. Kerr, G. N, \& Moore: K (2002). Attitudes and hintentions toward purdnasho GM food. Joumal of Economic Pychology, 23,557-572

Darley, J. M., \& Bason, C D. 1973). From Jerusatem to Jericho". A study of situational and dispositional variables in helping behawior, Journal of Personality and Social Psychology, 27, 1001018

Darley, M. Matane, B. (1968). When will people hetp in a crisis? Psychology Today, 2, 54,57,70-71.

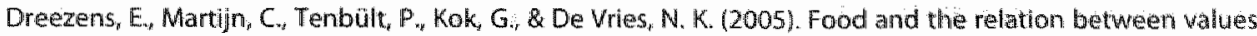
and attitude characteristics. Appetite, $45,40-46$.

Dreezens, E., Martijn, C, Tenbiolt, P., Kok, G.; \& De Wries, N. K. (2005). Food and values; An examination of values underlying attitudes toward genetically modifed and organically grown food products. Appetite, 44, 115-122.

Dreezens $E_{*}$ Martijn, C., Tenbült, P. Kok, G, \& De Uries; N. K. (2005). The missing link. On strengthening the relation between attitudes and values. Manuscript submitted for publication.

Eagly, A.H.\& Chaiken, S, (1993). The psychology of atitudes. Fort Worth, TX: Harcourt Brace Jovanovieh.

Eagly, A. H. Chaiken, S. (1995). Attitude strength, attitude structure and resistance to change. In R. E. Petty \& I: A. Krosnick (Eds.), Attitude strength: Antecedents and consequences. Ohio State University series on attitudes and persuasion. (Vol:4). Hillsdag, N1, US: Lawrence Eillbaum Associates, Inc.

Eagly, A. H., \& Chaiken, 5. (1998). Attitude structure and function. In: D. T. Gilbert, S. T. Fiske and G. Lindzey (Eds.) The handbook of social psychology (fourth edition, Pp. 169-322). McGraw-thill: New York.

Fazio, R. H., \& Williams, C. J. (1986). Attitude accessibillty as a moderator of the attitude-perception and attitude behavior relations: An imvestigation of the 1984 presidential election. Journal of Personalty and Social Psychology, 51,505-514.

Fazio, R. H. Sambonmatsu, D. M., Powell, M. C. \& Kardes, F. (1986). On the automatic activation of attitudes. Joumal of Personality and Social Psychology, 50, 229-238.

Fazio, R. H. (1995), Attitudes as object-evaluation associations: Determinants, consequences, and contelates of attitude accessibility. In R. E. Petty \& J. A. Krosnick (Eds.), Attitude strength: Antecedents and consequences (pp. 247-282). Hillsdale, NJ: Lawrence Erlbawim Associates.

Fazio, R. H. (2000). Accessible attitudes as tools for object appialsal: Their costs and benefits. In G. Maio \& J. Olson (Eds), Why we evaluate. Functions of attitudes (pp. 1-36). Mahwah, Nil: Erlbaum.

Feather, N. T. (1995). Values, valences and choice: The influences of values on the perceived attractiweness and choice of alternatives. Journal of Personality and Social Psychology, 68, 1135-1151.

Feather, N. T. Norman, M. A. (1998). Values and valences: Variables relating to the attractiveness and choice of food in different contexts. Journal of Applied Social Psychology, 28, 639-656.

Fishbein, M. (1963). An investigation of the relationships between beliefs about an object and the attitude toward that object. Human Relations, $16,233-239$.

Fishbein, M., Triandis, H. C. Kanfer, F. H, Becker, M, Middlestadt, \$. E, Eichlier, A. 20011. Factors influencing behawior and behavior change. In A. Baum, T. A. Revenson, A. Tracey, J. E Singer (Eds.); Handbook of health psychology. Mahwah, N.: Lawrence Erlbaum Associates.

Frewer, L. I. Howard, $C_{\text {, }}$ \& shepherd, R. 11996). Effective communication about genetic engineering. British Food Journal, 98, 48-52.

Gaskell, G. Bauer, M. W., Duirant, I. \& Allum, N.C. (1999). Worlds apart? The reception of genetlcally modifted foods in Europe and the U.S. Science, 285, 384-390.

Gibbons, F. X. (1983). Self-attention and self-report: The "veridicality" hypothesis. Joumal of Per sonality, 51 . 517-542.

Giner-Sorolla, R. (1999). Affect in attitude: Immediate and deliberative perspectives. In: $S$. Chalken $\&$ Y. Troope (Eds), Duall-process theories in Social Psychology (pp. 441-461). New York, NY, US: Guilford Press.

Giner-Sorolla; R. (2001). Affective attitudes are not always faster:" The moderating role of extremity. Personality and Social Psychology Bulletin, 27, 666-677.

Grankwist, G. \& Biel, A. (2001). The importance of beliefs and purchase criteria in the cholce of eco-labelled food products. Journal of Environmental Psychology, 21, 405-410.

Greenwald, A. G., \& Banaji, M. R., (1995). Implicit social cognitioni: Attikudes, self-esteem and stereotypes. Psychological Review, 102,4-27. 
Greenwald, A. G., MoGhee, D. E, \& Schwartz, J. L. K (1998). Measuring individual differences in implicit cognition: The implicit association test. Journal of Personality and 5ocial Psychology, 74, 1464-1480.

Grobe, $D_{*}$ Douthitt, R. Z Zepeda, L. (1999). A model of consumers" risk perceptions toward recombinant bovine growth hormone (rbiGH): The impact of risk characteristics. Risk Analysis, 19, 66 1-673.

Grunert, S. C. Juhl, H. J. (1995): Valies, enwironmental attittudes and buying of arganic foods: Journal of Economic Psychology, 16,39-62.

Harreveld $F_{i}$, Van Der Pligt; 1, De Vries, N. K. A Andreas; 5. (2000): The structure of attitudes: Attribute importance, accessibility and judgment. British Journal of Social Psychology, 39, 363-380.

Hautwast, $\mathrm{l}$, \& Van de Wiel, J. (2001): Biotechnologie en voedsel. [Biotechnology and food]. In INiaba (Ed.). Biotechnologie: een plaats in de samenleving. (Brochure].

Heider, F. (1946). Attitudes and cogniltive organization: Joumal of Psychology: Interdisciplinary and applied, 21, 107-112:

Higgins, E. T. (1996). The "self digest": Self knowledge serving self regulatory functions. Journal of Personality and Social Psychology, 71, 1062-1083:

Holland, $R . W_{.}$Verplanken, $B_{i}$ \& Van Knippenberg, A. (2002), On the nature of attitude-behavior relations: The strong guide, the weak follow. European Journall of Social Psychology, 32, 869-876.

Homer; P. M. \& Kahle, L. R. (1988). A structural equasion test of the value-attitude-behavior hierarchy. Journal of Personality and Social Psychology; $54,638-646$.

Honikanen, P. \& Verplanken, B: (2004). Understanding attitudes towards genetically modified food: The role of walues and attitude strength. Journal of Consumer Policy, 27, 401-420.

Hutton, D. G, \& Baumeister ${ }_{*}$ R. F. (1992). Self-awareness and attitude change: Seeing oneself on the central route to persuasion. Personality and Social Psychology Bulletin, 18,68-75.

Ito, T. A, Larsen, J. T., Smith N. K., \& Cacioppo, J. T. (1998). Negative information weighs more heavilly on the brain: The negativity bias in evaluative categorizations. Journal of Personality and Social Psychology, 75, 887:900.

Iwata $\mathrm{O},(2001)$. Relationships between proenvironmental attitudes and concepts of nature. The Journal of Social Psychology, 14, 75-83.

Vamieson, D.W. (1988). The influence of value conflicts on attitudinal ambivalence. Paper presented at the annual meeting of the Canadian Psychological Association. Montreal.

Johnson, B. T. \& Eagly, A. H. (1989). Effects of involvement on persuasion: A meta-analysis. Psychological Bulletin, 106, 290-314.

Jonas, $K_{2}$ Diehl, M., \& Brömer ${ }_{r}$ P. (1997). Effects of attitudinal ambivalence on information processing and attitude-intention consistency. Journal of Experimental Social Psychology, 33, 190-210.

Judd, C. M., Drake, R. A, Downing. J. W., \& Krosnick, J. A. (1991). Some dynamic properties of attitude structure: Context-induced response facilitation and polarization. Journal of Personality and Social Psychology, 60, 193-202.

Judd, C. M. \& Krosnick, J. A. (1982). Attitude centrality, organization and measurement. Journal of Personality and Social P'sychology, 42, 436-447.

Karpinsiki, A.t \& Hilton, J. L. (2001). Attitudes and the implicit association test. Journal of Personality and Social Psychology, $81,774-788$.

Katz; D. (1960). The functional approach to the study of attitudes, Public-Opinion-Quarterly, 24, 163-204.

Kawakami, K, Dovidio, J. F, \& Dijksterhuis, A (2003). Effect of social category priming on personal attitudes. Psychological Science, 14, 315-319.

Kehoe, J, W. (1975). Demonstrating the relationship between values and attitudes as a means of changing attitudes. Alberta Journal of Educational Research, 21, 207-212.

Kenny, D. A., Kashy, D. A., \& Bolger, N. B. (1998). Data analysis in sociall psychology. In D. T. Gillbert, S. T. Fiske, \& G. Lindzey (Eds.), The handbook of social psychology: Vol. 4. (4th ed., pp. 223-265). New York: McGraw Hill.

Kirk, S. F, Greenwood, D., Cade, J. E., \& Pearman, A. D. (2002). Public perception of a range of potential food risks in the United Kingdom. Appetite, 38, 189-197.

Kokkinakik, F. \& Lunt, P. (1997). The relationship between inwolvement, attitude accessibility and attitudebehavior consistency. Britisth Journal of Social Psychology, 36, 497-509. 
Krosnick, J. A. 1989). Attitude impiortance and attitude accessibility, Personality and Social Psychology Bulletin, 15, 297-308.

Krosnick, J. A., Boninger, D. 5. Chaung, Y. C, Berent, M. Kir \& Carnot, C, G. (1993); Attitude strength: One construct or many related constructs? Joumal of Personality and Social Psychology, 65, 1132-1151.

Krosnick, J A., \& Petty, R. E. (1996). Attitude strength: An overview. In R. E. Petry, \& J. A. Krosnick (Eds.), Attitude strength: Antecedents and consequences (pp. 1-24). Mahwah, New Jersey: Lawrence Erlbaum Associates:

Kubbered, E., Ueland, O., Tronstad, A., \& Risvik, E. (2002). Attitudes towards meat and meat-eating annong adolescents in Norway: A qualitative study. Appetite, $38,53-62$.

Langer \& Roth, 1975. The illusion of contrall. Joumall of Personality and Social Psychology. 32, 191-198.

Laros, F. J. M.r. \& Steenkamp, J-B. E. M. (2004). Importance of fear in the case of genetically modified food. Psychology and Marketing, 21, 889-908.

Lavine, H., Huff, J. W. Wagner, S. H., \& Sweeney, D. (1998). The moderating Influence of attitude strength on the susceptibility to context effects in attitude surveys. Journal of Personality and Social Psychology, 75, 359-373.

Lea, E., \& Worsley, A. (2001). Influences on meat consumption in Australia. Appetite, 36, 127-136.

Liberman, A., \& Chaiken, S. (1996). The direct effect of personal relevance on attitudes. Personality and Sociall Psychology Bulletin, 22, 269-279.

Lindeman, $M_{w}$ \& Sirelius, M. (2001). Food choice ideologies: The modern manifestations of normative and humanist views of the world. Appetite, 37, 175-184.

Lombardi, W. J., Higgins, E., \& Bargh, J. A. (1987). The role of consciousness in priming effects on categorization: Assimilation versus contrast as a function of awareness of the priming task. Personality and Social Psychology Bulletin, 13, 411-429.

Lord, C. G., Lepper M. R., \& Mackie, D. (1984). Attitude prototypes as determinants of attitude-behavior consistency. Journal of Personality and Social Psychology, 46, 1254-1266.

Luzar, E. J. \& Cosse, K. J. (1998). Willingness to pay or intention to pay: The attitude-behavior relationship in contingent valuation. Journal of Socio-Economics, 27, 427-444.

Magnusson, M. K., Arvola, A.r Hursti, U*K, K., Aberg, L., \& Sjödén, P.O. (2003) "Choice of organic foods is related to perceived consequences for human health and to environmentally friendly behavior. Appetite, 40, 109-117.

Magnusson, M. K. \& Husti, U-K, K. (2002). Consumer attitudes toward genetically modified foods. A.ppetite, $39,9-24$.

Maio, G. R., \& Olson, J. M. (1994), Value-attitude-behavior relations: The moderation role of attitude functionsi British Joumal of Social Psychology, 33, 301-312.

Maio, G. R., Olson, J. M. Allen, L., Bernard, M. M. (2001). Addressing discrepancies between walues and behavior: The motivating effect of reasons. Journal of Experimental Social Psychology, 37, 104-117.

MeConnell, A. R. \& Leibold, 1. M. (2001). Rellations among the Implicit Asisociation Test, discriminatory behavior and explicit measures of racial attitudes. Journal of Experimental Social Psychology, 37, 435442.

Moses, V. (1999). Biotechnology products and European consumers. Biotechnology Advarices, 17,647-678.

Niaba. (2001). Toepassing biotechnologie waardevol voor de samenleving. IApplication biotechnology valuable for society]. Report written under the jurisdiction of the Dutch Blotechnology Association.

Ostrom, T. M., \& Brock, T. C. (1968). A cognitive model of attitudinal involvement. In R. P. Abelson, E. Aronson, W. J. McGuire, T. M. Newcomb, M. 1. Rosenberg, \& P. H. Tannenbaum (Eds.), Theories of cognitive cansistency: A sourcebook (pp. 373-383). Chicago: Rand MCNally.

Pfister, H. R. Böhm, G. \& Jungermann, H. (2000) "The cognitive representation of genetic engineering: Knowledge and evaluations. New Genetics and Society, 19, 295-316.

Pomerantz, E. M., Chaiken, S., \& Tordesillas, R. S. (1995). Attitude strength and resistance processes. Journal of Personality and Social Psychology, 69, 408-419.

Povey, R. Wellens, $B_{w} \&$ Conner $M_{0}$. (2001). Attitudes towards following meat, vegetarian and vegan diets: An examination of the role of ambivalence. Appetite, 37, 15-26. 
Prislin, f., Wood, W., Pool, G. J: (1998). Structural consistency and the deduction of novel from existing attitudes. Joumal of Experimental Social Psychology, 34, 66-89.

Pryor, J. B, Gibbons, F. X, Wicklund, R. A, Fazio, R. H, \& Hood, R. (1977). Self-focused attention and selfreport wallidisy. Journal of Personality, 45, 514,527.

Rasinski, K. A. Visser, P, S, Zagatsky, M. Wickett, E M (2005), Joumal of Experimental Social Psychology. $41,321-327$.

Rohan, M. J. (2000). A rose by any hame? The values construct. Personality and Socfal Psychology Review, 4 , 255277

Rokeach, M (1968). Beliefs, attitudes and walues: $A$ theory of organization and change. San Francisco US: Jorsey-Bass Inc, Publishers.

Rokeach, M. (1973). The nature of human values, New York: Free Press.

Rotenberg, K. J. Lancaster, C., Marsden, J.. Pryce, S. Williams, J.n \& Lattimore, P. (2005). Effects of priming thoughts about control on anxiety and food intake as moderated by dietary restraint. Appetite, 44, $235-241$.

Sanbonmatsu, D. M. Fazio, R. H. (1990). The role of attitudes in memory-based decision making. Joumal of Personality and Social Psychology, 59, 614-622.

Sassenberg, $K_{i}$ \& Moskowitz, $G_{n}$ B. (2005). Don't stereotype, think different! Owercoming automatic stereotype activation by mindset priming, Joumal of Experimental Social Pisychology, 41, 506-51.4.

Schifferstein, H. N. J., \& Oude Ophuilis, P. A. M. [1998). Health-related determinants of organic food consumption in The Netherlands. Food Quallity and Preference, 9, 119-133.

Schuman, $H_{i}$ \& Johnson, M. P. (1976). Attitudes and behaviour. Annual review of Sociology, 2, 161-207:

Schwartz, S. H. (1992). Universals in the content and structure of values: Theoreticall advances and empirical tests in 20 countries. In M. P. Zanna (Ed.), Adwances in Experimental Social Psychology (Vol. 25, pp. 1-65). Waterloo: Academic Press, Inc:

Schwartz, S. H. \& Billsky, W. (1987). Toward a universal psychological structure of human wallues. Journal of Personality and Sociel Psychology, 53, 550-562.

Schwartz, S. H. \& Bilsky, W. (1990). Toward a theory of the universal content and structure of walues: Exterisions and cross-cultural replications. Joumal of Personality and Social Psychology, 58, 878-891.

Schwartz, S. H. \& Clausen, G. T. (1970). Responsibility, norms and helping in an emergency. Journal of Personality and Social Psychology, 16, 299-310.

Schwartz, S. H., Huismans, S. (1995). Value prioritites and religiosity in four Western religions. Social Psychology Quarterlly, 58, 8:8-107.

Schwertz, S. H., \& Sagie, G. (2000). Vallue consensus and importance: A. cross-national study, Journal of Gross-Cultural Psychology, 31, 465-497.

Shanahan, J., Scheufele, $D_{n}$ \& Lee, E. (200)). Attitudes albout agricultural biotechnology and genetically modified organisms. Public Opinion Quarterly, 65, 267-281.

Sherman, S. J. Gorkin, L. (1980). Attitude bolstering when behavior is inconsistent with central attitudes. Journat of Experimentall Sacial Psychology, 16, 388:403.

Smallwood, d. (2004). Self-reference, ambiguity and dysphoria. Cognition and Emotion, 18, 999-1007.

Snyder; $M_{1}$ \& Kendzierski; D. (1982). Acting on one's attitudes: Procedures for linking attitudes and behavior. Journal of Experimental Social Psychology ${ }_{*} 18,165 \cdots 183$.

Sparks, P. (2000). Subjective expected utility-based attitude-behavior models: The utility of self-identity. In D. E. Terry \& M. A. Hogg (Eds.), Attitudes, behaviour and social context: The role of norms and group membership (pp. 31-46). Mahwah, NJ: Lawrence Erlbaum Associates.

Stapel, D. A., \& Tesser, A. (2001). Self-activation increases social comparison. Journal of Personality and Social Psychology, 811,742-750.

Stienstra, J., Ruelle, $H_{\text {., }}$ \& Bartels, G. (2002). A closer look at eleven years of environment perception through laddering. In G. Bartels \& W. Nelissen (Eds.), Marketing for sustainability: Towards transactional policymaking. Amsterdam: IOS Press.

Taylor, S. E. (1991). Asymmetrical effects of positive and negative events: The mobilization-minimization hypothesis. Psychological Bulletin, 110, 67-85. 
Thompson, C. 1. \& Troester, M. (2002). Consumer value systems in the age of postmodem fragmentation: The case of the natural health microculture Joumal of Consumer Research, 28,550-572.

Thompson, M. M. Zanna, M. P. \& Griffin, D. W. (1995). Let's not be indifferent about uartitudinall ambivalence. In R. E. Petty \& J. A. Krosnick (Eds.), Attitude strength: Antecedents and consequences (pp. 191-214). Hillsdale, NJ: Eribaum.

Thegersen, 3, \& Olander, F. (2002). Human values and the emengence of a sustanable consumption pattern A panel study. Journal of Economic Psychology, 23,605-630.

Tourangeau, R., Rasinski, K. A.., Bradburn, N., \& O'Anrade; R. (1989). Belief accessibility and context effects in attitude measurement. Journal of Experimental Social Psychology, 25, 401-421.

Van der Pligt, J., De Vries, N. K. Manstead, A. S. R., Van Harreveld, F (2000). The importance of being selective: Weighing the role of attribute importance in attitudinal judgment. in: M. P. Zanna (Ed.), Advances in Experimental Socia! Psychology (wol. 32, pp.135-200). San Diego, CA: Academic Press.

Van der Meulen, M. (2007). Self-references among children's first fifty words: Indications for an emerging sense of self in Dutcli-speaking children. Infant and Child Development, 10, 161-171.

Verplanken, B., Hofstee, G., \& Janssen, H. J. W. (1998). Accessibility of affective versus cognitive components of attitudes. European Journal of Social Psychology, 28, 23-35.

Verplanken, B., \& Holland, R. W. (2002). Motivated decision making: Effects of activation and self-centrality of values on choices and behavior. Joumal of Personality and Social Psychology, 82, 434447.

Walther, E. (2002). Guilty by mere association: Evaluative conditioning and the spreading attitude effect. Journal of Personality and Social Psychology, 82, 919-934.

Wilson, T. D., \& Dunn, D. S. (1986). Effects of introspection on attitude-behavior consistency: Analyzing reasons versus focusing on feelings. Journal of Experimental Social Psychology, 22, 249-263.

Wilson, T. D., \& Hodges, S. D. (1992). Attitudes as temporary constructions. In L. L. Martin \& A. Tesser (Eds.). The construction of social judgments (pp. 37-65). Hillsdale, Nis: Er Ibaum.

Wilson, T. D., Lindsey, 5., \& 5chooler, T. Y. (2000). A model of dual attitudes. Psychological Review, 107, 101 126. 
The "Kunt Lewin Institute Dissertation Series" started in 1997. Since 2004 the following dissertations have been published:

2004-1: Wolfgang Steinel: Misleading in social decision-making: A motivational approach

2004-2: Edwin van Hooft: Job seeking as planned behavior. In search of group differences

2004-3: Kirsten Ruys: The influence of self and similarity on immediate affective impressions of people

2004-4: Michel Handgraaf: Self-interest and other-oriented motives in social decision making: An utimatum bargaining perspective

2004-5: Sjoerd Goslinga: Betrokkenheid, participatie en ledenverloop in vakbonden

2004-6: Nynke Frieswijk: Frail, but happy: The importance of self-management ability and social comparison among elderly persons

2004-7: Jaap Ham: Bridging attribution and spontaneous inferences: Spontaneous and intentional components of dispositional and situational inferences

2004-8: Mirjam Tazelaar: When things go wrong: The influence of noise on interactions

2004-9: Marjolein de Best-Waldhober: Coördinatie in interdependente situaties: Over de afweging van directe uitkomsten versus uitkomsten op lange termijn

2004-10: Hinke Groothof: When others are doing better or worse: Responses from the heart and the head

2004-11: Laetitia Mulder: Throwing light on the dark side of sanctions. Sanctioning systems in social dilemmas re-examined

2004-12. Annebel de Hoogh: Personality and charismatic leadership: A matter of context

2004 13: Brigitte ten Brink: Psychological contract: A useful concept?

2004-14: Gerben van Kleef: Emotion in social conflict. The interpersonal effects of emotions in negotiations

2004-15: Tom Frijns: Keeping secrets: Quantity, quality and consequences

2005-1: Elsbeth Steenland: Stereotype Change: Effects of disconfirming information

2005-2: Annet de Lange: What about causality? Examining longitudinal relations between work characteristics and mental health

2005-3: Reint Jan Renes: Sustained volunteerism: Justification, motivation and management

2005-4: Aloyse Augusta Dinsbach: Socialization in the warkplace: A focus on migrant groups

2005-5: Susanne Peters: The social psychology of being better off than others

2005-6: Winny Bakker: Emigration and well-being: The role of personality and cultural identity in acculturation

2005-7: Ruud Zaalberg: The expression of emotion in social situations. The mediating roles of display rules and social motives

2005-8: Catharine Evers: Sex differences in anger expressions. The shaping role of social appraisals

2005-9: Ed Sleebos: The Consequences of Perceived Intra-group Respect: The Effects of Differential Intra-group Respect on Behavior and Cognition

2005-10: Jeroen Stouten: Virtue Summons the Fury: Coordination Rules and Fairness in Social Dilemmas

2005-11: Irene de Pater: Doing Things Right or Doing the Right Thing: A New Perspective on the Gender Gap in Career Success 
2005-12: Rob Nelissen: Guided by Reason, Struck by Emotion: Integrating Motivational \& Expectancy-Value Accounts of Behavior

2005-13: Emely de Vet: Testing the Transtheoretical Model: Validity and Applicability for Fruit Intake

2005-14: Floor Rink: Diversity and Small Group Decision Making: Towards a social identity framework for studying the effects of task-related differences on dyods and groups

2005-15: Sven Zebel: Negative Associations: The Role of Identification in Group-Based Guilt

2005-16: Eric Rietzschel: From quantity to quality: Cognitive, motivational and social aspects of creative idea generation and selection

2006-1: Maria Dijkstra: Workplace Conflict and Individual Well-Being

2006-2: Ruud Custers: On the underlying mechanisms of nonconscious goal pursuit

2006-3: Ellen Dreezens: The missing link: the relationship between values and attitudes 